\title{
EFFECT OF LIQUID CONTAMINATION ON HERMETICITY AND SEAL STRENGTH OF FLEXIBLE POUCHES WITH LLDPE SEALANT
}

\author{
A Thesis \\ presented to \\ the Faculty of California Polytechnic State University, \\ San Luis Obispo
}

\author{
In partial Fulfillment \\ of the Requirements for the Degree \\ Master of Science in Business and Technology, Packaging Specialization
}

by

Francesca Delle Cese

March 2014 
(C) 2014

Francesca Delle Cese

ALL RIGHTS RESERVED 


\section{COMMITTEE MEMBERSHIP}

TITLE:

Effect of Liquid Contamination on Hermeticity and Seal Strength of Flexible Pouches with LLDPE Sealant

AUTHOR:

DATE SUBMITTED:

COMMITTEE CHAIR:

COMMITTEE MEMBER:

COMMITTEE MEMBER: Soma Roy, $\mathrm{PhD}$

Assistant Professor of Statistics

Francesca Delle Cese

March 2014

Koushik Saha, $\mathrm{PhD}$

Jay Singh, $\mathrm{PhD}$
Assistant Professor of Industrial Technology

Professor of Industrial Technology 


\begin{abstract}
Effect of Liquid Contamination on Hermeticity of Seal Strength of Flexible Pouches with LLDPE Sealant

Francesca Delle Cese

Flexible packaging is a growing successful market and the majority of flexible package applications are for the food industry. The demand for process optimization and reduced production costs, has led to an increase in flexible packaging. However, fast production lines can result in contamination in the seal area. For flexible food packaging, contamination is considered any food particle or substance trapped in the seal area. Current quality control processes can detect contamination in the seal area, but it is not determined if seal contamination effects seal quality. Oil-based and sodium based snack foods are two common categories that can be packaged on a horizontal flow film and seal (HFFS) flow-wrap machine. The study uses vegetable oil and a salt water solution to simulate the effect of liquid contamination along the Tpoint of flexible pouches made on an HFFS. The T-point refers to where the fin seal meets the end seal and requires the seal jaw to seal through four layers of film, which is the most difficult point to seal. The study tests a combination of different sealing temperatures and dwell time to determine the optimal sealing condition for a hermetic seal. A quality hermetic seal provides an enclosed seal with no leaks due to successful polymer chain entanglement between the two sealant layers. The different test categories of the study are non-contaminated (control), salt water solution for salt based foods, and vegetable oil for oil-based foods. Given the test parameters of the study, $140^{\circ} \mathrm{C}$ sealing temperature and 0.3 seconds dwell time are considered to be the optimal sealing condition for all three test categories. For Phase 1 of the study, salt water has a lower hermeticity pass rate compared to vegetable oil and non-contaminated seals. In addition, the effect of refrigerated storage temperature and ambient storage temperature did not show to be significant for any of the test categories. However, refrigerated conditions showed a higher hermeticity pass rate, but it was not statistically different. The findings for seal strength indicated no test category had higher or lower seal strength over the 14 day test period. Overall, the study shows there is no effect of liquid contaminant on hermeticity and seal strength for flexible film with LLDPE sealant layer.
\end{abstract}




\section{ACKNOWLEDGMENTS}

I would like to thank the following people who have helped me with my thesis:

- Dr. Koushik Saha - Assistant Professor, Cal Poly

- Dr. Jay Singh - Professor, Cal Poly

- Dr. Soma Roy - Assistant Professor, Cal Poly

- Cody Lawrence - The Dow Chemical Company 


\section{TABLE OF CONTENTS}

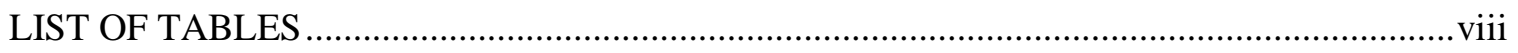

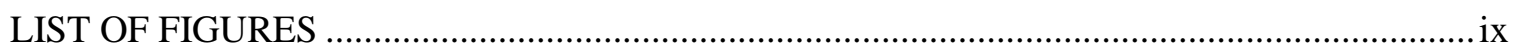

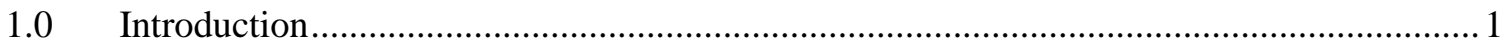

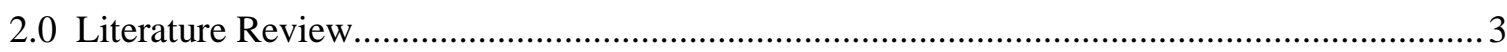

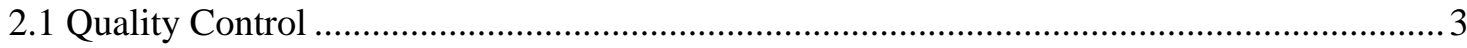

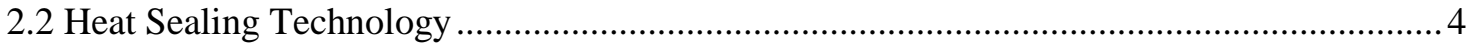

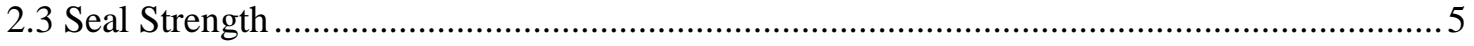

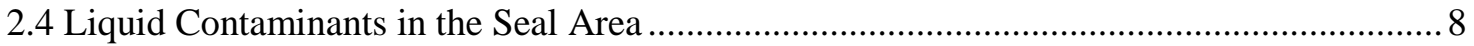

2.5 Previous Testing Methods for Leaks with Seal Contamination............................................ 10

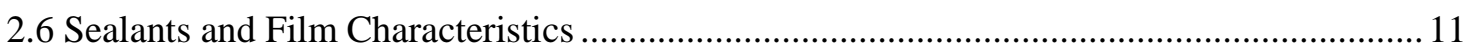

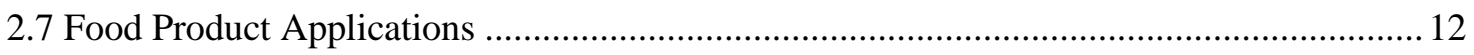

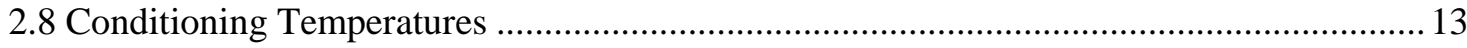

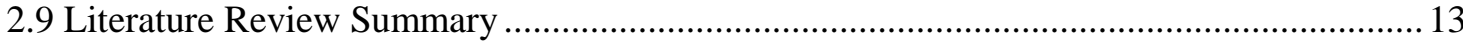

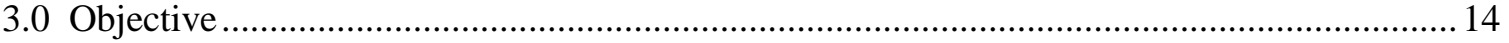

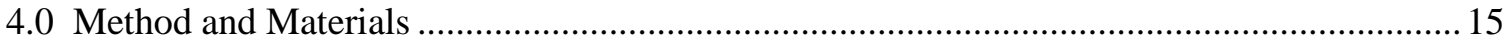

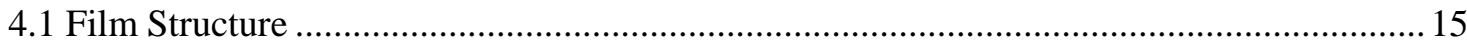

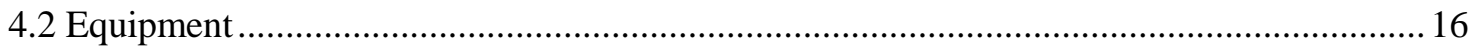

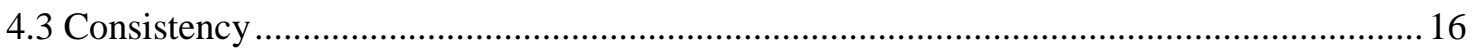

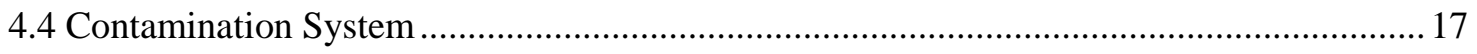

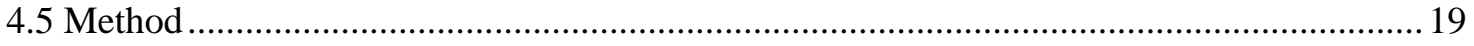

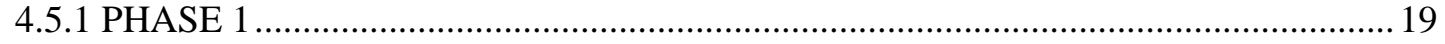

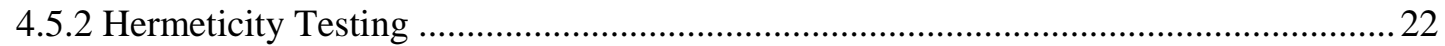

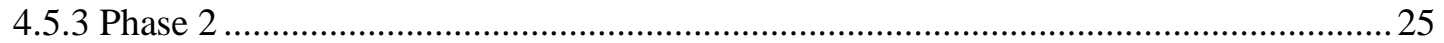

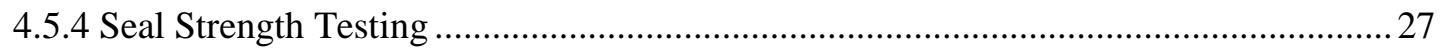

4.5.5 Determining Optimal Packaging Conditions ...........................................................28

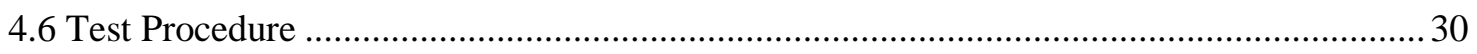

4.6.1 Horizontal Form, Fill and Seal Machine ...................................................................... 30

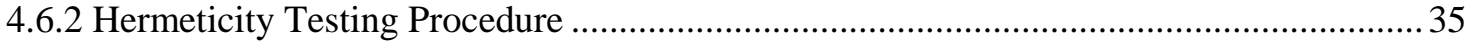

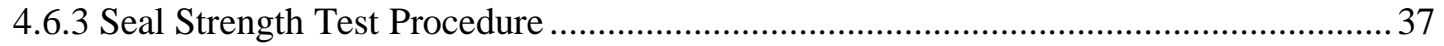

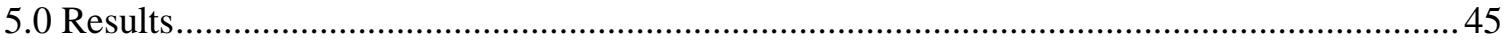

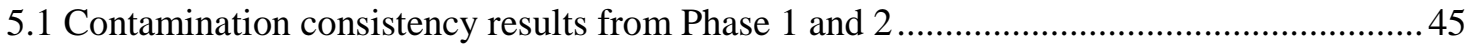

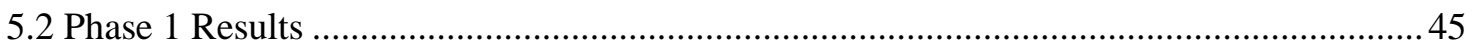




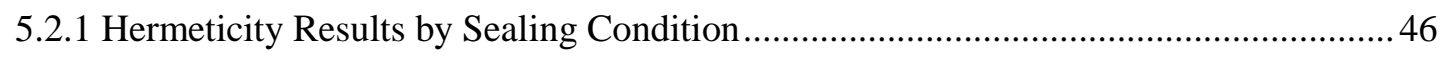

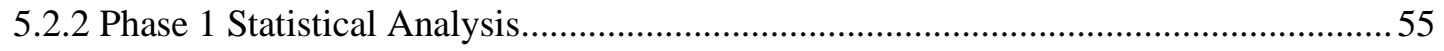

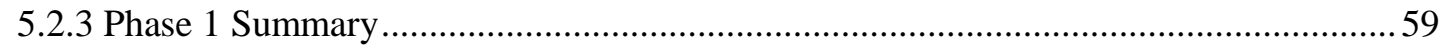

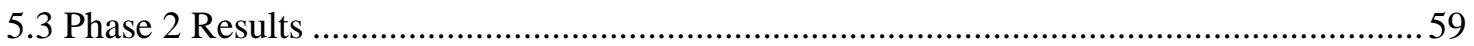

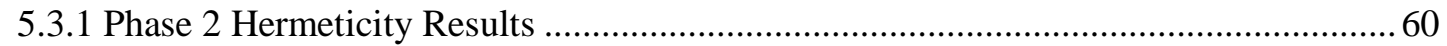

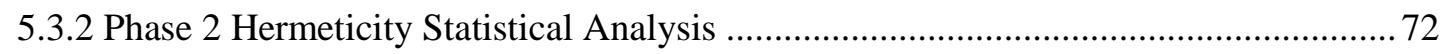

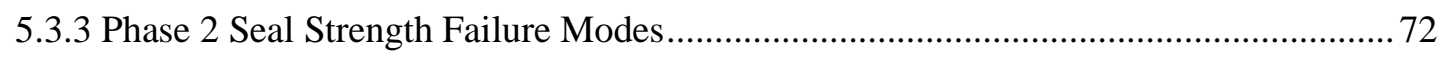

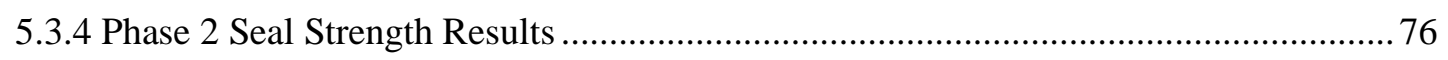

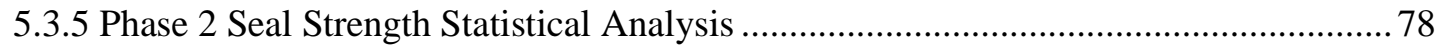

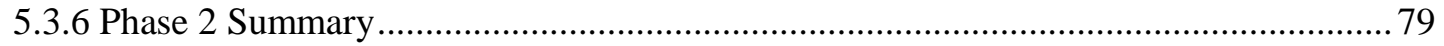

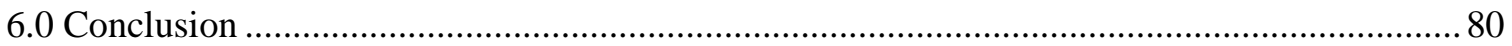

6.1 Significance of Contaminant Effect on Hermeticity and Seal Strength.............................. 80

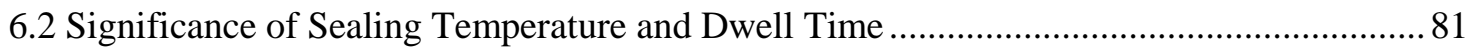

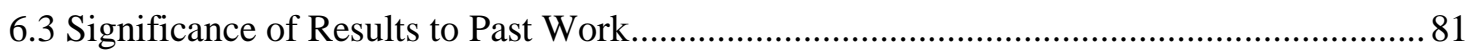

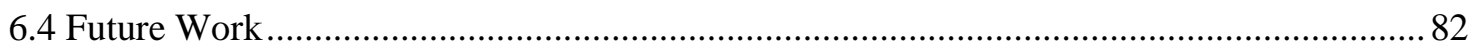

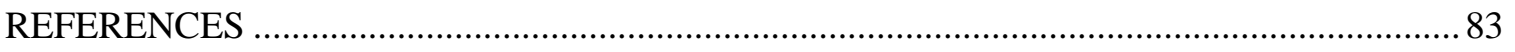

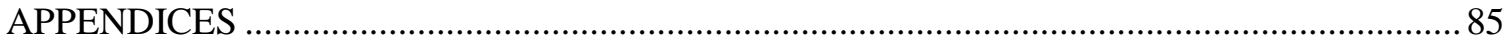

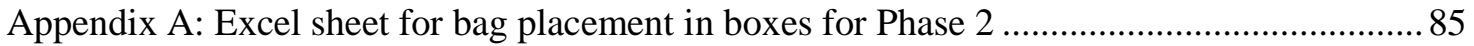

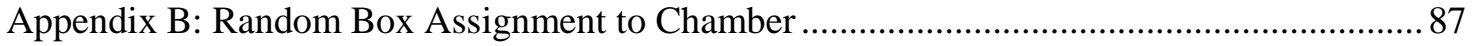

Appendix C: Random Order of Boxes Assigned by Test Day................................................. 88

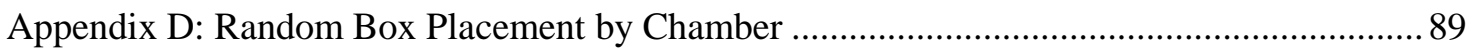

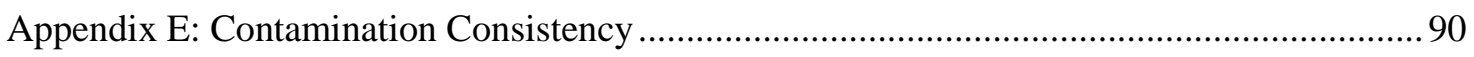

Appendix F: Phase 1 Binary Logistic Regression Analysis Results .......................................92

Appendix G: Phase 2 Binary Logistic Regression Analysis Results ...................................... 94

Appendix H: Phase 2 General Linear Model Analysis Results ..............................................94

Appendix I: Seal Strength Failure Modes by Test Category and Conditioning Temperature .................. 95

Appendix J: Seal Strength Raw Data Results ........................................................................ 97 


\section{LIST OF TABLES}

Table 1: Sealing Condition Combinations ……………………………………………….....2

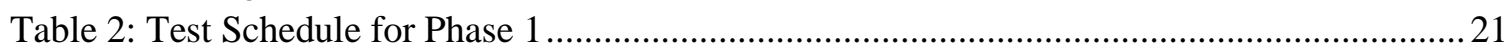

Table 3: Referenced Sealing Temperatures in Table 1 …………………………………….....21

Table 4: Referenced Dwell Time in Table 1..........................................................................21

Table 5: Bubble Size Categories for Hermeticity [20].........................................................22

Table 6: Hermeticity results based on leak location ...............................................................2

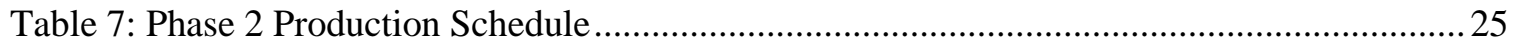

Table 8: Phase 2 Data Collection Schedule ……………………………………………….........2

Table 9: Phase 2 Expected Sample Size for Each Collection Day ..................................................26

Table 10: $120^{\circ} \mathrm{C}$ Sealing Temperature and 0.2s Dwell Time ………………………………........46

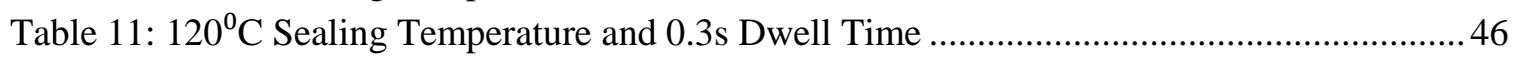

Table 12: $120^{\circ} \mathrm{C}$ Sealing Temperature and $0.4 \mathrm{~s}$ Dwell Time …………………………….............4 47

Table 13: $140^{\circ} \mathrm{C}$ Sealing Temperature and $0.2 \mathrm{~s}$ Dwell Time ……...............................................4

Table 14: $140^{\circ} \mathrm{C}$ Sealing Temperature and $0.3 \mathrm{~s}$ Dwell Time ……….........................................49

Table 15: $140^{\circ} \mathrm{C}$ Sealing Temperature and $0.4 \mathrm{~s}$ Dwell Time ……………................................50

Table 16: $160^{\circ} \mathrm{C}$ Sealing Temperature and 0.2s Dwell Time …………………………...............51

Table 17: $160^{\circ} \mathrm{C}$ Sealing Temperature and $0.3 \mathrm{~s}$ Dwell Time …………………………...............52

Table 18: $160^{\circ} \mathrm{C}$ Sealing Temperature and $0.4 \mathrm{~s}$ Dwell Time …………………………...............52

Table 19: Phase 1 Binary Logistic Regression Analysis ............................................................55

Table 20: Phase 1 Binary Logistic Regression Analysis ...........................................................57

Table 21: Binary Logistic Regression Analysis Results with Interactions ...................................58

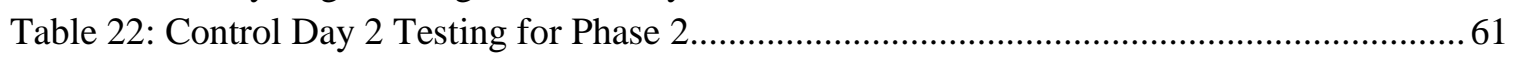

Table 23: Control Day 6 Testing for Phase 2.......................................................................61

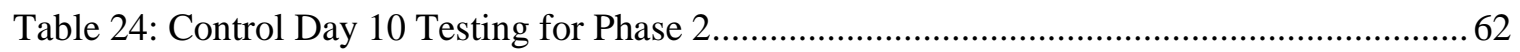

Table 25: Control Day 14 Testing for Phase 2 …………………………………………......62

Table 26: Salt Water Day 2 Testing for Phase 2 …………………………………………....63

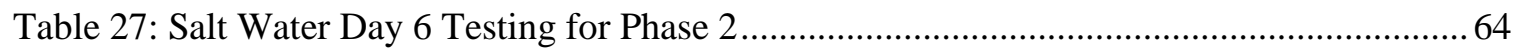

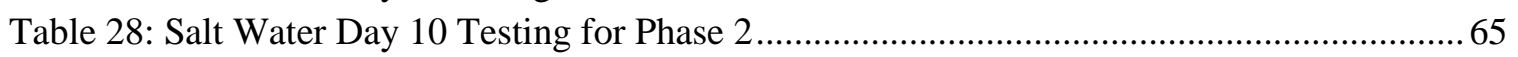

Table 29: Salt Water Day 14 Testing for Phase 2 …………………………………………....6 66

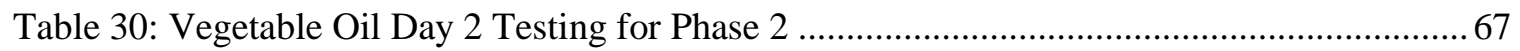

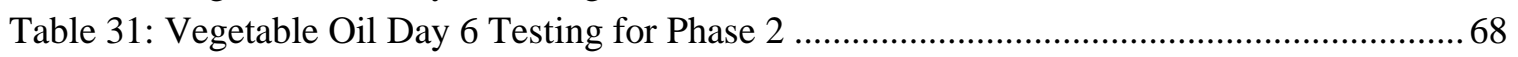

Table 32: Vegetable Oil Day 10 Testing for Phase 2 ……………………………………......... 69

Table 33: Vegetable Oil Day 14 Testing for Phase 2 ………………………………….........70

Table 34: Binary Logistic Regression Analysis for Phase 2 Hermeticity Testing...........................72

Table 35: Categories of Failure Modes .......................................................................................73

Table 36: Average Force (N) of Represented Samples for Refrigerated Condition .......................77

Table 37: Average Force (N) of Represented Samples for Ambient Condition ...............................77

Table 38: General Linear Model (ANOVA) Analysis Results for Phase 2 ....................................78 


\section{LIST OF FIGURES}

Figure 1: Relationship between Seal Bar Temperature and Apparent Seal Strength for

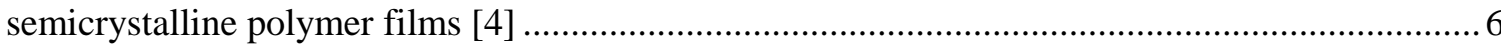

Figure 2: Previous Seal Strength Results found in study completed by [7] .................................. 7

Figure 3: Liquid Contact Angle with Solid Surface ............................................................... 9

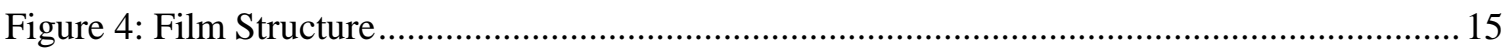

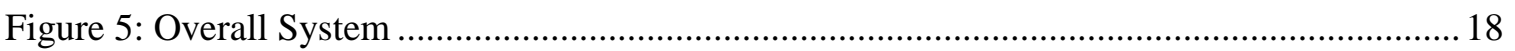

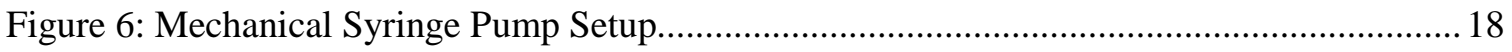

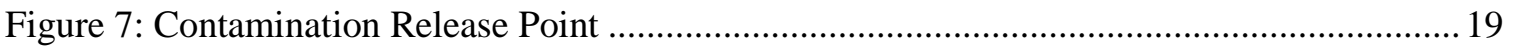

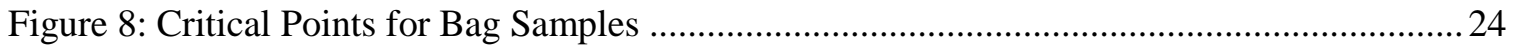

Figure 9: Specimen Setup for Unsupported Seal Strength Test................................................2

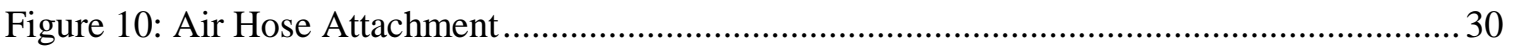

Figure 11: Air Pipe

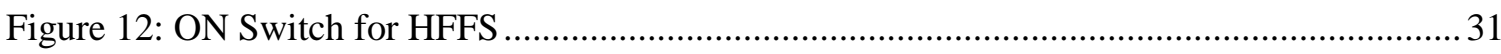

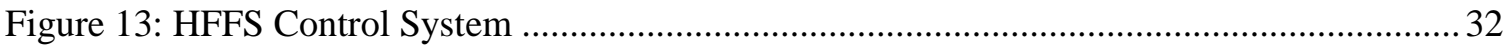

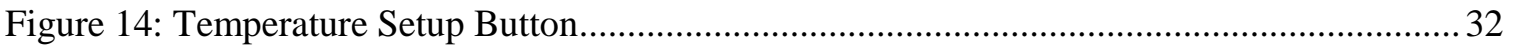

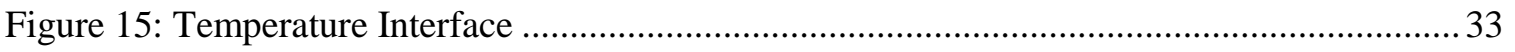

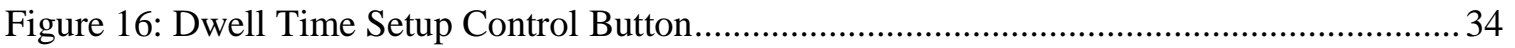

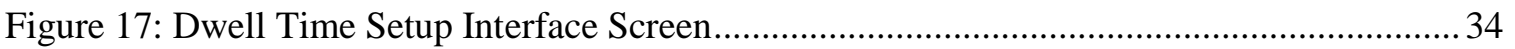

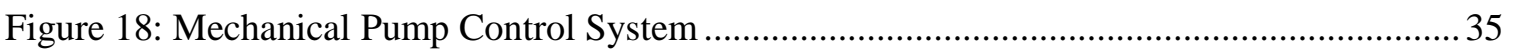

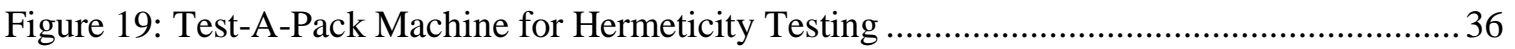

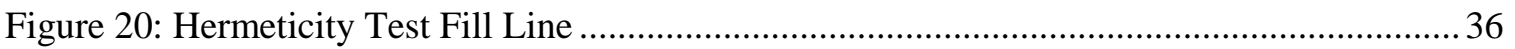

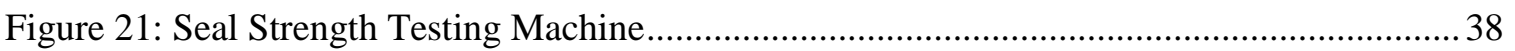

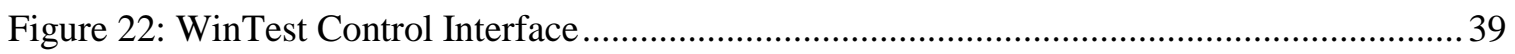

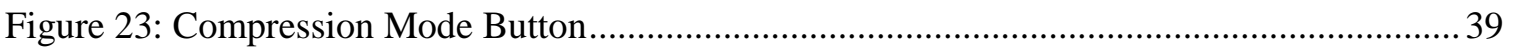

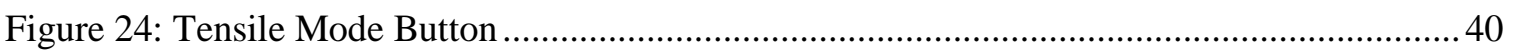

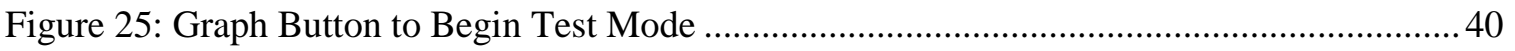

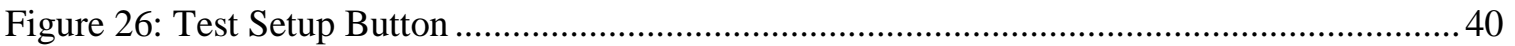

Figure 27: Front and Back T-Point Seal Samples Taken from Sample Bag.................................. 42

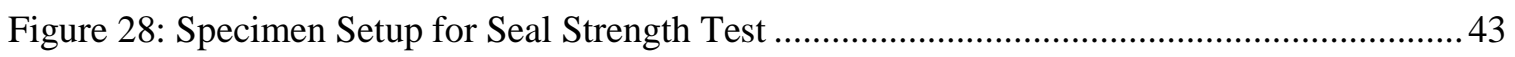

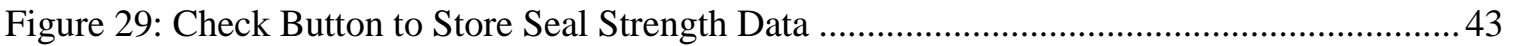

Figure 30: Contaminant Pass Rates by Dwell Time for $120^{\circ} \mathrm{C}$ Sealing Temperature ..................... 47

Figure 31: Contaminant Pass Rates by the Dwell Time for $140^{\circ} \mathrm{C}$ Sealing Temperature ..............50

Figure 32: Hermeticity Pass Rate for $160^{\circ} \mathrm{C}$ Sealing Temperature ............................................53

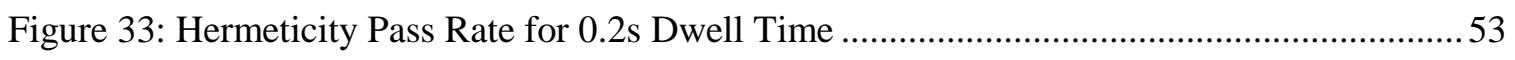

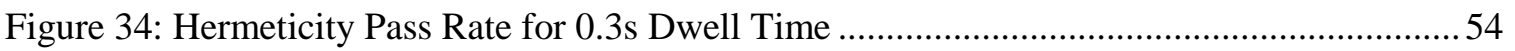

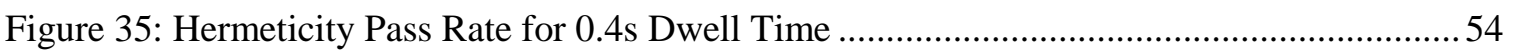

Figure 36: Phase 2 Refrigerated Condition Hermeticity Results for All Contaminants ................ 71

Figure 37: Phase 2 Ambient Condition Hermeticity Results for All Contaminants ...................... 71

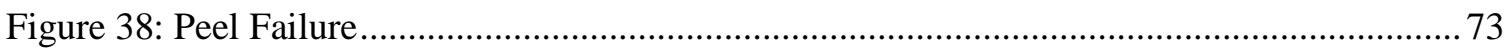

Figure 39: Peel Failure followed by Material Tear Mode at the T-point ....................................... 74 
Figure 40: Peel Failure followed by material tearing failure on edge of seal. .............................. 74

Figure 41: Material Tearing Failure along entire edge of seal. No peel failure observed. ............ 75

Figure 42: Material Failure not on edge of Seal. No peel failure observed. .................................. 75

Figure 43: Seal Strength Results for Refrigerated Conditioning Temperature ............................. 76

Figure 44: Seal Strength Results for Ambient Conditioning Temperature .................................... 77 


\subsection{Introduction}

The demand for high production volume requires fast production lines, and especially for flexible food packaging it is common to find food particles trapped in the seal area. Any food particle or substance found in the seal area of a flexible package is considered a contaminant. Quality control processes detect contamination and in some cases the package is discarded due to the assumption that the seal quality is compromised. The study is important to determining the effect of liquid contamination in the seal area for the flexible food packaging industry. As of June 2013, the flexible packaging industry grossed $\$ 26.7$ billion dollars in sales with 58 percent for the food packaging industry [1]. Flexible packaging uses less material weight and has the ability to optimize production. According to the Flexible Packaging Association, over a six year time frame, the packaging weight of a candy bar has reduced by 60 percent [1]. The ongoing successful research and development of advanced materials for specialty films gives flexible packaging a strong advantage among other packaging options. A wide range of different film structures offers solutions to prolonging shelf life and other package performance concerns such as contamination. In the food industry, two primary packaging functions are protecting the product from outside contamination and containing the product within the package. The demand for flexible packaging comes from the demand for low cost and high volume production capability. In comparison to rigid packaging, flexible packaging reduces packaging material weight per package. Thinner and lighter weight material can save costs for companies without compromising their packaging needs as well as reducing the environmental footprint. The switch to more flexible packaging requires a trial and error process to determine the optimal temperature and dwell time combination. Moreover, choosing the highest sealing temperature and dwell time is not the most effective option because it can slow down production and can effect seal properties. For flexible packaging, the film chosen for an automated packaging production will have an optimal or range of packaging conditions. In this study, nine different packaging 
conditions will be analyzed to compare the performance of seal through liquid contamination for oil-based and sodium-based food products. 


\subsection{Literature Review}

\subsection{Quality Control}

Currently, quality inspection for food production inspects for food particles in the seal area among other quality issues. Food particles found in the seal area are considered a contaminant and in some cases lead to leaking. The food particles in the seal area can be aesthetically displeasing to the consumer, and effect the consumer's perception of the product. It is time consuming to inspect every bag manually for contamination, so automated quality control processes were developed to efficiently find packaging defects. Polarized Light is one procedure used in industry to find food particles in the seal area. It is a non-destructive process that uses linear polarized light to pass through transparent film, which shows a color stress pattern once the light passes through the second light filter. Laser scattering imaging is another non-destructive process that measures the light that is deflected from the contaminant found in the seal area [2]. Both types of technologies produce images to inspect for food particles or other contaminants such as metal content in the seal area. In a study completed by Barnes et. al [2], polarized light and laser scatter technology had an accuracy of $96 \%$ and $90 \%$. Overall, polarized light and laser scatter technology identify defects in the seal but cannot determine if the defect has an effect on the hermetic seal. A hermetic seal provides a complete enclosed package with no leaks or holes. In addition to food contamination, wrinkles from film overlapping in the seal can also lead to poor seal integrity. These issues can be visibly seen during inspection and detected through automated quality control processes. In this study, liquid contaminants are forced into the seal area to test hermeticity and seal strength. The quality of the seal is determined by seal integrity, which includes seal strength properties and hermeticity. Seal strength is the amount of force required to separate the film progressively over time [3]. It is also important factor for containing the product from the time it is packed to the time it is consumed. However, too high of a seal strength can make it difficult for consumers to open the package. 


\subsection{Heat Sealing Technology}

Heat sealing is commonly used in the flexible packaging industry and includes jaw-type seal bars, rotary sealers, band rotary sealers, bead sealers, hot knife or side-weld sealers [4]. The study uses heat sealing technology using jaw-type seal bars for a horizontal form, fill, and seal flow-wrap machine. There are three parameters for heat sealing: 1) sealing temperature 2) dwell time 3) and pressure. The temperature is an important factor for the sealant surface to reach its molten or partially molten stage. Secondly, the dwell time is the duration the seal jaws come into contact with the film. In this study, the dwell time is considered the actual time period the seal jaws are in direct contact with the film versus the total time the seal jaws are in motion to make each seal. Dwell time allows for the polymer chains to reach molten or partially molten stage to entangle and create a hermetic seal. If dwell time is too short for the polymer chains to reach molten or partial molten stage, the corners and the T-point will have a weak seal and are more likely to show leaks during hermeticity testing. The T-point refers to the point on the seal where the fin seal meets the end seal. The pressure applied to seal both sides of the film together will remain the same throughout the study. Pressure is needed to seal two film surfaces together, but increasing the pressure has no effect on seal strength $[4,5]$.

The seal jaw temperature is a primary factor for seal properties but the interface temperature is the actual temperature of the sealed surface during the sealing process. Interfaced temperatures are important to reaching desirable sealing properties. This study did not record the interface temperature but monitored the actual sealing temperature of the machine. Future work can include determining the relationship between the set sealing temperature and interface temperature.

According to Meka and Stehling [4], the interfacial temperature is a lower value than the platen temperature. The study also tested the relationship between dwell time and platen temperature. At $130^{\circ} \mathrm{C}$, an increase of only $10 \%$ interface temperature was observed from 0.4 seconds to 1.4 
seconds dwell time. In addition, Meka and Stehling determined the effect of dwell time has less an effect on interface temperature as the sealing temperature increases. Moreover, sealing temperature has more of an effect on seal strength than dwell time.

Moreover, seal jaw styles can differ between machines and different sealing technologies. Matthews et. al [6], studied seal strength and the effect of crimp angle and pitch of the seal jaw for heat sealing processes.. The study compared Cellulose $(38 \mu \mathrm{m})$ and PLA $(35 \mu \mathrm{m})$ to OPP $(25 \mu \mathrm{m}, 35 \mu \mathrm{m}$, and $50 \mu \mathrm{m})$ and found that crimp angle is a secondary factor to seal strength. Moreover, the crimp styles with more than $80^{\circ}$ angles provide greater seal strength for films outside $25-45 \mu \mathrm{m}$. The film used in this study is $65 \mu \mathrm{m}$, and crimp style seals were used in the study. The crimp angles of the seal jaws were not determined in this study, but can be determined in future studies. Furthermore, the study showed crimp geometry as a secondary factor behind seal temperature.

Although sealing temperature is one of the two primary factors to reaching hermeticity, it is important to consider the peel force required to open the package. The temperature and dwell time combination may provide the strongest seal strength but it may make it impossible for the consumer to open the package. Companies can increase sealing temperatures with shorter dwell times to expedite the filling process. However, the change in temperature and dwell time to reach the desired interface temperature more quickly can change the seal properties [7].

\subsection{Seal Strength}

Testing the seal strength determines the amount of force or stress on the seal with respect to the elongation or strain to reach material or peel failure. In this study, the seal strength will be tested during Phase 2 after the optimal sealing condition is determined from Phase 1. Testing the seal strength of a flexible pouch determines the type of seal failure for the given sealing condition. 


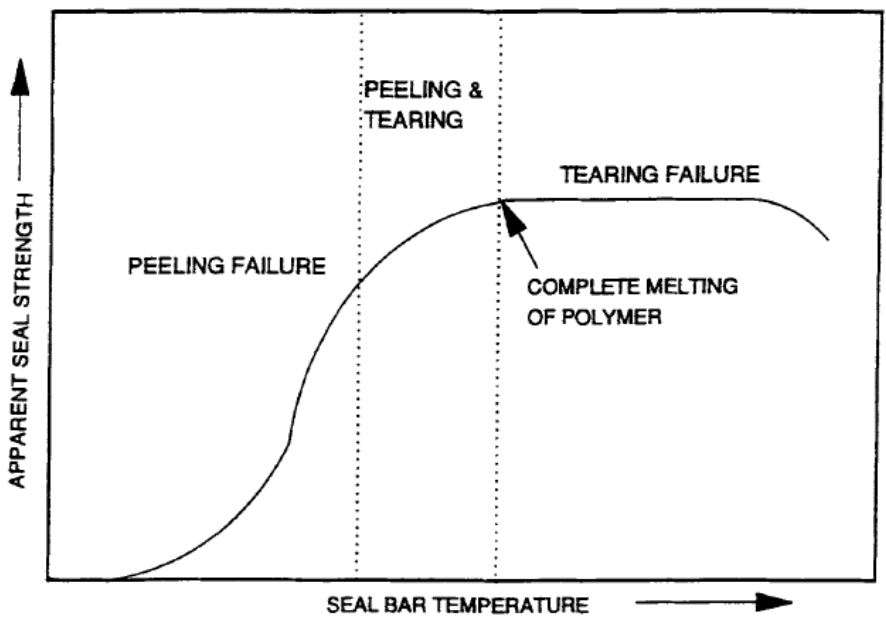

Figure 1: Relationship between Seal Bar Temperature and Apparent Seal Strength for semicrystalline polymer films [4]

The Figure 1 shows that if the seal bar temperature is above the melting point, $T_{m}$, of the sealant, then the seal strength test will show a tearing mode failure. On the other hand, the seal strength test will show a peel failure if the seal bar temperature is well below the $\mathrm{T}_{\mathrm{m}}$ of the sealant.

However, if the seal bar temperature is within close range of the $\mathrm{T}_{\mathrm{m}}$ but below the melting point, the seal strength test will more likely result in a peeling and tearing mode failure.

There are several types of results from a seal strength test: peel failure, tear failure, peel and tear failure, and elongation failure. A weld seal will result in a tear failure, which shows that the strength of the seal is stronger than the strength of the film [7]. In addition, there is also delamination failure mode that can occur in combination with the other failure types. Delamination occurs when one of the layers separates from the film during seal strength while either the outer layer or sealant layer remains attached during tensile testing. 


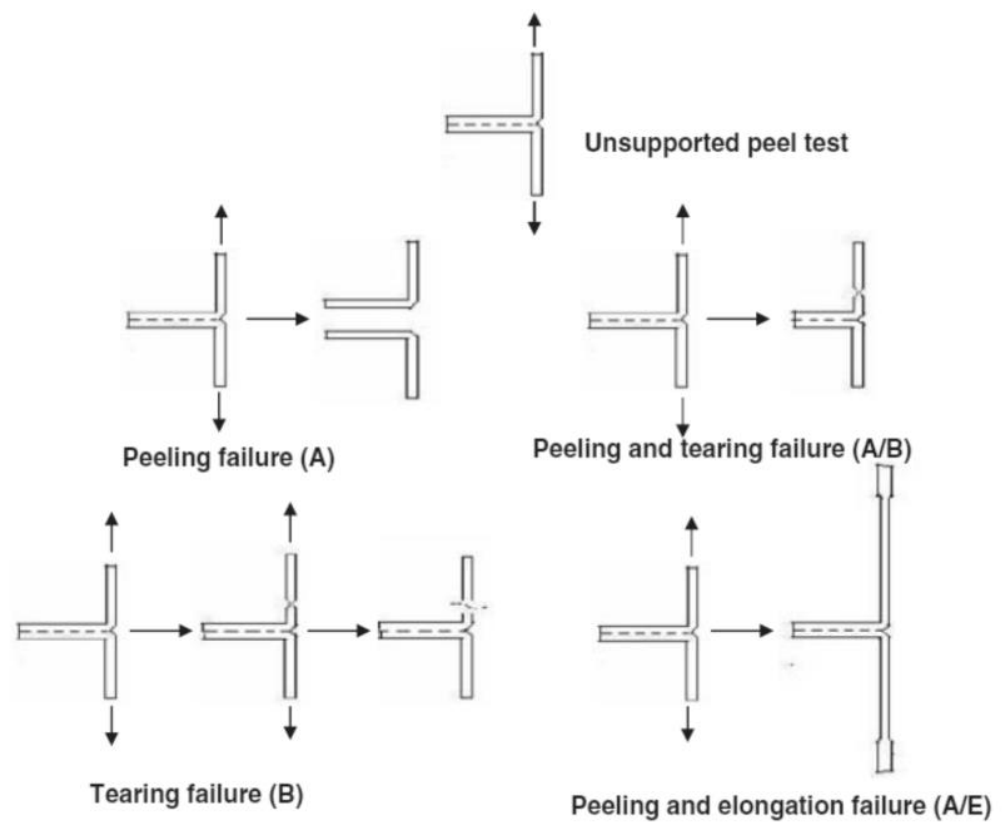

Figure 2: Previous Seal Strength Results found in study completed by [7]

According to Yuan et. al [5], a sealing temperature of a few degrees before the melting temperature, $\mathrm{T}_{\mathrm{m}}$, seal strength will significantly increase and result in a peel, delaminating a tear mode or combination of the failure modes. If the sealing temperature is more than a few degrees below the melting point, then a peel failure mode will more likely occur and the result will be a lower strength than the other failure modes. Yuan et. al [5] tested a similar structure to what is used in this study, Polyethylene-Terephthalate, PET (film laminate) and linear low-density polyethylene, LLDPE (sealant layer). An increase in seal strength occurred from 0.1 seconds to 1 second dwell time for the majority of sealing temperatures within the range of $103^{\circ} \mathrm{C}$ and $130^{\circ} \mathrm{C}$. Furthermore, the same seal strength can be made at different sealing conditions. For example, a $115^{\circ} \mathrm{C}$ and 0.2 seconds sealing condition showed the same results for a sealing temperature equal or greater than $118^{\circ} \mathrm{C}$ with 0.1 seconds.

Tetsuya et. al [8] studied OPP and CPP seal strength at different sealing temperatures and concluded that an increase in temperature showed an increase in material failure at edge of seal. 
The lower range sealing temperature of $115^{\circ} \mathrm{C}$ showed more immediate material failure compared to $170^{\circ} \mathrm{C}$ and $250^{\circ} \mathrm{C}$ that showed more necking before failure.

\subsection{Liquid Contaminants in the Seal Area}

A previous study completed by Mihindukulasuriya and Lim [9] investigated seal strength with contamination in the seal area. According to Mihindukulasuriya and Lim [9] the liquid contaminant will act as a heat sink by absorbing the thermal energy that passes from the seal jaws through both plies of film. The thermal diffusivity of vegetable oil, $0.09 \times 10^{-4} \mathrm{~m}^{2} / \mathrm{s}$ at $20^{0} \mathrm{C}$, is lower than water $1.4 \times 10^{-4} \mathrm{~m}^{2} / \mathrm{s}$ at $20^{\circ} \mathrm{C}$ Mihindukulasuriya and Lim [9]. However, this study uses a salt water solution instead of water. Therefore, the heat sink effect will be greater with salt water due to its ability to absorb more thermal energy than vegetable oil. Less thermal energy passing through the liquid contaminant may effect the interface temperature of the film. The thermal diffusivity of the liquid contaminants may effect the seal strength and hermeticity compared to the control, which has no contamination in this study.

Different oil-based and salt-based liquid contaminants have different surface tension with the film which refers to the contact area between the contaminant and film. The contact of the area of the liquid contaminant is due to the surface tension between the liquid and film. Young determined the equation for the relationship between liquid, solid, and vapor between a liquid droplet and a solid surface:

$$
\gamma_{\mathrm{SV}^{0}}-\gamma_{\mathrm{SL}}=\gamma_{\mathrm{LV}^{0}} \cos \theta
$$

$\gamma_{\mathrm{SV}^{0}}$ is the surface tension of the solid and vapor boundary. $\gamma_{\mathrm{SL}}$ is the surface tension of the solid and liquid boundary. $\gamma_{\mathrm{LV}^{0}}$ is the surface tension of the liquid and vapor boundary $[9,10]$. 


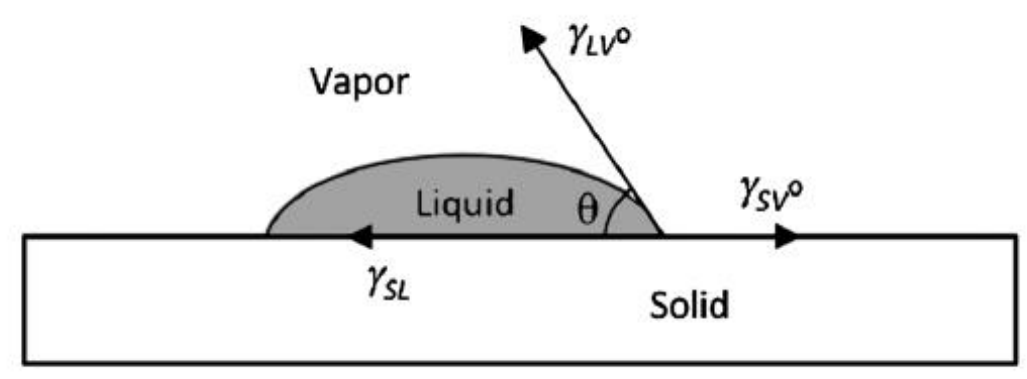

\section{Figure 3: Liquid Contact Angle with Solid Surface}

When in contact with a solid surface, the contact angle $\theta$ for water is $89.51^{\circ} \pm 1.17^{\circ}$ and vegetable oil is $29.96^{\circ} \pm 1.2^{0}$ [9]. Overall, the contact angle indicates the amount of contamination that comes in direct contact with the film over an area of the film. However, the movement of the seal jaws will cause the contaminant to displace over the area of the seal.

Furthermore, the surface tension and contact angle influence the displacement of the contaminant that occurs during the sealing process. Both contaminants apply the same volume of contamination, but the contaminant to film contact area will be different.

In addition to contact angle, the liquid's density is an important property for determining liquid displacement during the heat sealing process. The salt percentage used in the salt water solution is $8.2 \%$ to simulate contaminant performance more similar to salty foods. The density varies slightly for different vegetable oils, but soybean oil has a density of $0.9185 \mathrm{~g} / \mathrm{cm}^{3}$ at $20^{\circ} \mathrm{C}$ [11]. According to Rodenbush et.al [12], density for vegetable oil decreases by $0.00064 \mathrm{~g} / \mathrm{cm}^{3}$ for every $1^{0} \mathrm{C}$ increase in temperature.

$$
\rho=a+b \cdot T
$$

$\rho$ expresses the density in grams per cubic centimeter, $a$ is the intercept, $b$ is the negative slope referring to the relationship between density and temperature, and $T$ is the temperature in Celsius. 
Water has a density of $0.988 \mathrm{~g} / \mathrm{cm}^{3}$ at $21^{\circ} \mathrm{C}$ [13], which is greater than vegetable oil and will displace more compared to vegetable oil.

Different densities mean the contaminants will displace differently during the sealing process. Furthermore, the density indicates salt solution will displace more when the seal is made compared to vegetable oil because it has a greater density. The greater contact angle of the salt solution also shows there is less initial contact with the film for salt water for the same volume of contamination. Once the two seal jaws bring the two film surfaces together, then the water contaminant should be expected to spread over a greater area. In addition, the salt solution is expected to come in less contact with the film due to the surface tension.

\subsection{Previous Testing Methods for Leaks with Seal Contamination}

To test seal integrity, there is either destructive or non-destructive methods. Some destructive methods include tensile testing used for seal strength, water vacuum chamber used for hermeticity testing, and dye penetration to show leaks in seal. Dye penetration is a visual inspection to check for leaks shown by a path through the seal from the inside to the outside of the bag. Matthew et. al [6] determined dye penetration is a poor method to test the presence of seal leaks because only samples exposed to excessive sealing conditions pass the test.

Non-destructive tests include ultrasonic pulse-echo or ultrasonic transmission testing for defects in the seal such as contamination. Transmission uses transmitting and receiving transducers on opposite sides of the seal. A contaminant in the seal will decrease the amplitude of the ultrasonic beam passing through the seal [14]. On the other hand, pulse-echo used a reflective pulse to test for, cracks, folds, voids, shrinks, porosity and flaking in metals [14]. Prior to Ozguler's [14] study on ultrasonic pulse-echo technique for flexible packaging, it was assumed that the technology was insensitive to test seal integrity for flexible films [14]. Ultrasonic pulse-echo used backscattered amplitude integral (BAI), which is an acoustic technology compared to optical to record the 
reflective sound waves to detect seal defects. Furthermore, BAI measures sound waves at 17.3 $\mathrm{MHz}$ and can detect any defects whether it is water or an air bubbles as long as the test is done within $10 \mu \mathrm{m}$ range of the film [14].

\subsection{Sealants and Film Characteristics}

The sealant layer is the inner most layer of the packaging film that comes in direct contact with the opposing sealant layer during the sealing process. A high quality sealant has a broad sealing window and high hot tack strength [15]. A wide range of sealing temperature also allows for lower sealing temperatures without compromising the integrity of the seal. In addition, the hot tack strength refers to the film's ability to refrain from strains during its molten state [16]. A sealant with a low seal initiation temperature allows for lower process sealing temperatures, and a lower sealing temperature will use less energy than a higher sealing temperature.

Furthermore, the study uses a LLDPE commercial grade for its higher tensile strength, puncture resistance, and elongation compared to LDPE [16]. There are three polymerization processes - 1) high pressure 2) gas phase 3) slurry pressure 4) solution. More importantly, the linear low-density polyethylene sealant uses The Dow Chemical Company's constrained geometry catalyst systems (CGCT) or INSITETM technology. INSITE ${ }^{\mathrm{TM}}$ uses metallocene catalysts for a solution process for improved physical properties and process capabilities [17]. The improved long chain branching (LCB) of the polymer produced by INSITE technology is not found in other metallocene technology processes. The polymers produced with LCB have an improved melt fracture resistance and uniform shear resistance process capability [17]. Lastly, the metallocene copolymer has a lower melting point due to the increase in long chain branching to short chain branching ratio. The reduction in the comonomer short chains allows for a low seal initiation temperature. 
Package performance depends on the film structure chosen for a product. In addition to providing high quality seals, the film must support the product and its expected shelf life from the time the product is packaged, followed by transportation, and lastly consumed by the consumer. A Failed hermetic seal can shorten the shelf life of a product. Even though this study observes seal strength and hermeticity due to contamination, different food products react with the film over time. Depending on the food product application, oxygen and water vapor barriers are important characteristics of a film to ensure the shelf life of the product.

\subsection{Food Product Applications}

The horizontal flow wrap machine used in this lab is commonly used for snack foods such as bar type foods, sliced and block cheese, cookies and other baked goods. Packaging processes are best suited for each product application based on the product's needs. For example, a vertical form, fill, and seal machine is used to pack flexible pouches with product using gravity such as shredded cheeses or bagged lettuce. On the other hand, candy bars and cookies that require more delicate handling or thermoformed trays will use a horizontal flow wrap machine. In addition, some food product applications require modified atmosphere packaging or vacuum packaging to delay the oxidation or aging process of the product. For example, vacuum packaging is commonly used for cheese packaging to eliminate the oxygen in the headspace to prevent aerobic bacteria, yeasts, and molds [18]. Trapped air in the package can quickly shorten the shelf life of the cheese, but a poor seal can also lead to oxygen passing through to the product due to leaks in the seal.

The study relates most to snack bars such as cereal bars, protein bars, and candy bars, but it can be used to relate to the greater food industry. The majority of these foods are stored by the retailer and consumer at ambient conditions, which is considered to be $23^{\circ} \mathrm{C} \pm 1{ }^{\circ} \mathrm{C}[19]$. 


\subsection{Conditioning Temperatures}

The second phase of the study will test each contaminant's performance at standard conditions at $23^{\circ} \mathrm{C} \pm 1{ }^{0} \mathrm{C}\left(73.4^{0} \mathrm{~F} \pm 2{ }^{\circ} \mathrm{F}\right)$ and $50 \% \pm 2 \%$ relative humidity, and refrigerated conditions at $5{ }^{\circ} \mathrm{C} \pm$ $2^{0} \mathrm{C}\left(41^{0} \mathrm{~F} \pm 4^{0} \mathrm{~F}\right)$ and $85 \% \pm 5 \%$ relative humidity [19]. The conditioning temperatures are set at a constant for the two week test period to test the effect of temperature on hermeticity and seal strength for the two contaminant types.

\subsection{Literature Review Summary}

Overall, the flexible packaging market is a growing and successful market especially for the food industry. Developments in film and polymerization process technologies have made film packaging more desirable and applicable to many food industries. Previous work studied the seal strength of flexible pouches with seal contamination, but this study further determines the effect of seal through liquid contamination and temperature over time. Sealing temperature and dwell time are the two primary sealing factors to produce a quality seal. As mentioned previously, seal jaw pressure has little effect on the quality of the seal. Lastly, seal through liquid contamination may be able to be detected with current quality control processes, but the study determines the impact on the seal's properties. 


\subsection{Objective}

The objective of the study is determining the effect of liquid contamination found in the seal area on hermeticity and seal strength for flexible pouches with linear low-density polyethylene sealant. First, the study must determine if liquid contaminants perform differently at different sealing temperatures and dwell times. In addition, the study must determine if time and storage temperature effect the performance of liquid contamination in the seal area. The optimal sealing condition with the highest hermeticity pass rate is determined based on statistical analysis.

Furthermore, a shelf life study is used to ensure hermeticity does not change over time. If there is a seal leak two days after the package is produced, then it should also show a seal leak fourteen days after production. It is also important to observe the difference in results for both hermeticity and seal strength. The three test categories are salt water for sodium based foods, vegetable oil for oil-based foods, and non-contaminated seals (control). 


\subsection{Method and Materials}

\subsection{Film Structure}

The film used in this study was provided by The Dow Chemical Company and it is a commercial grade film currently used by the snack food industry. The film is a DOWLEX ${ }^{\mathrm{TM}} 2045 \mathrm{G}$ LLDPE 1.6mil film. The PET film is a laminate that is commonly used in films for improved puncture resistance, and barrier properties. An adhesive is used to adhere the PET laminate to the film. Overall, the film is tested for performance in addition to the sealant performance since it comes in direct contact with the contaminant.

The linear low-density polyethylene (LLDPE) sealant, with the trademark name ELITETM 5400G, has a $0.916 \mathrm{~g} / \mathrm{cm}^{3}$ density and has a low seal initiation temperature, $90^{\circ} \mathrm{C}$. The sealant's puncture resistance equals $107 \mathrm{~N}$ and 5.5 J. Three film rolls are supplied for the study from the beginning of Phase 1 to Phase 2.

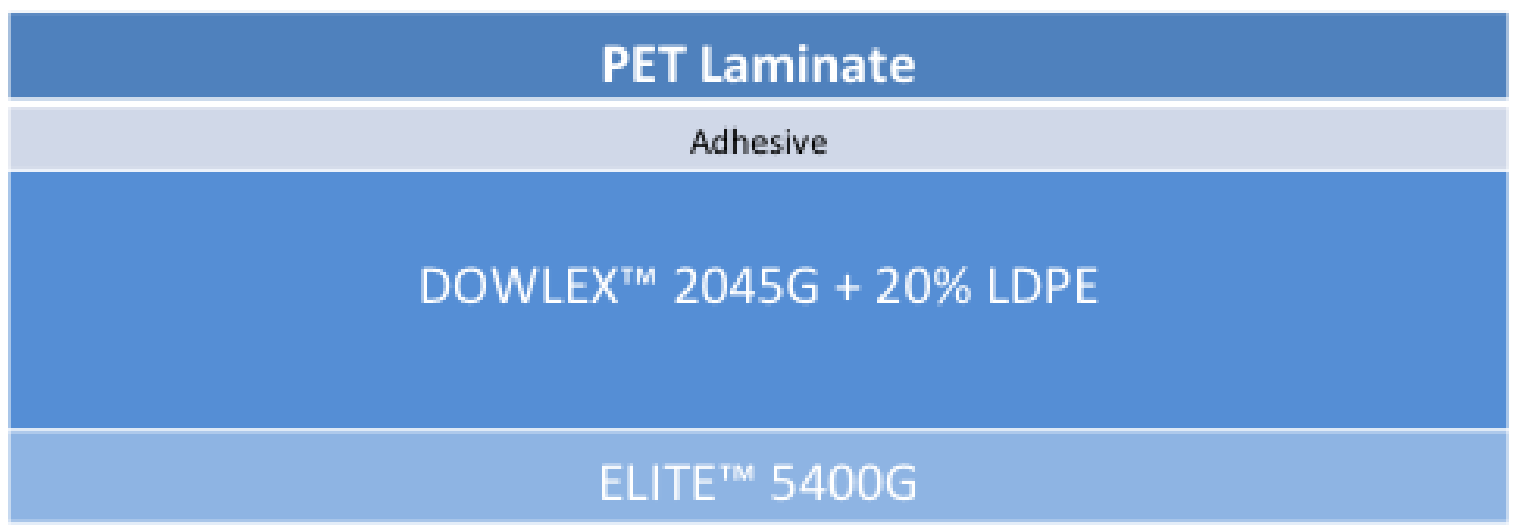

Figure 4: Film Structure 


\subsection{Equipment}

The experiment uses the horizontal form fill and seal (HFFS) machine manufactured by Delfin, and a Dow specialty film with a chosen sealant grade commonly used for commercial snack food applications. For hermeticity testing, the Test-A Pak integrity tester is a large cylindrical water tank with a lid that submerges one inch under water. The Test-A Pak is a vacuum chamber to inflate the sample bags and visually observe for seal leaks. The Testometric tensile tester is a pneumatic system for seal strength testing. A Raytek temperature gun is used to test the actual temperature of the environmental chambers and the actual temperatures of the sample bags. The two environmental chambers used for conditioning temperatures are manufactured by Darwin Chamber Company. Lastly, a JDC precision sample cutter, manufactured by Thwing-Albert Instrument Company is used for cutting the specimen samples for seal strength testing from the sample bags.

\subsection{Consistency}

The system must allow for consistent contamination from top to bottom seal for all types of contamination. The stream of contamination must be consistent from sample bag to sample bag to ensure data results are accurate. To measure consistent contamination, the width or thickness of the contamination must be measured during preliminary testing. The width measurements of the stream will be taken next to the front and back seals and the midpoint along the contamination stream. However, there is some tolerable variation allowed from sample bag to sample bag since the measurements are taken by the human eye. The acceptable coefficient of variation will be less than $15 \%$. A preliminary trial must be conducted to measure the contamination and to test the contamination system. The flow rate of contamination may vary between contamination types, so the flow rate must be measured for each contamination as well as the width or thickness of the contamination stream. 


\subsection{Contamination System}

The contamination stream falls along the path of the fin seal to contaminate the T-point, which is the most critical point of failure on the package. The T-point is chosen for point of contamination since the seal jaws will be sealing through four layers of film. The decision to contaminant on top of the fin seal was chosen because it is most difficult to seal through four layers of film at the optimal condition for temperature and dwell time.

The three test categories for this study are vegetable oil and a salt water solution, and noncontamination which is the control. Vegetable oil is used to simulate for oil based products that will be in a flexible film packaged on a horizontal flow wrap machine. Salt Water will be used to simulate snack food products that are sodium based packaged in a film on a horizontal flow wrap machine. Pure Wesson 100\% Natural Soybean Oil brand is used in the study for the vegetable oil contaminant. No additives such as water are added to the vegetable oil in the study. Morton Salt brand was mixed with water for the sodium water contaminant. The salt percentage in water was $8.2 \%$ or 41.92 grams per $465.16 \mathrm{ml}$ of water. The percentage of sodium water was chosen based on preliminary work to maximize the amount of salt in the solution with semi-dissolved characteristics. Once the solution was mixed with a tongue depressor for two minutes, the sodium was dissolved into the water but the salt grains remained visible in the contamination stream.

A system is created on the machine that uses a mechanical syringe pump, $60 \mathrm{ml}$ syringe, 1/4" OD 0.170 " ID clear vinyl tubing to attach the syringe to the $3 / 16$ " OD 0.148 " ID steel tube (three feet), one brass adapters (male), and one brass swivel straight nozzles (female). The system forces one stream of contamination inside the bag by exposing the nozzle right after the fin seal is created and before the two end seals are made. This allows for contamination to be contained in the bag during the tube form as well as contaminate the end seals. 
The syringe pump has a vinyl flexible tube (o.d.) which is extended to a stainless steel tube on the opposite end, which has a single nozzle to release the contaminant onto the film. The fin seal is created through rollers underneath the conveyor belt, which creates the tube of film. The nozzle hovers over the fin seal once it is created and passes the heated rollers underneath the conveyor belt. The nozzle hovers to avoid preventing the film from moving forward, but the tip of the nozzle still comes in direct contact with the film (Figure 7).

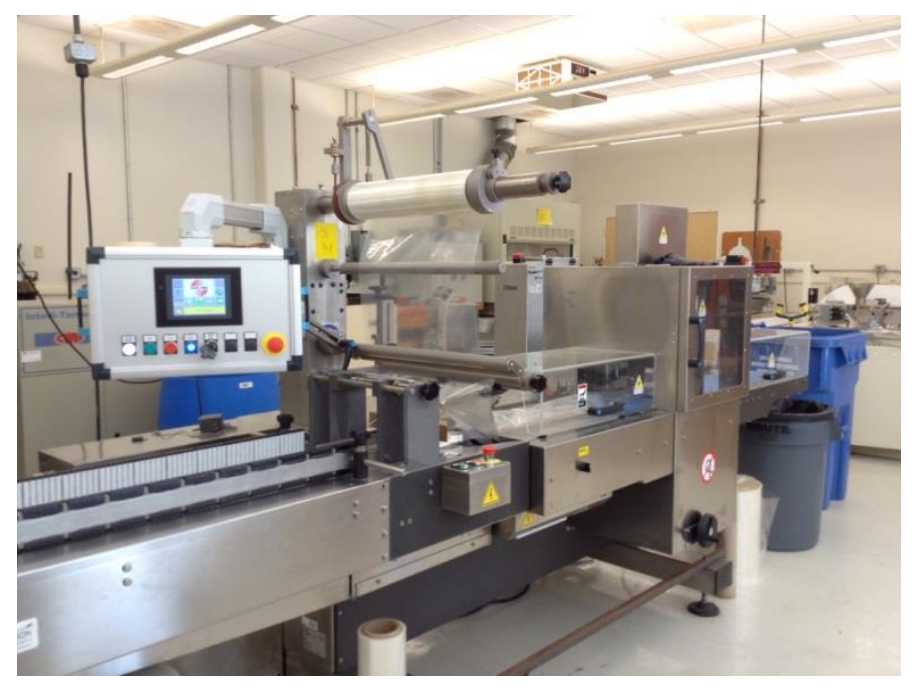

Figure 5: Overall System

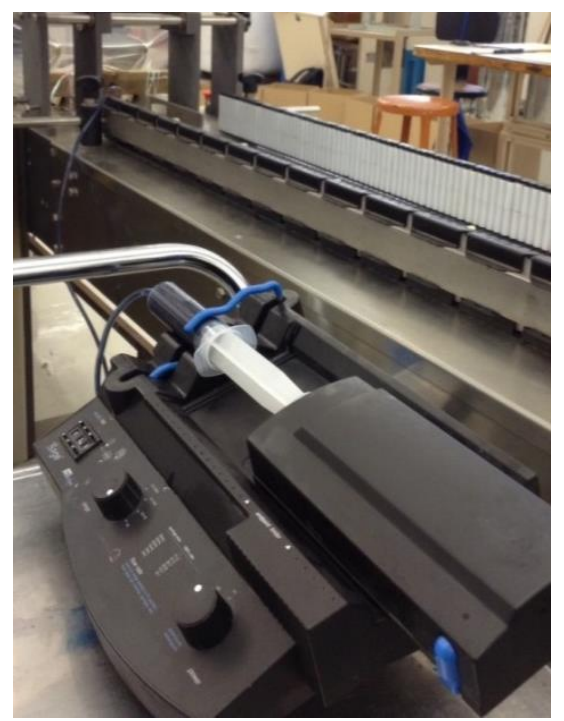

Figure 6: Mechanical Syringe Pump Setup 


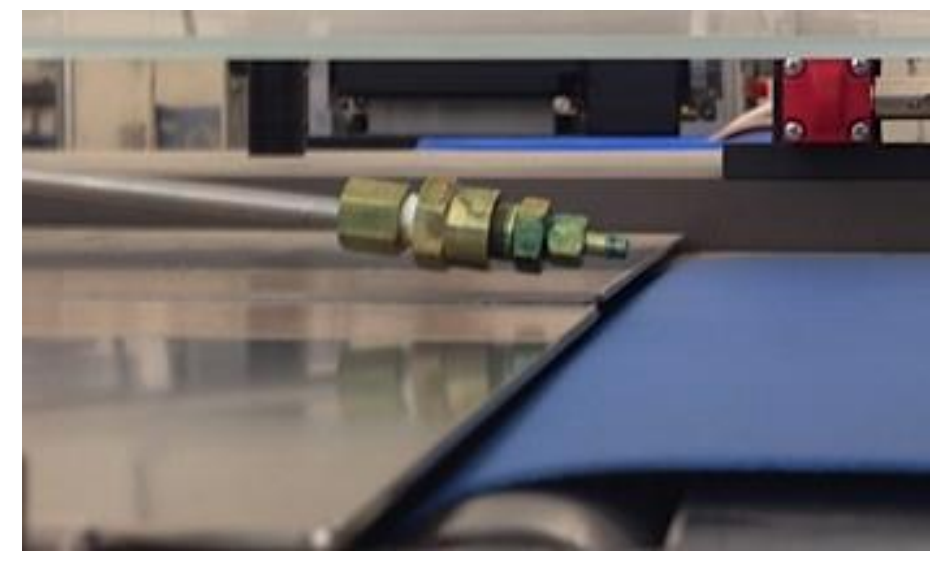

Figure 7: Contamination Release Point

The system has two tongue depressors attached to the right side of the stainless steel tube once the fin seal starts to form to prevent the tube of film to shift to one side of the conveyor belt. It is observed in the preliminary study that the tube will shift to the left causing a corner leak on the same side for the front and end seal. After the addition of the tongue depressors, the detection of corner leaks during the hermeticity test was reduced.

The stainless steel tube is placed through a wooden block that is attached to the inner former to keep it from moving freely during production. The wooden block is held in place to avoid unwanted movement during production of the sample bags.

\subsection{Method}

\subsubsection{PHASE 1}

There are a total of nine conditions (temperature and dwell time combinations) that will be used in Phase 1 and include different temperatures and dwell times. Phase 1 conducts hermeticity testing at all nine conditions to determine the most optimal sealing condition. The different conditions are as follows: 


\begin{tabular}{|l|l|}
\hline Temperature & Dwell Time \\
\hline $120{ }^{\circ} \mathrm{C}$ & 0.2 seconds \\
\hline & 0.3 seconds \\
\hline & 0.4 seconds \\
\hline $140{ }^{\circ} \mathrm{C}$ & 0.2 seconds \\
\hline & 0.3 seconds \\
\hline $160{ }^{\circ} \mathrm{C}$ & 0.4 seconds \\
\hline & 0.2 seconds \\
\hline & 0.3 seconds \\
\hline
\end{tabular}

\section{Table 1: Sealing Condition Combinations}

Phase 1 will test two contaminants - vegetable oil and salt water at all the above conditions. Noncontaminated bags will be the control in the study. A total of 13 samples for each bag type will be made at each condition to account for discarded samples during hermeticity testing. The discarded samples can result from poor fin seals, unwanted crease or folds in the seal, and sample bags bursting open under vacuum pressure.

Phase 1 will be conducted over a six day period. One contaminant type is randomly selected for each day over the six day period. Therefore, the nine machine conditions for each type of contaminant are randomly divided into two days. The random order is shown in Table 2. 


\begin{tabular}{|c|c|c|c|c|c|c|}
\hline & & Condition & Condition & Condition & Condition & Condition \\
& & $\mathbf{1}$ & $\mathbf{2}$ & $\mathbf{3}$ & $\mathbf{4}$ & $\mathbf{5}$ \\
\hline Day 1 & Control & T1, D2 & T2 D3 & T3 D1 & T2 D2 & T3 D3 \\
\hline Day 2 & Salt Water & T2 D3 & T1 D3 & T2 D1 & T3 D3 & \\
\hline Day 3 & Vegetable & T1 D3 & T3 D1 & T2 D1 & T2 D3 & \\
& Oil & & & & & \\
\hline Day 4 & Salt Water & T1, D2 & T1 D1 & T3 D1 & T2 D2 & T3 D2 \\
\hline Day 5 & Control & T2 D1 & T3 D2 & T1 D3 & T1 D1 & \\
\hline Day 6 & Vegetable & T3 D2 & T1 D1 & T3 D3 & T2 D2 & T1, D2 \\
& Oil & & & & & \\
\hline
\end{tabular}

Table 2: Test Schedule for Phase 1

\begin{tabular}{|l|l|}
\hline Temperature 1 (T1) & $120 \mathrm{C}$ \\
\hline Temperature 2 (T2) & $140 \mathrm{C}$ \\
\hline Temperature 3 (T3) & $160 \mathrm{C}$ \\
\hline
\end{tabular}

Table 3: Referenced Sealing Temperatures in Table 1

\begin{tabular}{|l|l|}
\hline Dwell Time 1 & 0.2 seconds \\
\hline Dwell Time 2 & \\
(D2) & 0.3 seconds \\
\hline Dwell Time 3 & \\
(D3) & 0.4 seconds \\
\hline
\end{tabular}

Table 4: Referenced Dwell Time in Table 1

After each day, the bags will be stored at ambient temperature $\left(20{ }^{\circ} \mathrm{C}\right)$ for two hours to ensure that the polymer chains have reached "equilibrium" and the polymer chains have reached 
maximum entanglement. After the two hour waiting period, the samples are sent to hermeticity testing to check for leaks.

\subsubsection{Hermeticity Testing}

Hermeticity of the Flexible Bags will be tested using ASTM Standard D3078 - Test Method for Determination of Leaks in Flexible Packaging by Bubble Emission [20]. Each sample bag will be placed in the vacuum chamber with an attached cover plate immersed under water by one inch. One sample bag will be placed in the chamber with the fin seal faced down.

The vacuum is set to $22.0 \mathrm{inHg}$ and the package is observed for air bubbles. However, bubbles will be of different sizes depending on the total area of the leaked seal. According to ASTM Standard D3078, a small bubble will release $1 / 2 \mathrm{ml}$ of air over 365 seconds [20].

\begin{tabular}{|l|l|l|l|l|l|}
\hline Size (He) & Average & Sr & SR & r & R \\
\hline Big 6E-02 & 26.11 & 2.667 & 3.918 & 7.467 & 6.122 \\
\hline Medium 7E- & 82.11 & 4.073 & 6.196 & 11.406 & 13.019 \\
03 & & & & & \\
\hline Small 3E-03 & 365.00 & 18.963 & 32.549 & 53.096 & 69.962 \\
\hline Very Small & 0.037 & 0.192 & 0.192 & 0.000 & 1.235 \\
\hline
\end{tabular}

Table 5: Bubble Size Categories for Hermeticity [20]

The above table indicates that small leaks will produce $0.41 \mathrm{ml}$ per 30 seconds; medium leaks will produce will release $0.1826 \mathrm{ml}$ per 30 seconds; and large leaks will release $0.574 \mathrm{ml}$ per 30 seconds. In addition, the bubbles must continuously surface from one seal point to be considered a failed hermetic seal. Using the above table from ASTM D3078 [20], three continuous bubbles released over 30 seconds will be considered a failed hermetic seal. There are different size leaks 
which will release different sizes. However, in this study the size of the bubbles cannot be determined without access to Helium leak detector, which is explained in ASTM D3078 [20].

Hermeticity of the seals will be tested by using a vacuum chamber that places the bags into a contained tub of water and the pressure is brought down to $22.0 \mathrm{in} \mathrm{Hg}$. The standard ASTM D3078 suggests three vacuum levels - low vacuum $(12.5 \pm 0.5$ in. $\mathrm{Hg})$, medium vacuum $(18.5 \pm$ 0.5 in. $\mathrm{Hg})$, and high vacuum $(24.5 \pm 0.5 \mathrm{in} . \mathrm{Hg})$. The preliminary work tested the three vacuum levels were tested with the film used in the experiment as well as different films with different film structures. The different films required different vacuum test levels, and it was determined that the suggested vacuum levels were inadequate for the test. For the film used in the experiment, the high vacuum level caused every test bag to burst open in the vacuum chamber and the medium vacuum level did not apply enough vacuum pressure to inflate the bags. Therefore, the preliminary test included testing vacuum pressures between $24.5 \mathrm{in}$. $\mathrm{Hg}$ and 18.5 in. $\mathrm{Hg}$. As a result, $22.0 \mathrm{in} . \mathrm{Hg}$ seemed to be the best fit for this type of film and bag structure. The size of the test bags and the film structure seem to be two factors that influence the vacuum pressure for hermeticity testing.

Overall, the vacuum pressure causes the bag to expand, and allows bubbles to form at the leaking points at the seal. The bubbles indicate a failed hermetic seal and no bubbles indicate a pass hermetic seal. The bags will be placed in the hermetic fish tank for 30 seconds, which is a sufficient time period to observe bubble formations. Bubbles may tend to form that are trapped at the surface along the surface of the seal. Furthermore, a failed hermetic seal will show continuous bubbles from a leaking point.

Bubble formations may occur at different points on the seals of the sample bags. The locations of the leaks will be recorded and categorized based on type of leak. Bubbles forming at the corners of the seal will be considered a "pass" in this study since the corners are not subject to 
contamination. However, corner leaks that also have a leak at the T-point point will be considered a "fail".

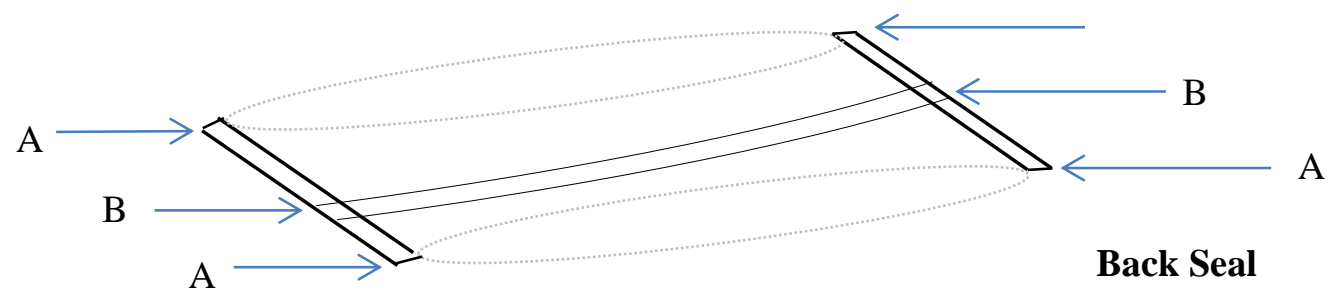

Front Seal

Figure 8: Critical Points for Bag Samples

A = Seal Corners; B = T-point Point

\begin{tabular}{|l|l|}
\hline Leak Location & Hermeticity Result \\
\hline No leaks & True Pass \\
\hline At corners & Pass \\
\hline At T-point & True Fail \\
\hline At T-point and corners & True Fail \\
\hline At contamination area (near T-point point) & True Fail \\
\hline
\end{tabular}

Table 6: Hermeticity results based on leak location

Figure 8 shows the critical point where the seal jaws must seal through four layers of film. For a successful seal to be produced at the T-point, the polymer chains in the sealant layer should reach their molten stage and completely entangle. However, a low sealing temperature and dwell time can limit the chains from entangling and result in a failed hermetic seal. 


\subsubsection{Phase 2}

Phase 2 tests the effect of storage temperature, time, and contaminants with the film using the optimal packaging condition determined in Phase 1. Control samples will be made for each contaminant's packaging condition if the optimal packaging condition is different for each contaminant. However, Phase 1 results indicate that both contaminants have an optimal packaging condition of $140^{\circ} \mathrm{C}$ sealing temperature with 0.3 seconds dwell time. The following test procedure for Phase 2 is randomly created using Microsoft Excel.

\begin{tabular}{|l|r|c|c|c|}
\hline & & $\begin{array}{l}\text { Total Sample } \\
\text { Bags Produced }\end{array}$ & $\mathbf{( + 1 0 \% \text { more samples } )}$ & Total \\
\hline $2 / 19 / 204$ & Salt Water & 120 & 12 & $\mathbf{1 3 2}$ \\
\hline $2 / 20 / 2014$ & Vegetable Oil & 120 & 12 & $\mathbf{1 3 2}$ \\
\hline $2 / 21 / 2014$ & Control & 120 & 12 & $\mathbf{1 3 2}$ \\
\hline
\end{tabular}

Table 7: Phase 2 Production Schedule

The sample bags will be produced over a three day period in a complete random block design schedule. Once all bags are produced each day, they will all be randomly placed in the environmental chambers and chosen at random each day for sample testing. In addition, the bags will be randomly placed during production into each of the eight corrugated boxes.

Ten samples for hermeticity and five samples for seal strength will be taken each day on Day 2, 6, 10 and 14 from each of the refrigerated and ambient temperature chambers. A 14 day period was chosen to assume the average time period between packing and production to consumer.

\begin{tabular}{|l|r|r|r|r|}
\hline & \multicolumn{1}{l}{ Day 2 } & \multicolumn{1}{l|}{ Day 6 } & \multicolumn{1}{l|}{ Day 10 } & \multicolumn{1}{l|}{ Day 14 } \\
\hline Salt Water & $2 / 21 / 2014$ & $2 / 25 / 2014$ & $3 / 1 / 2014$ & $3 / 5 / 2014$ \\
\hline Vegetable Oil & $2 / 22 / 2014$ & $2 / 26 / 2014$ & $3 / 2 / 2014$ & $3 / 6 / 2014$ \\
\hline Control & $2 / 23 / 2014$ & $2 / 27 / 2014$ & $3 / 3 / 2014$ & $3 / 7 / 2014$ \\
\hline
\end{tabular}

Table 8: Phase 2 Data Collection Schedule 


\begin{tabular}{|r|r|r|r|r|r|}
\hline & \multicolumn{2}{|c|}{$\begin{array}{c}\text { Hermeticity Testing Sample } \\
\text { Size }\end{array}$} & \multicolumn{2}{c|}{$\begin{array}{c}\text { Seal Strength Testing Sample } \\
\text { Size }\end{array}$} \\
\hline $\begin{array}{c}\text { Testing } \\
\text { Procedure }\end{array}$ & Refrigerated & Ambient & Refrigerated & Ambient & \\
\hline & 10 & 10 & 5 & 5 & 0 \\
\hline Day 2 & 10 & 10 & 5 & 5 & 0 \\
\hline Day 6 & 10 & 10 & 5 & 5 & 0 \\
\hline Day 10 & & & & & 3 \\
\hline Day 14 & 10 & 10 & 5 & 5 & 0 \\
\hline Total: & 40 & 40 & 20 & 20 & \\
\hline
\end{tabular}

Table 9: Phase 2 Expected Sample Size for Each Collection Day

Each contaminant has 120 samples randomly placed in 12 boxes with an additional 12 to 24 bag samples to account for necessary discarded samples throughout Phase 2. Please refer to Appendix 1 for the random placement of each sample bag into each box. In addition, the 12 boxes are randomly chosen for each conditioning temperature using Microsoft Excel. Lastly, each of the 6 boxes are randomly chosen for hermeticity and seal strength, and randomly placed in each chamber. The random box assignment to each chamber is listed in Appendix 2.

The temperature and relative humidity of each chamber is recorded on each data collection day at the beginning of testing. The actual chamber temperature is measured using a Raytek temperature hand gun, but no accurate tool was used to measure actual relative humidity. For each testing period, one box for hermeticity and one box for seal strength is removed from the chamber and opened immediately to determine the actual temperature of the sample bags. However, each testing period requires only five bags for seal strength testing, so the seal strength box is returned to its placement in the designated chamber after the necessary sample bags are removed from the box for testing. The boxes chosen for hermeticity and seal strength for each test day are randomly selected and listed in Appendix 3. 


\subsubsection{Seal Strength Testing}

In addition to hermeticity, the seal strength is tested to determine if there is a significant difference between contaminated and non-contaminated seals. The purpose of testing the seal strength is determining the consistency of seal strength from sample bag to sample bag with contamination and without contamination. It is also used to validate the sealing conditions for packaging production. According to ASTM F88 - Standard Test Method for Seal Strength of Flexible Barrier Materials, the sample for peel force will be one inch wide and three inches long from the end point of the seal [3]. The standard does not indicate a necessary sample number, so ten samples are chosen for each condition.

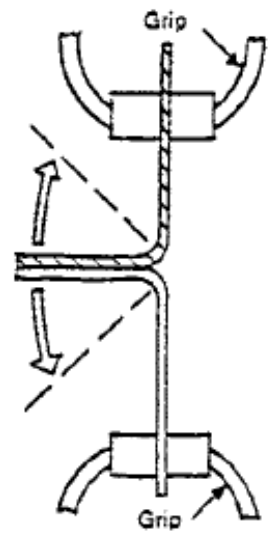

Unsupported

\section{Figure 9: Specimen Setup for Unsupported Seal Strength Test}

The unsupported seal strength test will be used for this study. It is not expected to have another force affecting the seal strength as is shown in the above Figure 9. Each leg or unsealed section is fastened to the top and bottom grip on the tensile tester. The seal is tested at a rate of 12 inches/min. and the maximum force to failure is recorded. The average seal strength (n) is the average force per unit width of seal at failure. $[3,5,6]$ 


\subsubsection{Determining Optimal Packaging Conditions}

The hermeticity test will show how the pass percentage of each contaminant at the different conditions. It is assumed that there will be a difference between contaminated and noncontaminated seals. In addition, the contaminated seals have a lower hermetic pass rate than noncontaminated bags. The optimal packaging condition considers the temperature and dwell time of the end seals that gives the highest pass rate that remains insignificantly different than noncontaminated bags. The lower the temperature the lower the amount of energy needed to package the bags, and the lower the dwell time indicates a faster production speed. In addition to determining the statistical difference within one condition, it is also important to determine if there is a statistical difference between the contaminated hermetic pass percentage with a lower dwell time to a higher dwell time. If between the two dwell times at the optimal temperature is insignificant, than the lower dwell time would be used. However, if the hermetic pass percentage is significant between the two dwell times, then the longer dwell time will be the optimal condition. One sealing condition of one temperature and dwell time will be used for each contaminant type for Phase 2.

After determining the optimal packaging condition for each contaminant, Phase 2 tests the performance of the contaminated compared to non-contaminated seals over a shelf life of 14 days. A two week period is chosen because this is the common time period a package is on the shelf for these product types. The same size bags will be made using the HFFS machine, but only using the optimal packaging condition for each contaminant. Empty or non-contaminated bags will also be made as the control for each of the contaminants optimal condition if all contaminants do not have the same optimal condition.

Each contaminant will be tested for two types of environmental conditions - refrigerating conditions at $5^{\circ} \mathrm{C}$ and $85 \%$ humidity and ambient conditions of $23^{\circ} \mathrm{C}$ and $50 \%$ humidity [19]. The bags are prepared at ambient temperature of approximately $22^{\circ} \mathrm{C}$ and $33 \% \mathrm{RH}$. 


\subsection{Test Procedure}

\subsubsection{Horizontal Form, Fill and Seal Machine}

1. Attach the green compressed air hose to the machine.

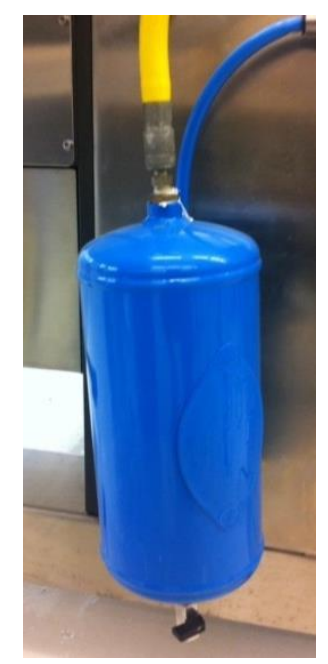

Figure 10: Air Hose Attachment

2. Turn the air supply on by turning the black handle on the air pipe counterclockwise until it is upright as shown in the picture below.

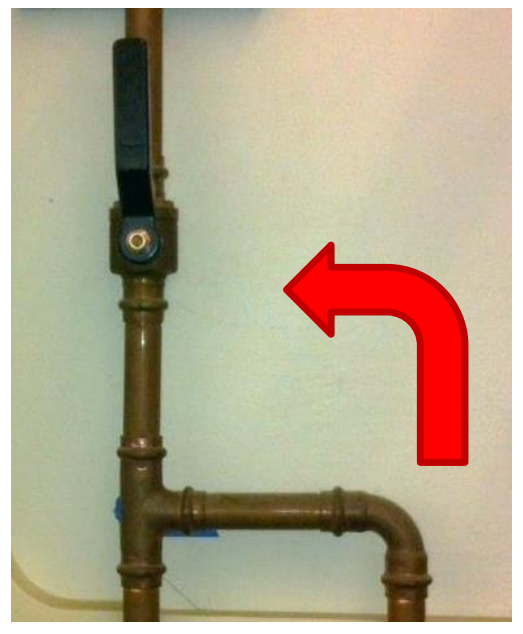

Figure 11: Air Pipe 
3. Turn on the machine by using turning the power switch clockwise until it reads ON.

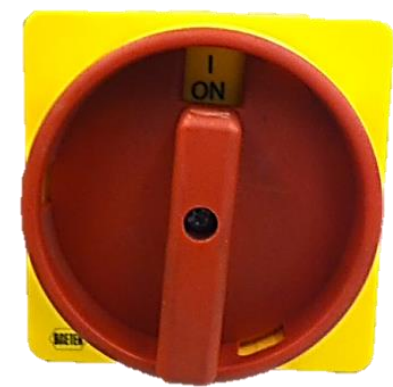

Figure 12: ON Switch for HFFS

4. Insert the machine key into the machine next to the RESET button and turn it to the RIGHT. Turning the key to the RIGHT turns SAFETY OFF and allows the user to open and close the safety guards located on both sides of the seal jaws without disarming the machine. Ensure the safety guards are down, and turn the key to the LEFT to enable the safety guard. Press the RESET button to enable to the compressed air to pass through the machine. 


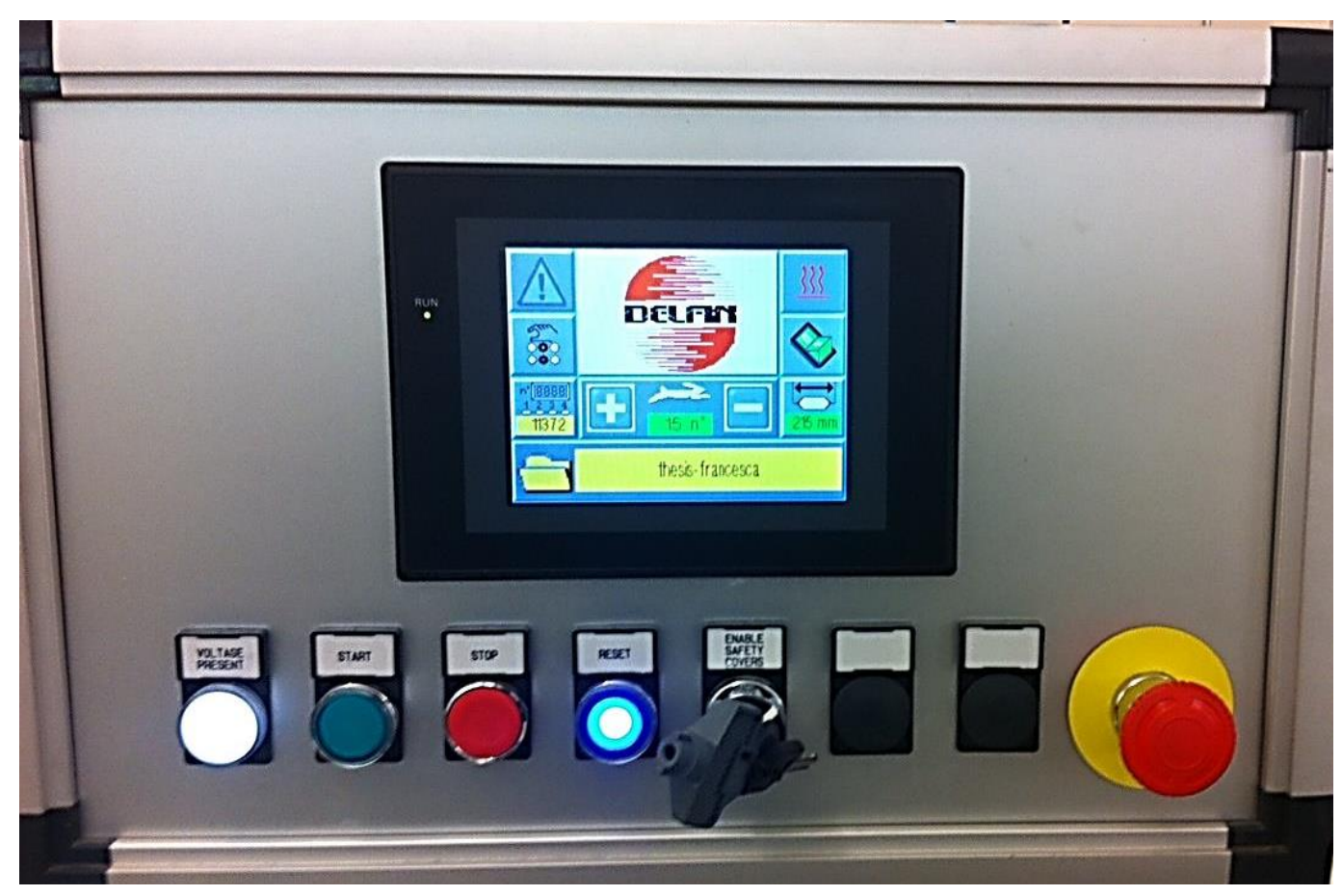

Figure 13: HFFS Control System

5. The initial interface may have a warning sign with an $X$ at the top of the screen. Press the $\mathrm{X}$ on the interface to go to the home screen which is shown in the Figure 15. The rabbit should read $15^{\circ}$ which indicate the machine will make 15 bags per minute. Use the + or keys next to the rabbit if it does not read $15^{\circ}$. To the right of the rabbit indicates that the bag length should be $215 \mathrm{~mm}$ from seal to seal. If it does not read $215 \mathrm{~mm}$, press the key with the bag image to adjust the bag length.

6. Next, temperature can be adjusted by clicking on the top right button on the home interface page.

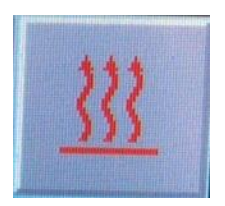

Figure 14: Temperature Setup Button 
7. The next page will show the temperature interface shown below in Figure 15. The first temperature value indicates that the first roller of three for the fin seal is set to $30^{\circ} \mathrm{C}$. The second roller is set to $135^{\circ} \mathrm{C}$ and the last roller has no heat. The last two temperatures are for the top and bottom seal jaws. The top and bottom seal jaws will have the same temperature and will be adjusted for each sealing temperature in the study. However, the rolling wheel temperature will remain the same for all sealing conditions. All values located in the green boxes are the set values and the number above is the actual temperature. The machine will not run unless the actual temperature is within nine degrees of the set temperature. Testing will begin and continue when the actual sealing temperatures reach the set temperature.

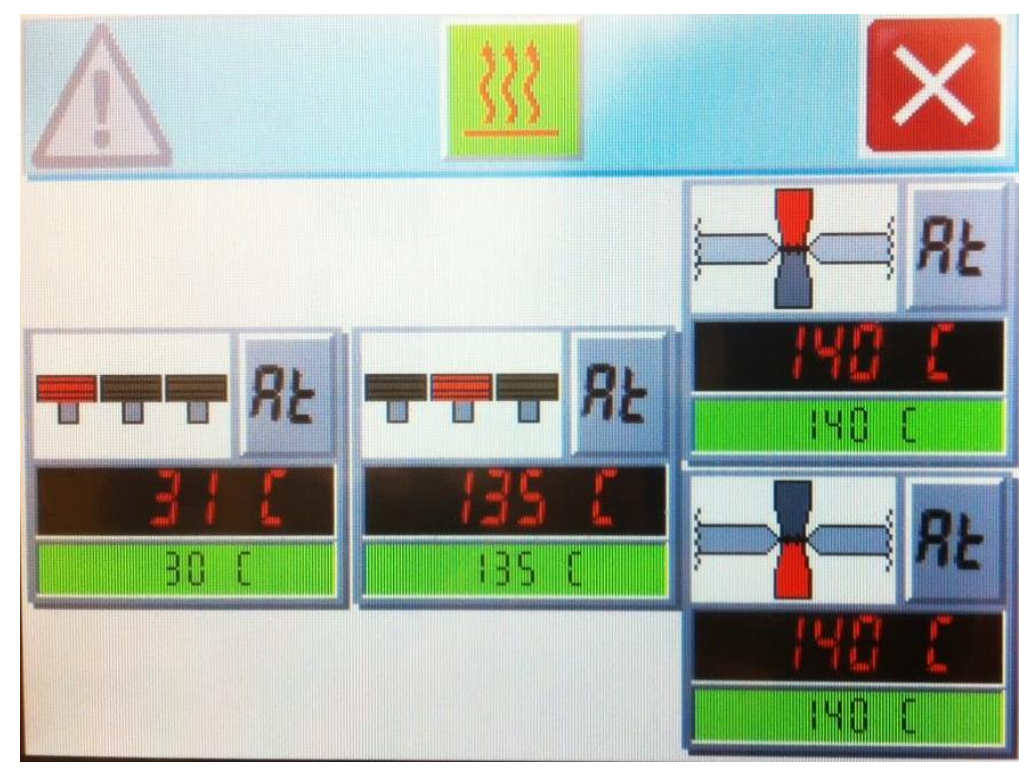

Figure 15: Temperature Interface

8. Pressing the $\mathrm{X}$ button in the top left corner of the screen will lead to the home page.

9. To change the dwell time, press the second key down from the top right of the home screen shown in Figure 13. Next, press the image that is highlighted in green in Figure 16 below. 


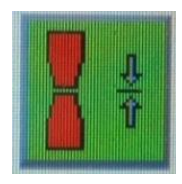

\section{Figure 16: Dwell Time Setup Control Button}

10. The next screen indicates two degree values. The second degree value, $52^{0}$ indicates that the dwell time is 0.2 seconds. For 0.3 seconds, the degrees for dwell time will need to change to $61^{\circ}$ by pressing on the $52^{\circ}$ value in the green box. For 0.4 seconds dwell time, press the degree value in the same box and change the value to $71^{\circ}$. The top degree, $250^{\circ}$ indicates the amount of time allotted for the seal jaws to move up and down per seal. The time allotted for the seal jaws to move up and down will remain the same at $250^{\circ}$.

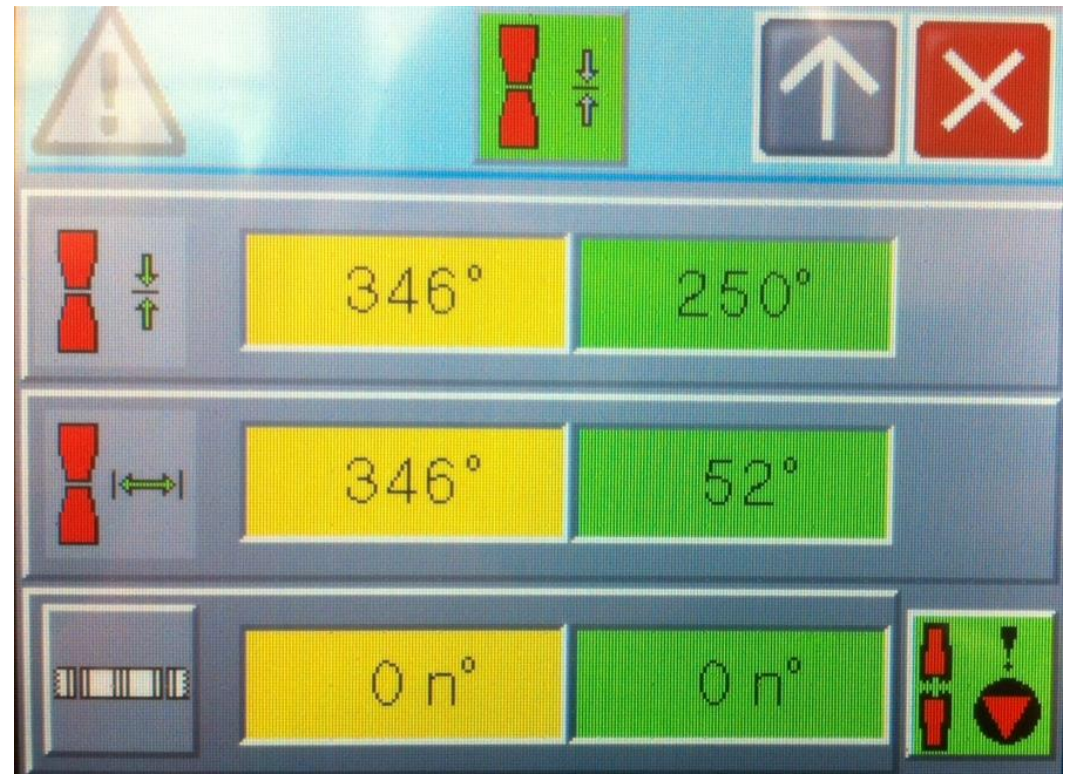

Figure 17: Dwell Time Setup Interface Screen

11. Vegetable oil and salt water require the contaminant system that starts with the mechanical syringe pump. The syringe is filled of $60 \mathrm{ml}$ of the contaminant type and secured to the syringe pump. Vegetable oil will be set to $\mathrm{X} 1$ range and $7.7 \%$ flow rate 
and salt water $5.7 \%$ flow rate. The power will be set to $\mathrm{ON}$ immediately prior to collecting sample and running the machine. The image below has the $\%$ flow rate set to 7.7\% for the vegetable oil contaminant, but salt water can use the + and - buttons located above and below the flow rate value shown to reach $5.7 \%$.

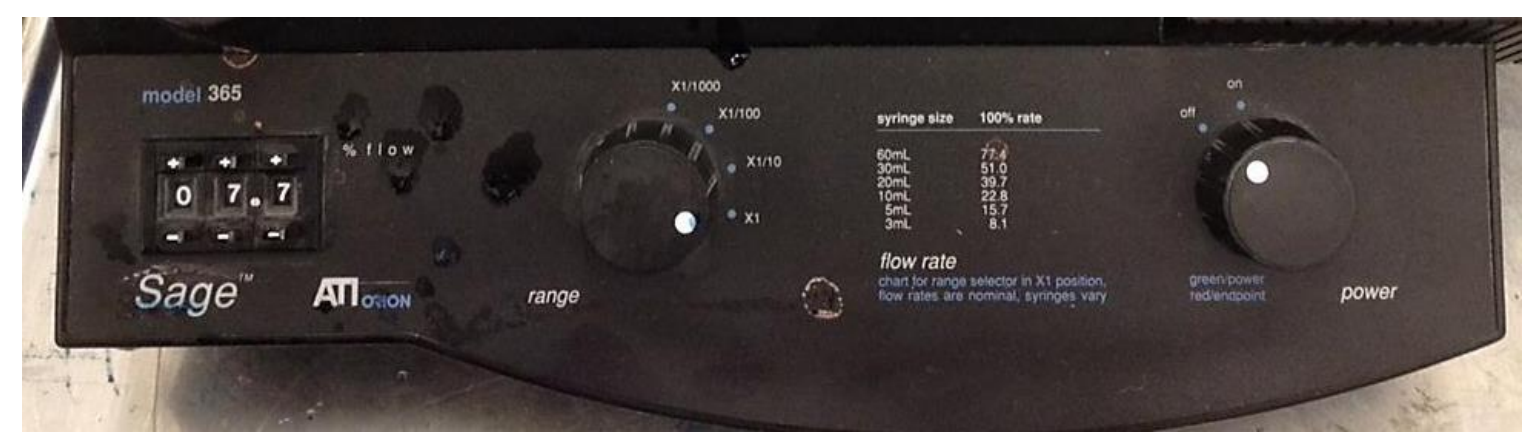

\section{Figure 18: Mechanical Pump Control System}

The syringe pump is connected to a flexible vinyl tube, which is attached on the other end to a three foot stainless steel tube. On the other end of the stainless steel tube, a nozzle is screwed in place to provide a narrow passage for consistent contamination.

12. The stainless steel tube slides into the tube of film on the packaging line and secured in place through the drilled hole in the wooden block. The block prevents the tube from moving during operation. The flexible vinyl tube is attached to the filled syringe and attached the stainless steel tube once it is placed in the block.

13. In order to begin testing, turn the power knob on the syringe pump to ON, pull down all safety guards, turn safety key to the left, and push the green $\mathrm{ON}$ button on the control panel. Push the RED button on the control panel once testing is done for each test category.

\subsubsection{Hermeticity Testing Procedure}

1. Turn on the Test-A-Pack Integrity Tester machine by the power button located on the back of the machine. 


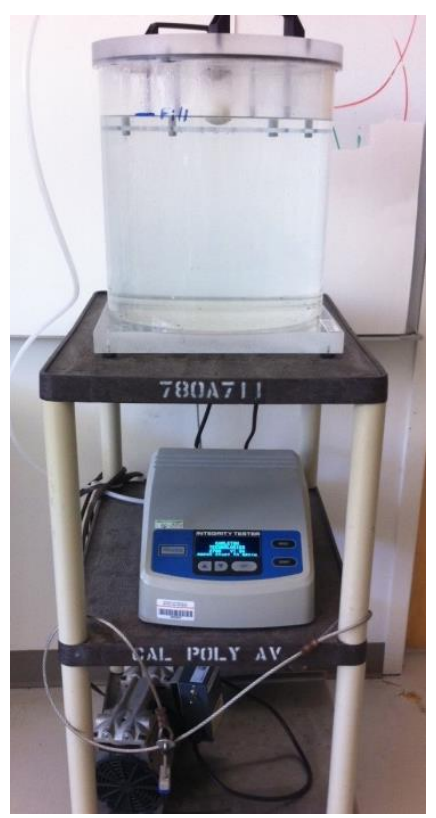

Figure 19: Test-A-Pack Machine for Hermeticity Testing

2. The level of the water should be filled to one inch above the top platen of the vacuum chamber. If it is not filled to the indicated line on the chamber, water can be added to the chamber.

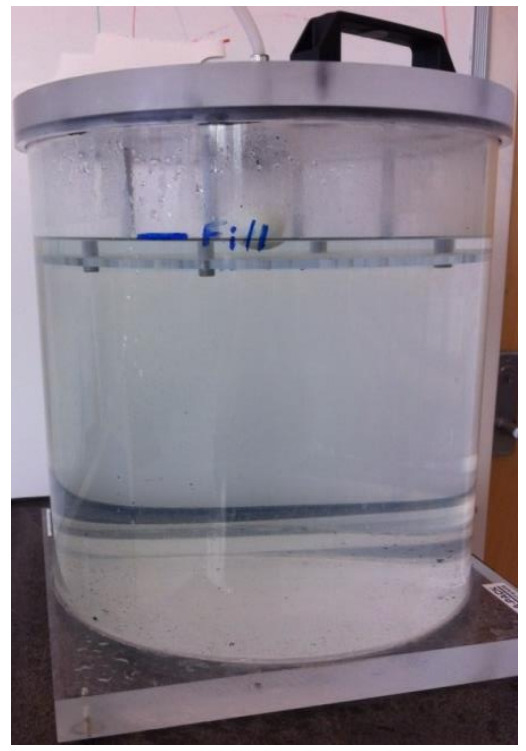

Figure 20: Hermeticity Test Fill Line 
3. The motor switch should be flipped to the ON position, which will start the motor.

4. To start the test, push the START button and press the down arrow until TEST SETUP is selected. Press the SET button and UNITS is first selected indicated by an arrow to the left of UNITS. Press the SET button and use the UP arrow until it reads the units inHg GAGE. Press SET again so inHG GAGE stops blinking.

5. Next, use the down arrow to select the VALUE to set the test to $22.0 \mathrm{inHg}$. Once VALUE is selected, press the SET button and use the UP arrow to reach 2 for the first digit then use the DOWN arrow to then choose 2 for the next digit. Next, press the SET button to confirm the value is set to $22 \mathrm{inHg}$.

6. Next use the DOWN arrow to select the TIME setting. Press the SET button and use the UP arrow until 3 is shown for the first digit. Use the DOWN arrow to move to the second digit to select 0 and press the SET button. The time should be set to 30 seconds.

7. Push the START button which will show the TEST home page. Next, press START again to begin the test.

8. The inHg value in the bottom right corner of the screen indicates the actual vacuum pressure of the chamber. The interface shows the time in seconds of the test and will read EVACUATE until the vacuum pressure is held at $22.0 \mathrm{inHg}$ for 10 consecutive seconds. The timer will then reset to HOLD and count down from 30 seconds. The chamber will reset to ambient pressure once the 30 seconds test is completed.

\subsubsection{Seal Strength Test Procedure}

The test method for seal strength used in the study follows ASTM Standard F88 [3]. 


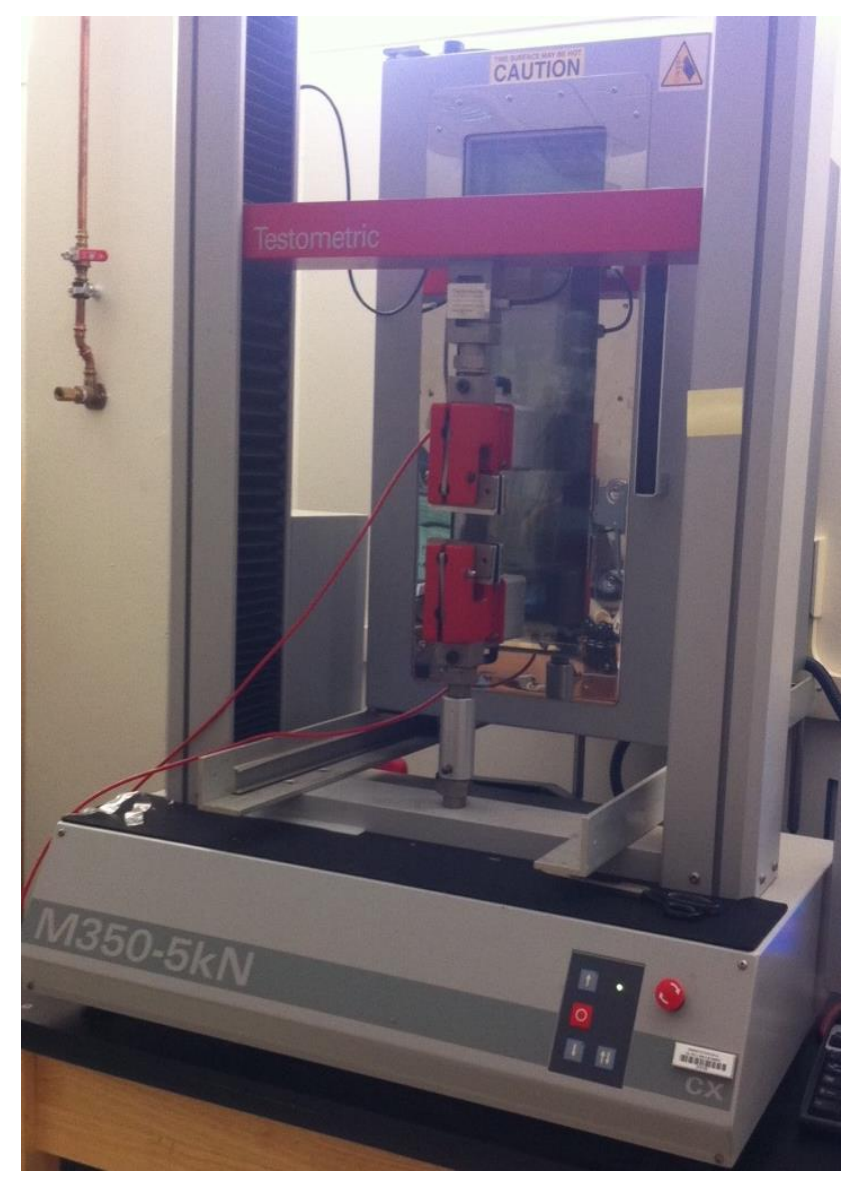

Figure 21: Seal Strength Testing Machine

1. Turn on the computer by pushing the power button ON.

2. Choose Tester User Login and Open WinTest located on the desktop. The WinTest software will open with the main control interface. Use the DOWN arrow to bring the top jaw to exactly 1 inch above the bottom jaw on the TESTOMETRIC Tensile Tester. Check the air compressor to ensure there is at least 100 psi before testing begins. Adjust setting to compression versus tensile testing to bring top jaw down. Once at 1 inch, change the test mode to tensile. The jaw clamps are pneumatic and require enough compressed air in the system to secure each tail of the specimen. 


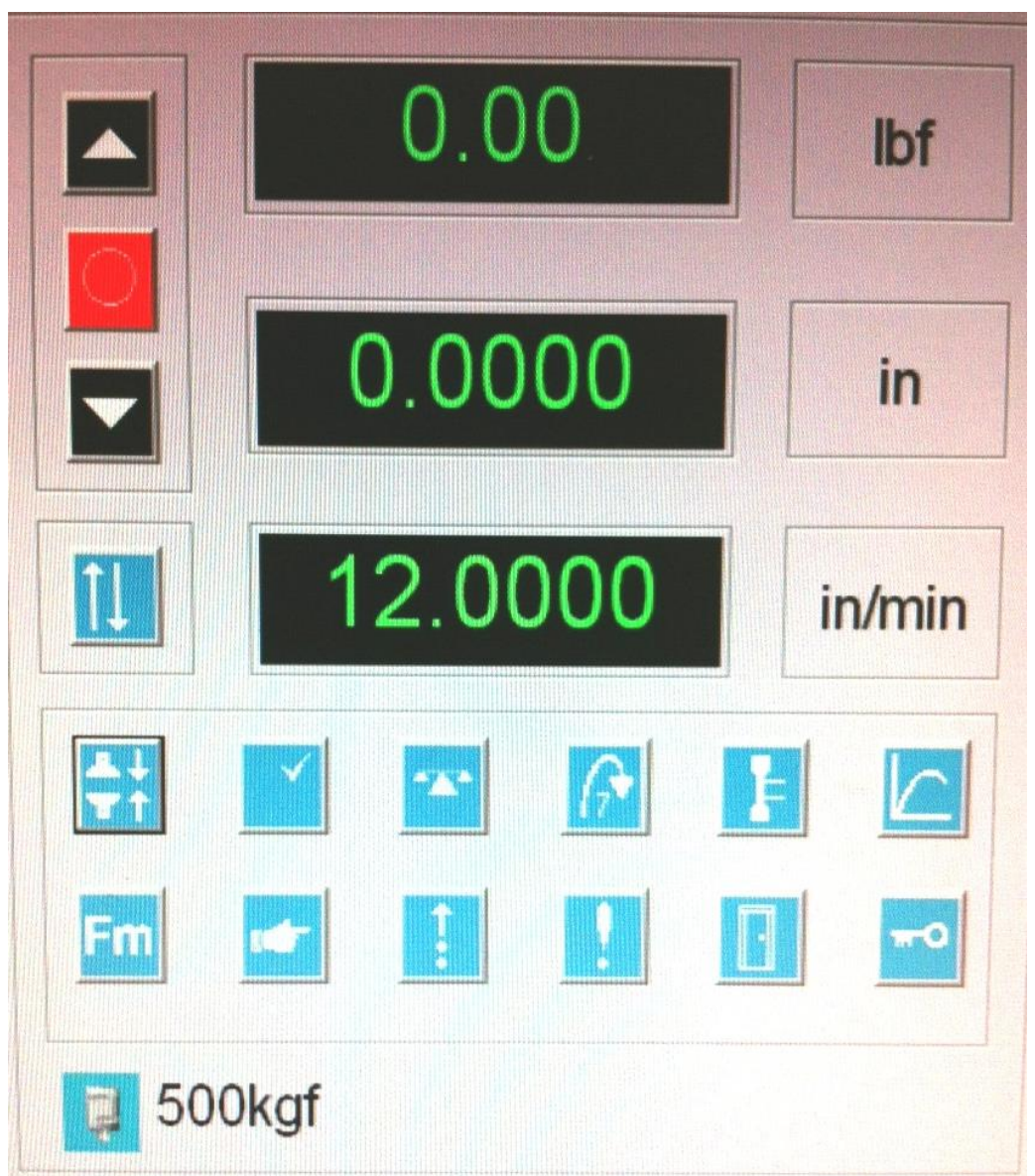

Figure 22: WinTest Control Interface

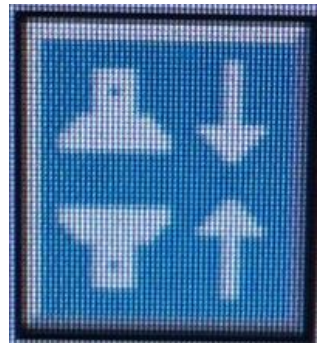

Figure 23: Compression Mode Button 


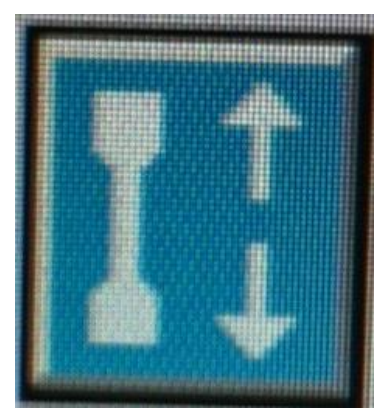

\section{Figure 24: Tensile Mode Button}

3. Next, click the button with the graph image to begin test mode.

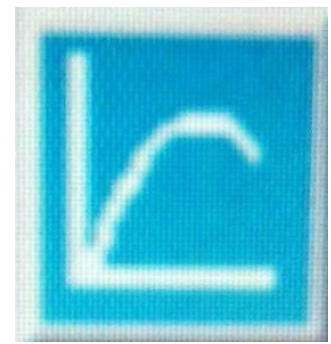

\section{Figure 25: Graph Button to Begin Test Mode}

4. In order to go to test setup, close the top window which shows the graph of the current test to open the overall test log. Select the following Test Setup button to set the Force to Newtons $(\mathrm{N})$ units with a range from 0 to $75 \mathrm{~N}$, and elongation to $\mathrm{mm}$ with a range from 0 to $50 \mathrm{~mm}$.

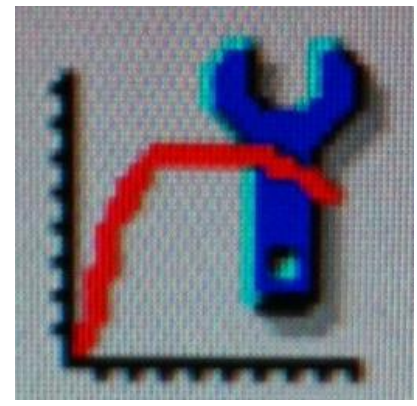

Figure 26: Test Setup Button 
5. Next, select TEST at the top menu followed by START TEST. The current test window will open with the Force and Elongation values located on the right side. Before starting the test, both values are set to zero by clicking the zero button the left of each value. The graph should be blank prior to each test.

6. Each sample bag will have two replicates from the front and back end seals at the T-point shown in Figure 27 below. The front and back seals are named based on the order of which the seal is made during production. The fin seal direction, located on the bottom face of the bag in Figure 27, indicates which is the front and back seal. The fin seal is forced in the direction of the right hand side of the bag from the perspective at the end of the production line. 


\section{Back Seal}

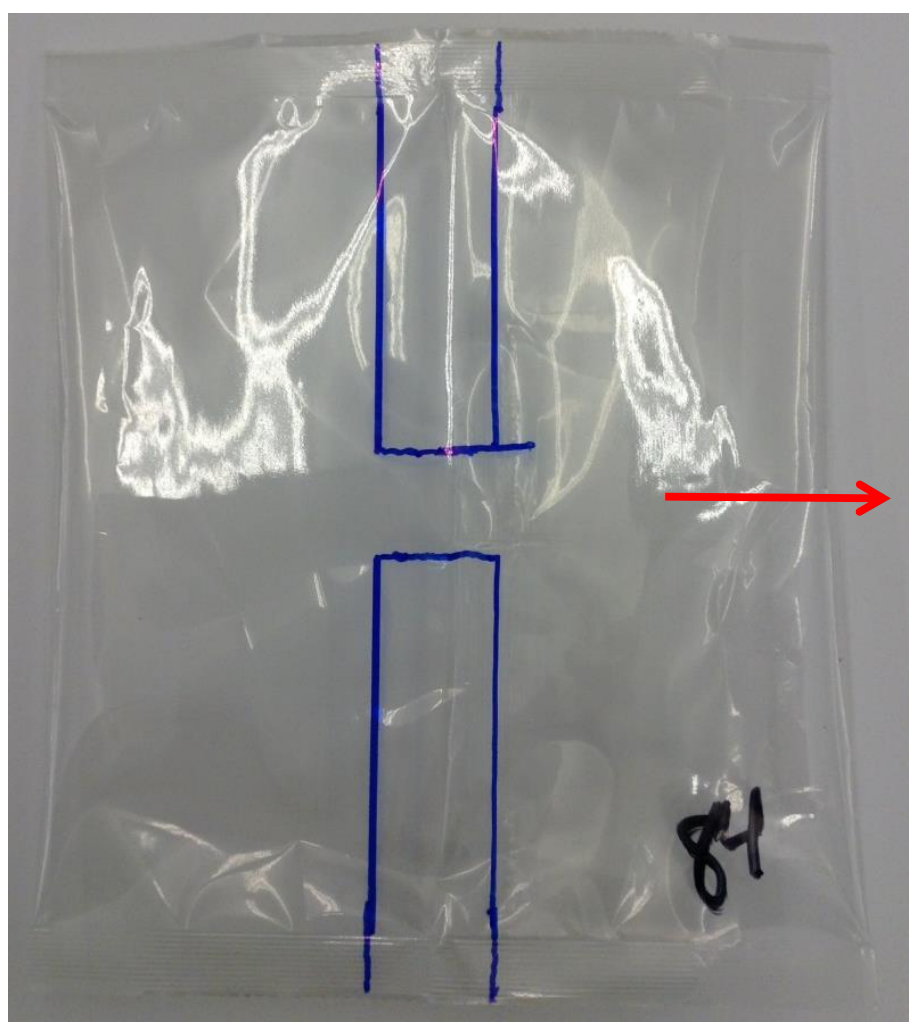

\section{Direction of Fin}

Seal Placement

\section{Front Seal}

\section{Figure 27: Front and Back T-Point Seal Samples Taken from Sample Bag}

7. Following ASTM F88 [3], each sample is 1 inch in width and 3 inches in length with the T-point approximately in the middle of the cut sample. Both samples are cut from the bag using a 1 inch width JDC Precision Sample Cutter, manufactured by Thwing-Albert Instrumental Company.

8. The bottom tail of the specimen is first secured into the bottom jaw using the foot petal attached to the Testometric machine to enable the pneumatic system. Before locking the bottom tail into the bottom jaw, the seal is raised approximately equidistant between the two grip jaws. 


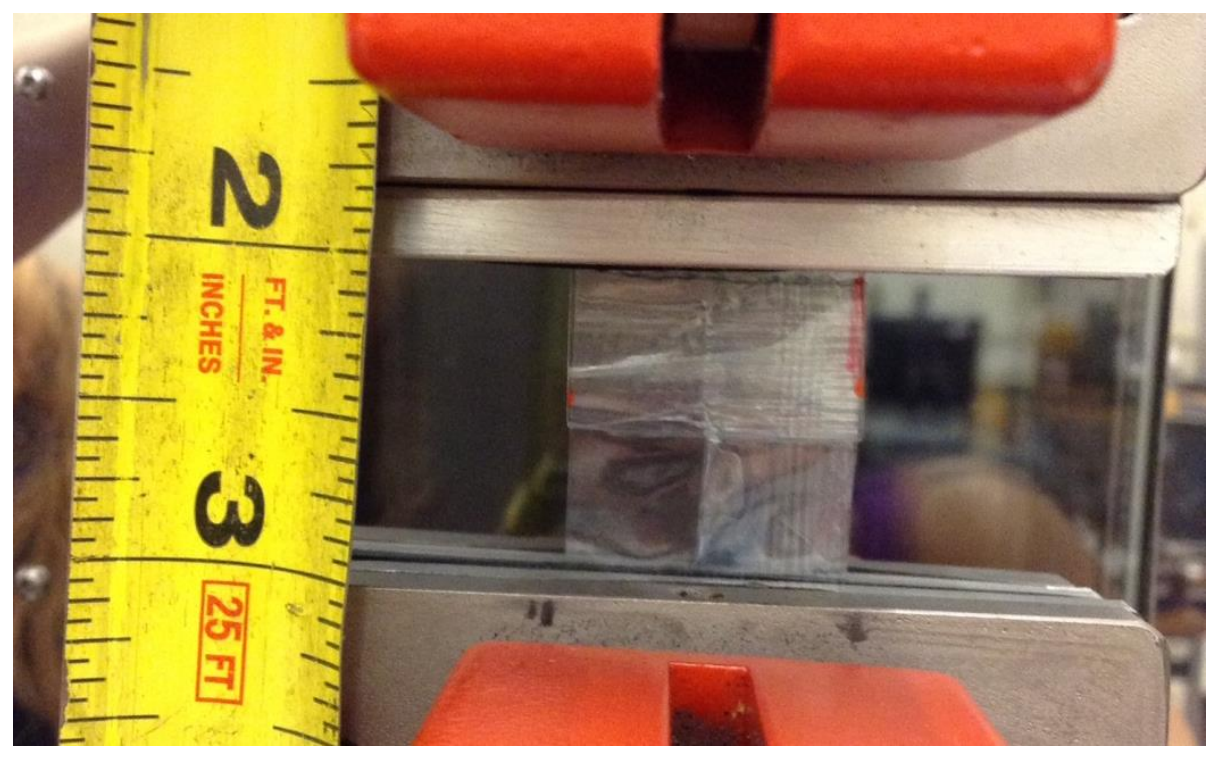

Figure 28: Specimen Setup for Seal Strength Test

9. Next, the top tail of the specimen can be secured in the top jaw using the designated foot petal to enable the pneumatic system.

10. Start the test by clicking the UP arrow on the current test screen. The tensile test will run until it reach failure mode.

11. The current test results will be stored in the test log by clicking the check button. Record the results of the graph and raw data by right clicking on each trial name. The raw data and a .pdf image of each trial's graph are stored in a recognized folder in the computer.

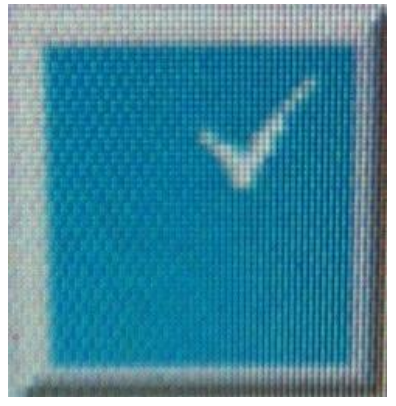

Figure 29: Check Button to Store Seal Strength Data 
12. Release the jaw grips using the foot petals, followed by selecting TEST from the top menu to then select START TEST. Repeat steps 8 through 11 from the Seal Strength Test Procedure. 


\subsection{Results}

\subsection{Contamination consistency results from Phase 1 and 2}

Throughout preliminary work and Phase 1 and Phase 2 of the study, the consistency of contamination from sample bag to sample bag was measured. A ruler was used to measure the width of the contamination stream near the front and back seals as well as the midpoint of the stream. Overall, vegetable oil had an average coefficient of variation of 0.217 which is greater than 0.15 . As mentioned previously, 0.15 coefficient of variation was the goal of the study to have almost no variation from sample bag to sample bag. On the other hand, the salt water contaminant had a higher coefficient of variation of 0.211 , which is greater than the desired 0.15 coefficient of variation. The greater C.O.V of salt water could be due to the density and contact angle of the solution. In comparison to vegetable oil, the salt water solution is more prone to move during production. A greater amount of sample bags were measured for salt water to measure its incline to move away from the fin seal path. Even though the salt water solution has a higher coefficient of variation, both contaminants are considered to have an acceptable consistent stream. The raw data for consistency is listed in Appendix E.

\subsection{Phase 1 Results}

The results showed an increase in temperature increase the pass rate within $120^{\circ} \mathrm{C}$ to $160^{\circ} \mathrm{C}$. For each temperature, there is also an increase in pass rate as the dwell time increases. The hermeticity test observes the leaks in the seals for the sealing conditions and what type of leaks are occurring. Contaminants fall only along the fin seal and contaminate the T-point, so any fails that are not along the T-point are considered a pass such as corner leaks. It was found that some leaks occur at the corners of the seal which are considered pass but not a true pass since they were not contaminated. T-point failures are what we are comparing in this study, so all corner leaks are considered a pass. 


\subsubsection{Hermeticity Results by Sealing Condition}

\section{$120^{\circ} \mathrm{C}$ Sealing Temperature}

\begin{tabular}{|r|r|l|l|}
\hline & \multicolumn{1}{|l|}{ Pass } & Fail & Fail Type \\
\hline Control & 7 & & corners \\
\hline & & 3 & T-point \\
\hline Total: & 7 & 3 & \\
\hline
\end{tabular}

\begin{tabular}{|r|r|r|l|}
\hline & \multicolumn{1}{|l|}{ Pass } & \multicolumn{1}{l|}{ Fail } & Fail Type \\
\hline Salt Water & 0 & 10 & T-point \& corners \\
\hline & & & \\
\hline Total: & 0 & 10 & \\
\hline
\end{tabular}

\begin{tabular}{|r|r|r|l|}
\hline & \multicolumn{1}{|l|}{ Pass } & \multicolumn{1}{l|}{ Fail } & Fail Type \\
\hline Vegetable Oil & 0 & 10 & T-point \& corners \\
\hline & & & \\
\hline Total: & 0 & 10 & \\
\hline
\end{tabular}

Table 10: $120^{\circ} \mathrm{C}$ Sealing Temperature and 0.2s Dwell Time

\begin{tabular}{|r|r|r|l|}
\hline & \multicolumn{1}{|l|}{ Pass } & Fail & Fail Type \\
\hline & & & T-point \& \\
Control & 1 & 3 & corners \\
\hline & & 6 & T-point \\
\hline Total: & 1 & 9 & \\
\hline
\end{tabular}

\begin{tabular}{|r|r|l|l|}
\hline & \multicolumn{1}{|l|}{ Pass } & Fail & Fail Type \\
\hline Salt Water & 2 & 1 & T-point \\
\hline & 2 & & corner \\
\hline & & 4 & $\begin{array}{l}\text { T-point \& } \\
\text { corners }\end{array}$ \\
\hline Total: & 4 & 5 & \\
\hline
\end{tabular}

\begin{tabular}{|r|r|r|l|}
\hline & \multicolumn{1}{|l|}{ Pass } & \multicolumn{1}{l|}{ Fail } & Fail Type \\
\hline Vegetable Oil & 1 & 7 & T-point \\
\hline & 2 & & corner \\
\hline Total: & 3 & 7 & \\
\hline
\end{tabular}

Table 11: $1^{\circ} \mathrm{C}$ Sealing Temperature and 0.3s Dwell Time 


\begin{tabular}{|r|r|r|l|}
\hline & \multicolumn{1}{|l|}{ Pass } & \multicolumn{1}{l|}{ Fail } & Fail Type \\
\hline Control & 4 & 1 & T-point \& corners \\
\hline & & 3 & T-point \\
\hline & 2 & & corner \\
\hline Total: & 6 & 4 & \\
\hline
\end{tabular}

\begin{tabular}{|r|r|r|l|}
\hline & \multicolumn{1}{|l|}{ Pass } & Fail & Fail Type \\
\hline Salt Water & 3 & 3 & T-point \\
\hline & 1 & & corner \\
\hline & & 3 & T-point \& corners \\
\hline Total: & 6 & 6 & \\
\hline
\end{tabular}

\begin{tabular}{|r|r|r|l|}
\hline & \multicolumn{1}{|l|}{ Pass } & Fail & Fail Type \\
\hline Vegetable Oil & 4 & 6 & T-point \\
\hline & & & \\
\hline Total: & 3 & 7 & \\
\hline
\end{tabular}

Table 12: $120^{\circ} \mathrm{C}$ Sealing Temperature and 0.4s Dwell Time

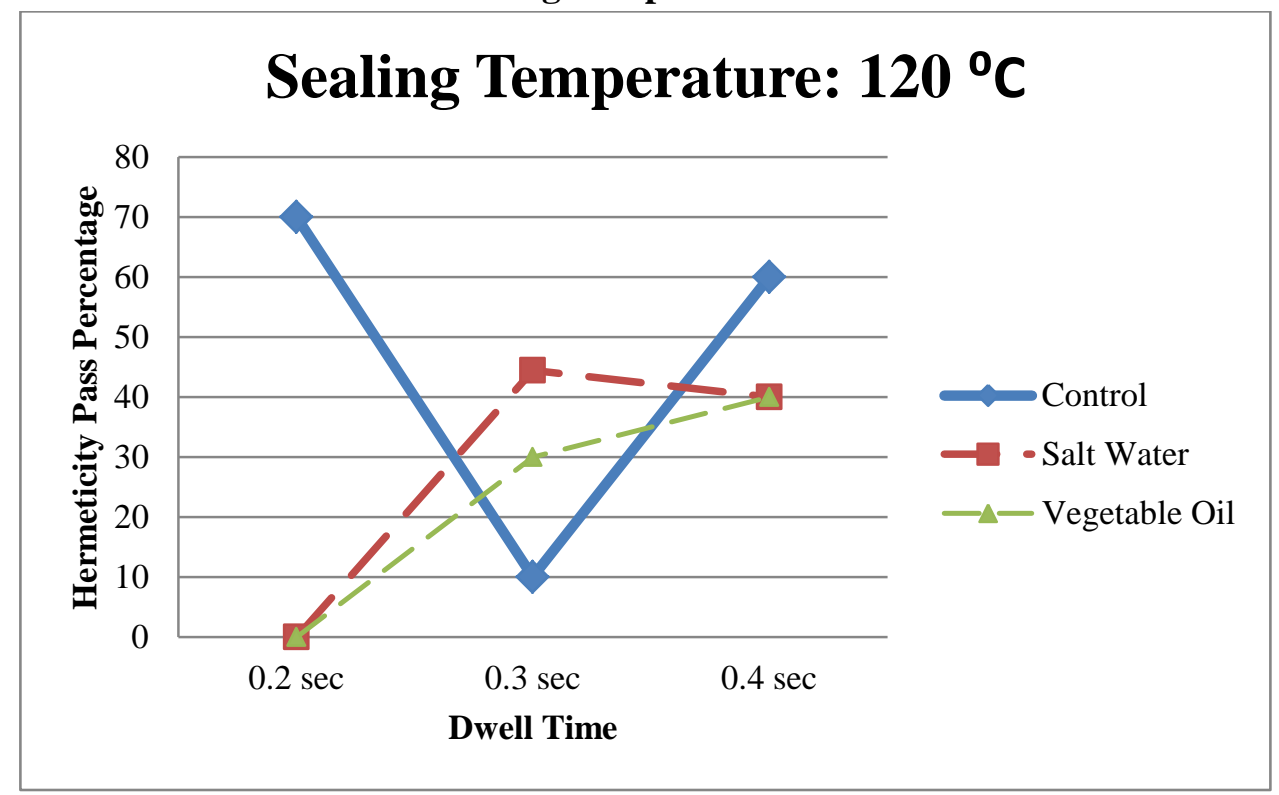

Figure 30: Contaminant Pass Rates by Dwell Time for $120^{\circ} \mathrm{C}$ Sealing Temperature

Due to the above results for $120^{\circ} \mathrm{C}$, it can be inferred that the results for 0.3 seconds dwell time are inconclusive since the pass rate for both vegetable oil and salt water is greater than the control. Therefore, $120^{\circ} \mathrm{C}$ with 0.3 seconds dwell time will not be considered an optimal 
packaging condition for Phase 2. The error for 0.3 seconds dwell time could be a result of the small sample size of 10 replicates. It is possible that a larger sample size may eliminate the error. However, the pass rate for $120^{\circ} \mathrm{C}$ and 0.3 seconds dwell time has a low pass rate for all contaminants and control compared to the other conditions in Phase 1. The results indicate that there is a large difference between the contaminants and the control for 0.2 seconds and less of a difference for 0.4 seconds dwell time. Overall, there is an increase in pass rate as the dwell time increases for $120^{\circ} \mathrm{C}$ sealing temperature. As mentioned previously, the pass rate also includes leaks only at the corners during the test.

\section{$140^{\circ} \mathrm{C}$ Sealing Temperature}

\begin{tabular}{|r|r|r|l|}
\hline & \multicolumn{1}{l|}{ Pass } & Fail & Fail Type \\
\hline Control & 2 & 3 & T-point \\
\hline & & 3 & T-point \& corners \\
\hline & 1 & & corner \\
\hline Total: & 3 & 6 & \\
\hline
\end{tabular}

\begin{tabular}{|r|r|r|l|}
\hline & \multicolumn{1}{|l|}{ Pass } & Fail & Fail Type \\
\hline Salt Water & 3 & 6 & T-point \\
\hline & 1 & & corner \\
\hline Total: & 4 & 6 & \\
\hline
\end{tabular}

\begin{tabular}{|r|r|r|l|}
\hline & \multicolumn{1}{|l|}{ Pass } & Fail & Fail Type \\
\hline Vegetable Oil & 3 & 7 & T-point \\
\hline & & & \\
\hline Total: & 3 & 7 & \\
\hline
\end{tabular}

\section{Table 13: $140^{\circ} \mathrm{C}$ Sealing Temperature and 0.2s Dwell Time}

Salt water has a slightly higher pass rate than the control, but the control has a smaller sample size. Testing led more than three discarded samples during the hermeticity test due to the vacuum pressure, failed fin seal, or creases in the seal. 13 total replicates were made at each condition, and four discarded samples led to a sample size of nine for the control at $140^{\circ} \mathrm{C}$ and 0.2 seconds dwell time. 


\begin{tabular}{|r|r|r|l|}
\hline & \multicolumn{1}{|l|}{ Pass } & Fail & Fail Type \\
\hline Control & 6 & 2 & T-point \\
\hline & & & $\begin{array}{l}\text { T-point \& } \\
\text { corners }\end{array}$ \\
\hline & 1 & & corner \\
\hline Total: & 7 & 3 & \\
\hline
\end{tabular}

\begin{tabular}{|r|r|r|l|}
\hline & \multicolumn{1}{|l|}{ Pass } & Fail & Fail Type \\
\hline Salt Water & 6 & & T-point \\
\hline & & & \\
\hline Total: & 6 & 4 & \\
\hline
\end{tabular}

\begin{tabular}{|r|r|r|l|}
\hline & \multicolumn{1}{|l|}{ Pass } & Fail & Fail Type \\
\hline Vegetable Oil & 6 & 2 & T-point \\
\hline & 2 & & corner \\
\hline Total: & 8 & 2 & \\
\hline
\end{tabular}

Table 14: $140^{\circ} \mathrm{C}$ Sealing Temperature and 0.3s Dwell Time

Vegetable Oil has a slightly higher pass rate than the control at $140^{\circ} \mathrm{C}$ and 0.3 seconds dwell time. However, both the control and the vegetable oil have the same number of true passes and the vegetable oil has one more corner pass than the control. Furthermore, the control had an additional sample that showed leaks at the corners, but that same sample had a T-point leak. A Tpoint leak and a corner leak indicate a failed sample compared to a sample that only leaks from the corners. 


\begin{tabular}{|r|r|r|l|}
\hline & Pass & Fail & Fail Type \\
\hline Control & 7 & 2 & T-point \\
\hline & 1 & & corner \\
\hline Total: & 8 & 2 & \\
\hline
\end{tabular}

\begin{tabular}{|r|r|r|l|}
\hline & Pass & Fail & $\begin{array}{l}\text { Fail } \\
\text { Type }\end{array}$ \\
\hline Salt Water & 5 & 5 & T-point \\
\hline & & & \\
\hline Total: & 5 & 5 & \\
\hline
\end{tabular}

\begin{tabular}{|r|r|r|l|}
\hline & Pass & Fail & $\begin{array}{l}\text { Fail } \\
\text { Type }\end{array}$ \\
\hline Vegetable Oil & 7 & 3 & T-point \\
\hline & & & \\
\hline Total: & 7 & 3 & \\
\hline
\end{tabular}

Table 15: $140^{\circ} \mathrm{C}$ Sealing Temperature and 0.4s Dwell Time

The results for $140^{\circ} \mathrm{C}$ and 0.4 seconds dwell time show that vegetable oil has a higher pass rate compared to salt water. Control has a higher pass rate than both contaminants at this condition.

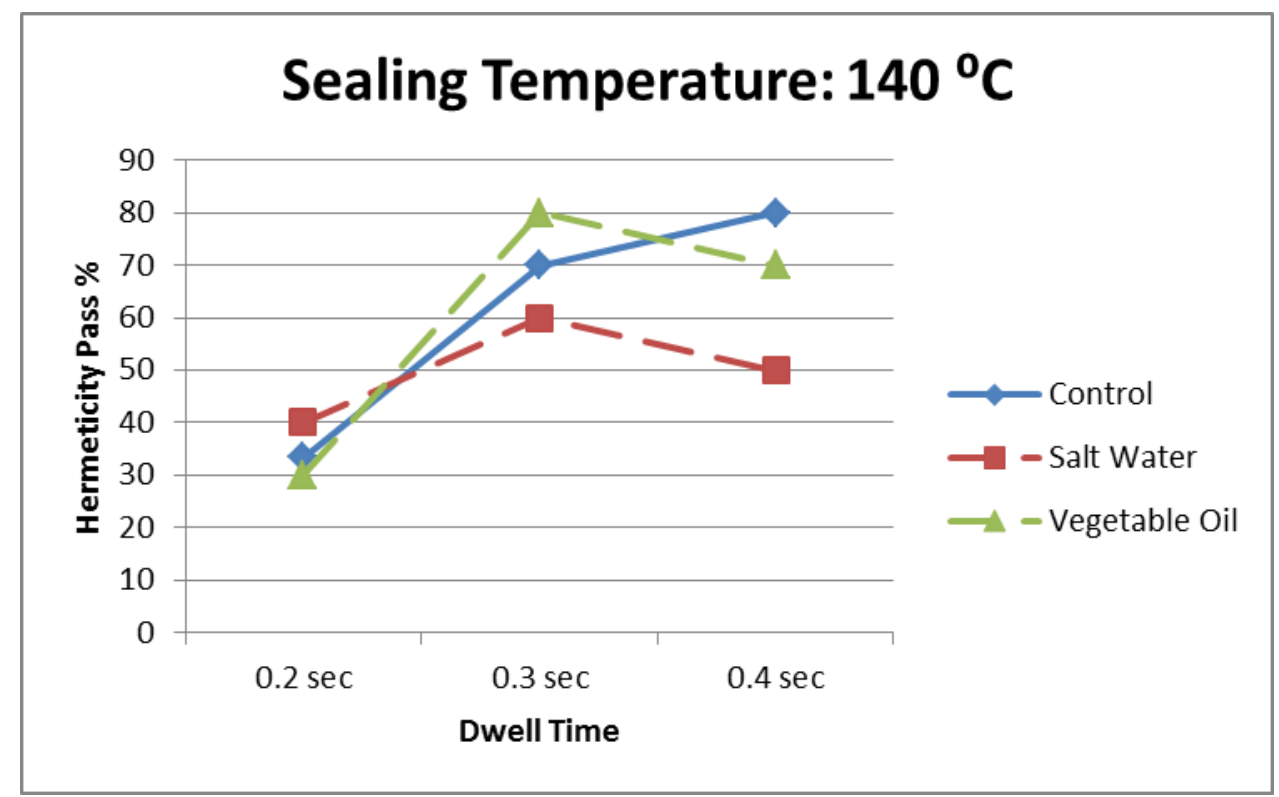

Figure 31: Contaminant Pass Rates by the Dwell Time for $140^{\circ} \mathrm{C}$ Sealing Temperature 
At $140^{\circ} \mathrm{C}$ sealing temperature, there is no test category has a consistently higher pass rate than the other test categories or a consistently lower pass rate at all dwell times. The condition for the highest pass rate that is statistically significant for all test categories is $140^{\circ} \mathrm{C}$ and 0.3 seconds dwell time. This condition has a higher pass rate than $120^{\circ} \mathrm{C}$ for all dwell times.

\section{$160^{\circ} \mathrm{C}$ SEALING TEMPERATURE}

\begin{tabular}{|r|r|l|l|}
\hline & \multicolumn{1}{|l|}{ Pass } & Fail & Fail Type \\
\hline Control & 5 & 3 & T-point \\
\hline & 1 & & corner \\
\hline Total: & 6 & 3 & \\
\hline
\end{tabular}

\begin{tabular}{|r|r|r|l|}
\hline & \multicolumn{1}{|l|}{ Pass } & Fail & Fail Type \\
\hline Salt Water & 2 & 5 & T-point \\
\hline & & 2 & T-point \& corner \\
\hline Total: & 2 & 7 & \\
\hline
\end{tabular}

\begin{tabular}{|r|r|r|l|}
\hline & \multicolumn{1}{|l|}{ Pass } & \multicolumn{1}{l|}{ Fail } & Fail Type \\
\hline Vegetable Oil & 3 & 5 & T-point \\
\hline & & 1 & T-point \& corner \\
\hline & & 1 & contamination \\
\hline Total: & 3 & 7 & \\
\hline
\end{tabular}

\section{Table 16: $160^{\circ} \mathrm{C}$ Sealing Temperature and 0.2s Dwell Time}

At $160^{\circ} \mathrm{C}$ sealing temperature and 0.2 seconds dwell time, there is a difference between the contaminants and the control. The control has a $40 \%$ higher pass rate than salt water and $30 \%$ higher pass rate than vegetable oil. Vegetable oil had one failed sample that showed a leak at the contaminate area near the T-point. Although the contaminant lies along the T-point, the contaminant will spread within the area near the T-point when the two surfaces come together. Even though this total area is not measured in this study, the initial thickness of the contamination is recorded. 


\begin{tabular}{|r|r|l|l|}
\hline & \multicolumn{1}{|l|}{ Pass } & \multicolumn{1}{l|}{ Fail } & Fail Type \\
\hline Control & 9 & 0 & \\
\hline & 1 & & corner \\
\hline Total: & 10 & 0 & \\
\hline
\end{tabular}

\begin{tabular}{|r|r|r|l|}
\hline & \multicolumn{1}{|l|}{ Pass } & Fail & Fail Type \\
\hline Salt Water & 5 & 4 & T-point \\
\hline & & 1 & contamination \\
\hline Total: & 5 & 5 & \\
\hline
\end{tabular}

\begin{tabular}{|r|r|r|l|}
\hline & \multicolumn{1}{|l|}{ Pass } & Fail & Fail Type \\
\hline Vegetable Oil & 6 & 4 & T-point \\
\hline & & & \\
\hline Total: & 6 & 4 & \\
\hline
\end{tabular}

Table 17: $160^{\circ} \mathrm{C}$ Sealing Temperature and 0.3s Dwell Time

As mentioned previously for the last condition, the salt water contaminant had one failed sample that showed leaks from the contaminated area near the T-point. The control had nine samples that were true passes, and one sample that showed a leak at the corners. Salt water and vegetable oil contaminants each had four samples that failed at the T-point. In comparison to the previous condition of $160^{\circ} \mathrm{C}$ and 0.2 seconds dwell time, pass rates increased for all test categories.

\begin{tabular}{|r|r|r|l|}
\hline & \multicolumn{1}{l|}{ Pass } & \multicolumn{1}{l|}{ Fail } & Fail Type \\
\hline Control & 10 & 0 & None \\
\hline Total: & 10 & 0 & \\
\hline
\end{tabular}

\begin{tabular}{|r|r|r|l|}
\hline & \multicolumn{1}{|l|}{ Pass } & \multicolumn{1}{l|}{ Fail } & Fail Type \\
\hline Salt Water & 7 & 2 & T-point \\
\hline & & 1 & T-point \& corner \\
\hline Total: & 7 & 3 & \\
\hline
\end{tabular}

\begin{tabular}{|r|r|l|l|}
\hline & \multicolumn{1}{l|}{ Pass } & \multicolumn{1}{l|}{ Fail } & Fail Type \\
\hline Vegetable Oil & 10 & 0 & None \\
\hline Total: & 10 & 0 & \\
\hline
\end{tabular}

Table 18: $160^{\circ} \mathrm{C}$ Sealing Temperature and $0.4 \mathrm{~s}$ Dwell Time

At $160^{\circ} \mathrm{C}$ sealing temperature and 0.4 seconds dwell time, vegetable oil contaminant and the control had all ten samples pass with no leaks. The salt water contaminant had the lowest pass 
rate of $70 \%$ with two samples failed at the T-point point and one sample failed with T-point and corner leaks.

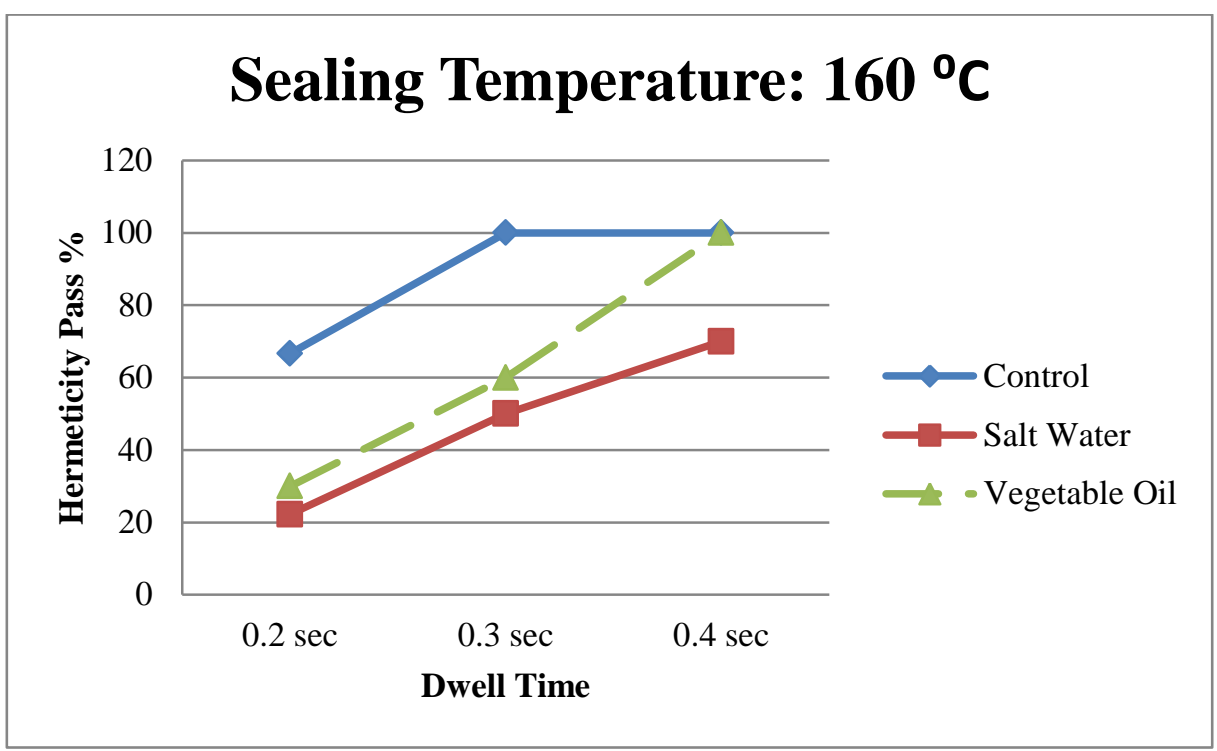

Figure 32: Hermeticity Pass Rate for $160^{\circ} \mathrm{C}$ Sealing Temperature

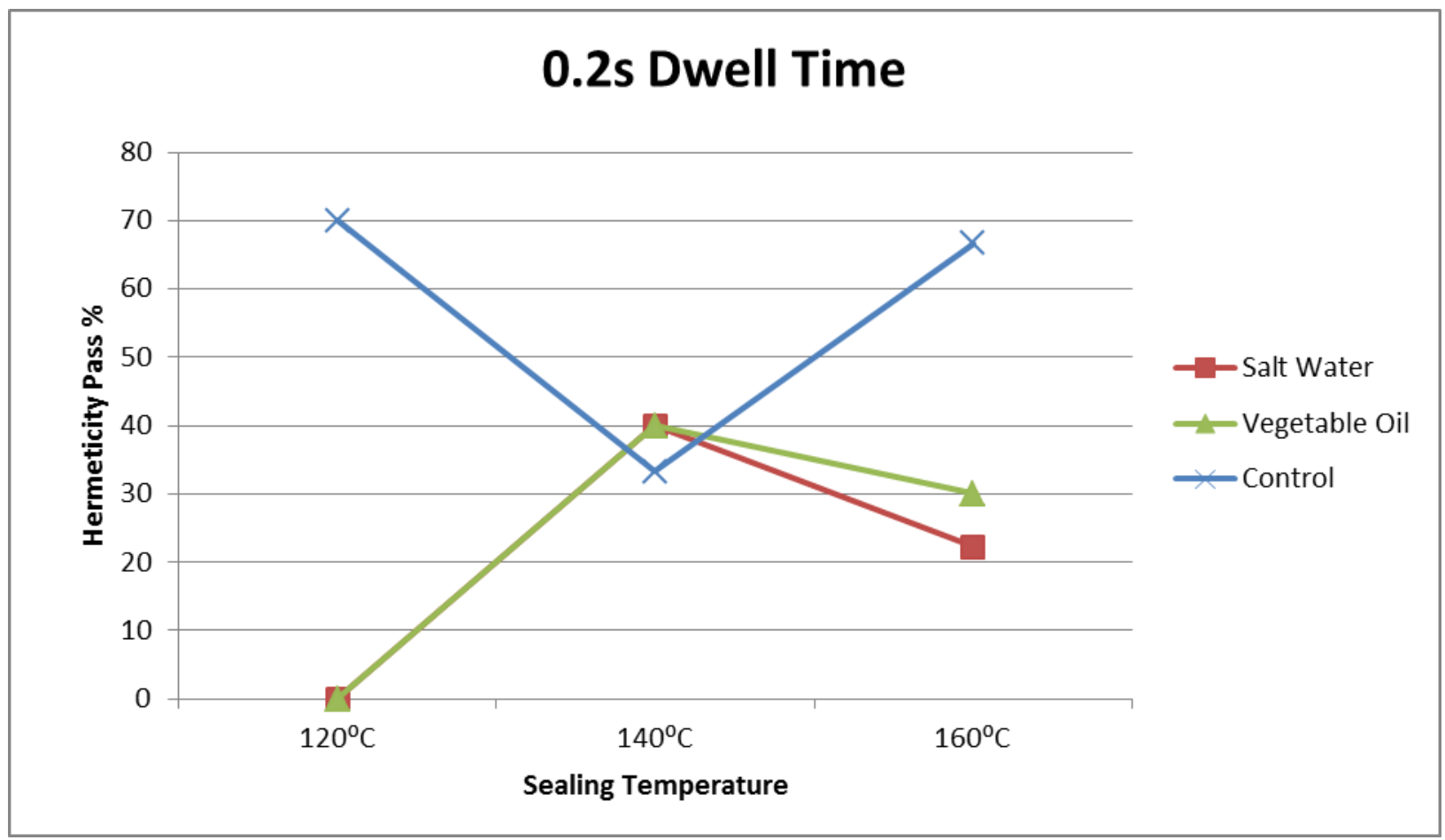

Figure 33: Hermeticity Pass Rate for 0.2s Dwell Time 


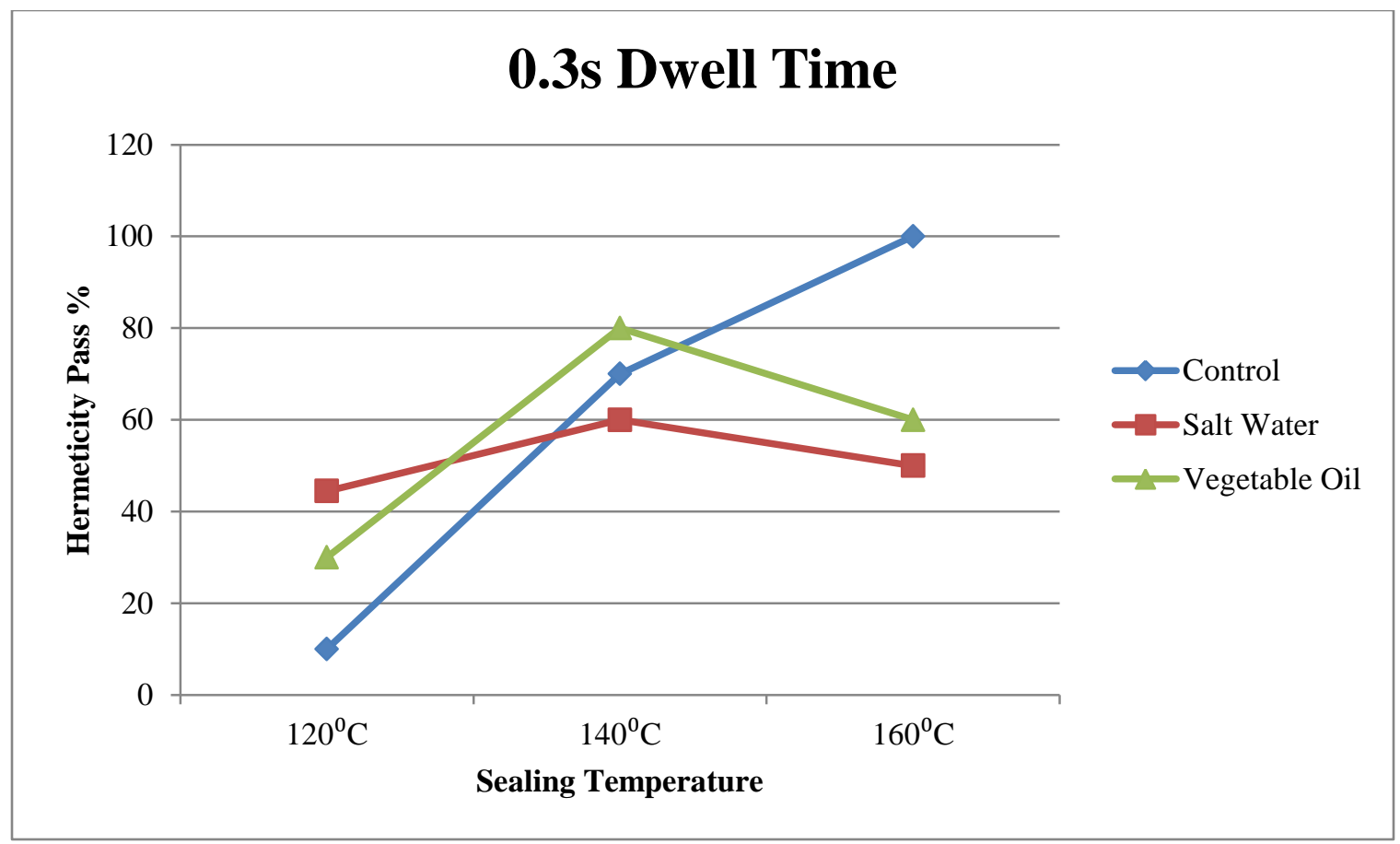

Figure 34: Hermeticity Pass Rate for 0.3s Dwell Time

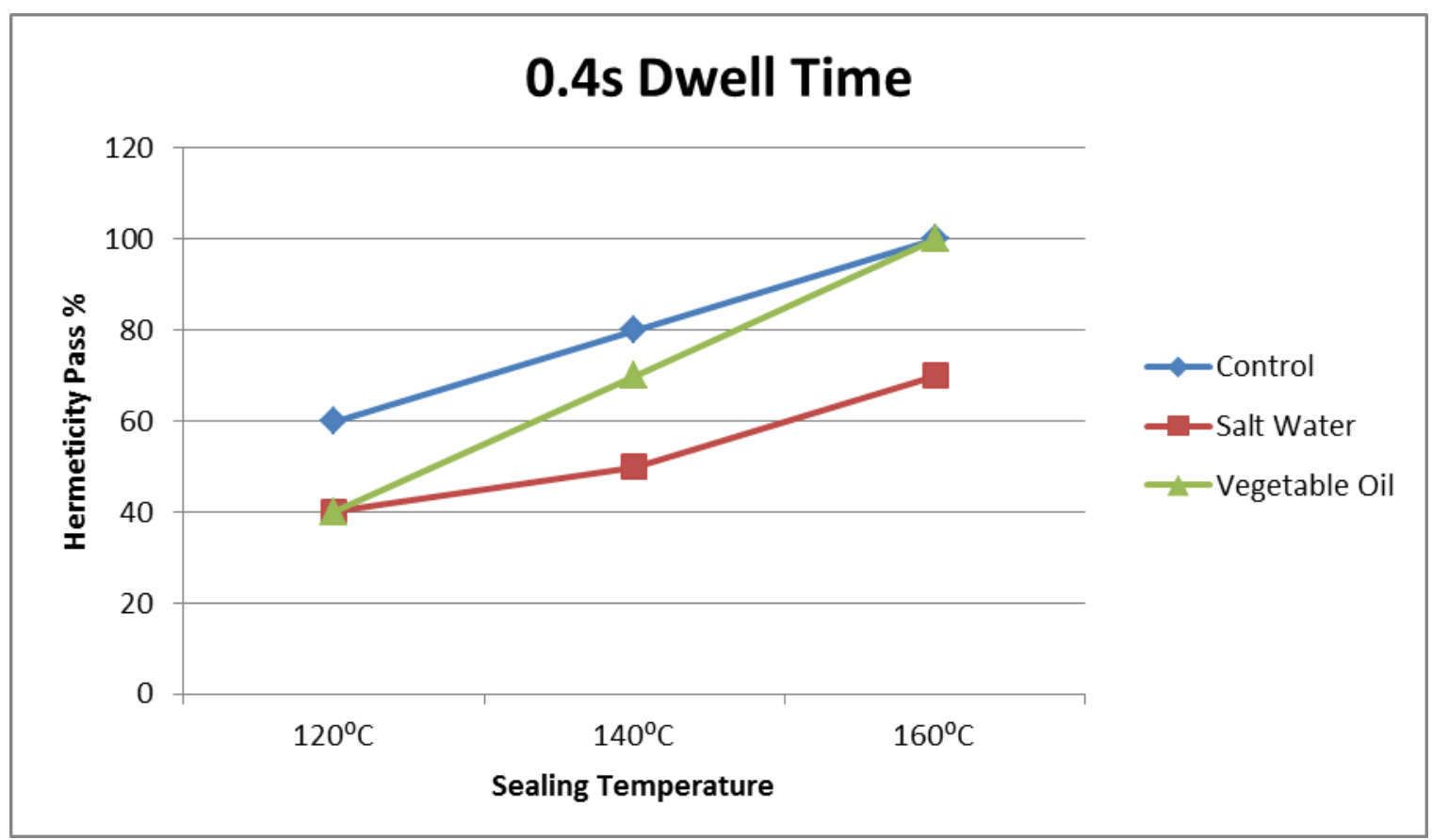

Figure 35: Hermeticity Pass Rate for 0.4s Dwell Time 


\subsubsection{Phase 1 Statistical Analysis}

A binary logistic regression is used in this study to analyze the odds ratio for the hermeticity pass rate. The results show the odds of passing between the different sealing temperatures and the dwell times. The alpha $(\alpha)$ equals 0.05 , which is the probability of rejecting the null hypothesis.

Phase 1 Null and Alternative Hypotheses:

$\mathrm{H}_{\mathrm{O}(\mathrm{temp})}$ :There is no difference in hermeticity pass rate between $120^{\circ} \mathrm{C}, 140^{\circ} \mathrm{C}$, and $160^{\circ} \mathrm{C}$.

$\mathrm{H}_{\mathrm{A}(\mathrm{temp})}$ :There is a difference in hermeticity pass rate between $120^{\circ} \mathrm{C}, 140^{\circ} \mathrm{C}$, and $160^{\circ} \mathrm{C}$

$\mathrm{H}_{\mathrm{O}(\mathrm{dwell} \text { time) }}$ :There is no difference in hermeticity pass rate between $0.2 \mathrm{~s}, 0.3 \mathrm{~s}$, and $0.4 \mathrm{~s}$

$\mathrm{H}_{\mathrm{A}(\mathrm{dwell} \text { time })}$ :There is a difference in hermeticity pass rate between $0.2 \mathrm{~s}, 0.3 \mathrm{~s}$, and $0.4 \mathrm{~s}$

$\mathrm{H}_{\mathrm{O}(\text { (contaminant) }}$ :There is no difference in hermeticity pass rate between the control and salt water and vegetable contaminants.

$\mathrm{H}_{\mathrm{A}(\mathrm{contaminant})}$ :There is a difference in hermeticity pass rate between the control and salt water and vegetable oil.

\begin{tabular}{|r|r|r|r|}
\hline \multicolumn{1}{|l|}{ TEMP (Ref. $\left.140{ }^{\mathbf{0}} \mathbf{C}\right)$} & $\begin{array}{l}\text { Odds } \\
\text { Ratio }\end{array}$ & $\mathbf{9 5 \%}$ C.I. & P-Value \\
\hline $120^{\circ} \mathrm{C}$ & 0.32 & $(0.16,0.62)$ & 0.001 \\
\hline $160{ }^{\circ} \mathrm{C}$ & 1.60 & $(0.82,3.10)$ & 0.166 \\
\hline DWELL TIME (Ref. 0.3 s) & & & \\
\hline 0.2 seconds & 0.33 & $(0.17,0.65)$ & 0.001 \\
\hline 0.4 seconds & 1.92 & $(0.99,3.71)$ & 0.054 \\
\hline Contaminant (Ref. Control) & & & \\
\hline Salt Water & 0.30 & $(0.15,0.60)$ & 0.001 \\
\hline Vegetable Oil & 0.45 & $(0.23,0.89)$ & 0.021 \\
\hline
\end{tabular}

Table 19: Phase 1 Binary Logistic Regression Analysis

*The odds ratio refers to the category associated with the odds ratio compared to the reference category Table 19 compares $120^{\circ} \mathrm{C}$ and $160^{\circ} \mathrm{C}$ to $140^{\circ} \mathrm{C}$ sealing temperature. The table shows that $160^{\circ} \mathrm{C}$ sealing temperature has greater odds of passing the hermeticity test compared to $140^{\circ} \mathrm{C}$. For example, for every 10 sample bags that have a hermetic seal with $140^{\circ} \mathrm{C}$ sealing temperature 16 
sample bags will have a hermetic seal when accounting for dwell time and contaminants. However, the p-value of $160^{\circ} \mathrm{C}$ equals 0.166 . Therefore, we are $95 \%$ confident that there is not enough evidence to conclude that there is a difference in pass rate between $160^{\circ} \mathrm{C}$ and $140^{\circ} \mathrm{C}$ when accounting for the effect of $d$ well time and contamination. In addition, $120^{\circ} \mathrm{C}$ sealing temperature has a lower pass rate than $140^{\circ} \mathrm{C}$ because the odds ratio, 0.32 is less than one. The odds ratio indicates that $120^{\circ} \mathrm{C}$ sealing temperature has the odds of producing a hermetic seal 0.32 compared to every control sample has a hermetic seal. The p-value for $120^{\circ} \mathrm{C}$ compared to $140^{\circ} \mathrm{C}$ equals 0.001 . Therefore, we are $95 \%$ confident that there is a difference in pass rate between $120^{\circ} \mathrm{C}$ and $140^{\circ} \mathrm{C}$ when accounting for the effect of $d$ well time and contamination. Vegetable oil and salt water have a lower pass rate than the control, but vegetable oil has greater odds of passing than salt water. The odds for vegetable oil and salt water are 0.45 and 0.30 , which are both less than one. If the odds ratio was greater than one, then the contaminants would have greater odds for a hermetic seal than the control. The $\mathrm{p}$-values for both salt water and vegetable oil are 0.001 and 0.021 , so there is enough evidence to reject the null hypothesis, $\mathrm{H}_{\mathrm{O}(\mathrm{contaminant}) \text {. }}$ Therefore, we are $95 \%$ confident that there is enough evidence to conclude that the contaminants will have a lower pass rate compared to the control when accounting for the effect of dwell time and sealing temperature. The dwell time of 0.2 seconds compared to 0.3 seconds has an odds ratio less than one and a p-value less than 0.05 . Therefore, we are $95 \%$ confident that there is a difference between 0.2 seconds and 0.3 seconds when accounting for contamination and sealing temperature. Also, the dwell time of 0.4 seconds compared to 0.3 seconds has a p-value that is 0.054 which is slightly more than 0.05 . Since it is more beneficial to use a shorter dwell time for production, 0.4 will not be used for the dwell time in Phase 2. Therefore, we are $95 \%$ confident that there is not a significant difference between 0.4 seconds and 0.3 seconds dwell time. 


\begin{tabular}{|r|r|r|r|}
\hline \multicolumn{1}{|l|}{ TEMP (Ref. 120 $\left.{ }^{\mathbf{C}} \mathbf{C}\right)$} & Odd Ratio & \multicolumn{1}{l|}{ 95\% C.I. } & \multicolumn{1}{l|}{ P-Value } \\
\hline $140^{\circ} \mathrm{C}$ & 3.13 & $(1.61,6.08)$ & 0.001 \\
\hline $160^{\circ} \mathrm{C}$ & 5.00 & $(2.51,9.95)$ & 0.000 \\
\hline $\begin{array}{l}\text { DWELL TIME (Ref. 0.2 } \\
\text { s) }\end{array}$ & & & 0.001 \\
\hline 0.3 seconds & 3.01 & $(1.55,5.84)$ & 0.000 \\
\hline 0.4 seconds & 5.76 & $(2.88,11.53)$ & \\
\hline $\begin{array}{l}\text { Contaminant (Ref. } \\
\text { Control) }\end{array}$ & & & 0.001 \\
\hline Salt Water & 0.30 & $(0.15,0.6)$ & 0.021 \\
\hline Vegetable Oil & 0.45 & $(0.23,0.89)$ & \\
\hline
\end{tabular}

Table 20: Phase 1 Binary Logistic Regression Analysis

*The odds ratio refers to the category associated with the odds ratio compared to the reference category

Table 20 compares $140^{\circ} \mathrm{C}$ and $160^{\circ} \mathrm{C}$ to $120^{\circ} \mathrm{C}$, and $0.3 \mathrm{~s}$ and $0.4 \mathrm{~s}$ to $0.2 \mathrm{~s}$. In comparison to $120^{\circ} \mathrm{C}$, both $140^{\circ} \mathrm{C}$ and $160^{\circ} \mathrm{C}$ have an odds ratio that is greater than one. The p-value for both temperatures are less than 0.05 and can reject the null hypothesis, $\mathrm{H}_{\mathrm{O}(\mathrm{temp})}$. Therefore, we are $95 \%$ confident that there is a difference between $120^{\circ} \mathrm{C}$ and $140^{\circ} \mathrm{C}$ as well as $120^{\circ} \mathrm{C}$ and $160^{\circ} \mathrm{C}$ when accounting for the effect of dwell time and contamination. Looking at the dwell time comparison, $0.3 \mathrm{~s}$ dwell time and $0.4 \mathrm{~s}$ dwell time have an odds ratio of 3.01 and 5.76. The values are greater than one, which imply that $0.3 \mathrm{~s}$ and $0.4 \mathrm{~s}$ dwell time have greater odds for passing hermeticity than $0.2 \mathrm{~s}$ dwell time. Furthermore, the p-values for both dwell times are less than 0.05 and can reject the null hypothesis, $\mathrm{H}_{\mathrm{O}(\mathrm{dwell} \text { time) }}$. Therefore, we are $95 \%$ confident that there is a difference between 0.2 seconds and 0.3 seconds as well as 0.2 seconds and 0.4 seconds for dwell time when accounting for the effect of sealing temperature and contamination. The contaminants' odds ratio indicates vegetable oil will have a higher pass rate compared to salt water when comparing against the performance of the control. The p-values for salt water and vegetable oil are 0.001 and

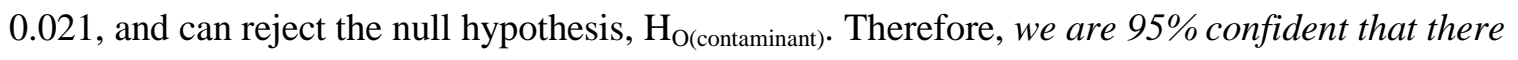
is a difference in pass rate for both contaminants compared to the control when accounting for the effect of dwell time and sealing temperature. 
The interaction between two factors indicates one factor is affected by the other. If there is a significant p-value for the interaction (less than 0.05), then there is an association between the two factors when determining the pass rate. For example, if the p-value for the interaction between $120^{\circ} \mathrm{C}, 0.2 \mathrm{~s}$ and $140^{\circ} \mathrm{C}, 0.3 \mathrm{~s}$ is less than alpha $(\alpha=0.05)$ then there is an association between the temperature and dwell time when testing hermeticity.

\begin{tabular}{|c|c|c|c|}
\hline TEMP (Ref. $\left.140{ }^{\circ} \mathrm{C}\right)$ & Odds Ratio & 95\% C.I. & P-Value \\
\hline $120^{\circ} \mathrm{C}$ & 0.25 & $(0.06,1.05)$ & 0.25 \\
\hline $160{ }^{\circ} \mathrm{C}$ & 4.34 & $(0.75,24.95)$ & 4.34 \\
\hline \multicolumn{4}{|l|}{ DWELL TIME (0.3 s) } \\
\hline 0.2 seconds & 0.58 & $(0.14,2.45)$ & 0.58 \\
\hline 0.4 seconds & 1.66 & $(0.36,7.57)$ & 1.66 \\
\hline \multicolumn{4}{|l|}{ CONTAMINANT (Ref. Control) } \\
\hline Salt Water & 1.51 & $(0.35,6.48)$ & 1.51 \\
\hline Vegetable Oil & 1.9 & $(0.42,8.53)$ & 1.9 \\
\hline \multicolumn{4}{|l|}{ TEMP*CONTAMINANT (Ref. $140^{\circ} \mathrm{C}$ ) } \\
\hline $120 *$ Salt Water & 0.7 & $(0.15,3.34)$ & 0.7 \\
\hline $120 *$ Vegetable Oil & 0.36 & $(0.07,1.88)$ & 0.36 \\
\hline $160 *$ Salt Water & 0.1 & $(0.01,0.67)$ & 0.1 \\
\hline $160 *$ Vegetable Oil & 0.18 & $(0.03,1.29)$ & 0.18 \\
\hline \multicolumn{4}{|l|}{ DWELL TIME*CONTAMINANT (Ref. 0.3 s) } \\
\hline $0.2 *$ Salt Water & 0.28 & $(0.05,1.49)$ & 0.28 \\
\hline $0.2 *$ Vegetable Oil & 0.2 & $(0.04,1.14)$ & 0.2 \\
\hline $0.4 *$ Salt Water & 0.24 & $(0.04,1.38)$ & 0.24 \\
\hline $0.4 *$ Vegetable Oil & 0.63 & $(0.1,3.9)$ & 0.63 \\
\hline \multicolumn{4}{|l|}{ TEMP*DWELL TIME $\left(140^{\circ} \mathrm{C} * 0.3 \mathrm{~s}\right)$} \\
\hline $120^{\circ} \mathrm{C}^{*} 0.2$ seconds & 3.05 & $(0.58,16.04)$ & 3.05 \\
\hline $120^{\circ} \mathrm{C}^{*} 0.4$ seconds & 3 & $(0.62,14.43)$ & 3 \\
\hline $160^{\circ} \mathrm{C} * 0.2$ seconds & 1.05 & $(0.19,5.76)$ & 1.05 \\
\hline $160^{\circ} \mathrm{C}^{*} 0.4$ seconds & 7.69 & $(1.06,55.99)$ & 7.69 \\
\hline
\end{tabular}

Table 21: Binary Logistic Regression Analysis Results with Interactions

*The odds ratio refers to the category associated with the odds ratio compared to the reference category

The $\mathrm{p}$-values for the interactions shown in the analysis above indicate that we are $95 \%$ confident that there is not enough evidence to conclude that there is an association between sealing 
temperature and contaminant type, dwell time and contaminant type, and sealing temperature and $d$ well time. Moreover, the significance of the interaction does not change the optimum sealing condition for Phase 2 of the study.

\subsubsection{Phase 1 Summary}

Vegetable oil and salt water pass rates increase from 0.2 second to 0.4 seconds dwell time. The control showed no difference between 0.3 second and 0.4 seconds since all 10 sample bags passed with no leaks. At 0.2 seconds dwell time, vegetable oil contaminant showed one sample that leaked during hermeticity from the seal area that was contaminated near the T-point point. In addition, salt water had one sample at 0.3 seconds that failed due to leaking from the contaminated area near the T-point. Even though the study aims to observe the performance of the T-point, the stream of contamination spreads across the seal area near the T-point. Furthermore, the force from the seal jaws to bring the two film surfaces together causes the contaminant to spread in the seal area.

Overall, the binary logistic regression analysis indicates the optimal sealing condition for all contaminant types is $140^{\circ} \mathrm{C}$ and $0.3 \mathrm{~s}$ dwell time. The first binary logistic regression analysis in Table 19 shows there is not enough evidence to conclude there is a difference in pass rate between $140^{\circ} \mathrm{C}$ and $160^{\circ} \mathrm{C}$ sealing temperature and $0.3 \mathrm{~s}$ and $0.4 \mathrm{~s}$ dwell time. However, there was enough evidence to conclude that there is a difference between $120^{\circ} \mathrm{C}$ and $140^{\circ} \mathrm{C}$ sealing temperature and $0.2 \mathrm{~s}$ and $0.3 \mathrm{~s}$ dwell time. Furthermore, the analysis indicates $120^{\circ} \mathrm{C}$ sealing temperature has a lower pass rate compared to $140^{\circ} \mathrm{C}$ sealing temperature. In addition, the analysis shows $0.2 \mathrm{~s}$ dwell time has a lower pass rate compared to $0.3 \mathrm{~s}$ dwell time.

\subsection{Phase 2 Results}

Phase 2 tests the effect of temperature, time and contamination given the parameters of the test. Each contaminant was tested four times over the 14 day shelf life study on Days 2,6,10 and 14 . 
On each day, it was hopeful to test at least 10 sample bags for hermeticity in order to have an adequate representation for each contaminant type. Unfortunately, even with 10-20\% more samples than what was needed each day, some sample sizes were less than 10 due to wrinkles in the seal and insignificant bag inflation during hermeticity testing. To test a hermetic seal, the sample bag must fully expand under the vacuum chamber. In addition to hermeticity testing, at least five sample bags were tested each day for each temperature for seal strength. Each sample bag had two replicates for front and back seal, which provided 10 to 12 samples for each conditioning temperature on each day. However, samples were only represented in the results if the failure mode was peel or a combination of peel and material failure. The seal strength graphs of the raw data by testing period and by conditioning temperature are shown in Appendix 8 .

\subsubsection{Phase 2 Hermeticity Results}

Hermeticity was tested for both conditioning temperatures during each testing period - Days $2,6,10$, and 14 . Hermeticity testing was conducted to determine if hermeticity had a significant change over time due to contamination. 


\section{Control}

Day 2 Tested on 2/23/2014

\begin{tabular}{|c|c|c|c|}
\hline $\begin{array}{l}\text { Refrigerated } \\
\text { Condition } \\
\end{array}$ & $\underline{\text { Pass }}$ & Fail & Notes: \\
\hline & 1 & & Corners \\
\hline & 6 & 3 & Crossover \\
\hline & & & Crossover \& Corners \\
\hline & & & Contamination \\
\hline Total: & 7 & 3 & \\
\hline Pass \% & $70 \%$ & & \\
\hline
\end{tabular}

\begin{tabular}{|r|r|r|l|}
\hline $\begin{array}{l}\text { Ambient } \\
\text { Condition }\end{array}$ & Pass & Fail & Notes: \\
\hline & & & Corners \\
\hline & 5 & 4 & Crossover \\
\hline & & 1 & Crossover \& Corners \\
\hline & & & Contamination \\
\hline Total: & 5 & 5 & \\
\hline Pass \% & $50 \%$ & & \\
\hline
\end{tabular}

Table 22: Control Day 2 Testing for Phase 2

Day 6 Tested on 2/27/2014

\begin{tabular}{|r|r|r|l|}
\hline $\begin{array}{l}\text { Refrigerated } \\
\text { Condition }\end{array}$ & \multicolumn{1}{|l|}{ Pass } & Fail & Notes: \\
\hline & 1 & & Corners \\
\hline & 5 & 3 & Crossover \\
\hline & & & Crossover \& Corners \\
\hline & & 1 & Contamination \\
\hline Total: & 6 & 4 & \\
\hline Pass \% & $60 \%$ & & \\
\hline
\end{tabular}

\begin{tabular}{|r|r|r|l|}
\hline $\begin{array}{l}\text { Ambient } \\
\text { Condition }\end{array}$ & Pass & Fail & Notes: \\
\hline & & & Corners \\
\hline & 3 & 5 & Crossover \\
\hline & & 1 & Crossover \& Corners \\
\hline & & & Contamination \\
\hline Total: & 3 & 6 & \\
\hline Pass \% & $33 \%$ & & \\
\hline
\end{tabular}

Table 23: Control Day 6 Testing for Phase 2 
Day 10 Tested On 3/3/2014

\begin{tabular}{|r|r|r|l|}
\hline $\begin{array}{l}\text { Refrigerated } \\
\text { Condition }\end{array}$ & Pass & Fail & Notes: \\
\hline & & & Corners \\
\hline & 6 & 4 & Crossover \\
\hline & & & Crossover \& Corners \\
\hline & & & Contamination \\
\hline Total: & 6 & 4 & \\
\hline Pass \% & $60 \%$ & & \\
\hline
\end{tabular}

\begin{tabular}{|r|r|r|l|}
\hline $\begin{array}{l}\text { Ambient } \\
\text { Condition }\end{array}$ & Pass & Fail & Notes: \\
\hline & & & Corners \\
\hline & 6 & 4 & Crossover \\
\hline & & & Crossover \& Corners \\
\hline & & & Contamination \\
\hline Total: & 6 & 4 & \\
\hline Pass \% & $60 \%$ & & \\
\hline
\end{tabular}

Table 24: Control Day 10 Testing for Phase 2

Day 14 Tested on 3/7/2014

\begin{tabular}{|r|r|r|l|}
\hline $\begin{array}{l}\text { Refrigerated } \\
\text { Condition }\end{array}$ & Pass & Fail & Notes: \\
\hline & & & Corners \\
\hline & 5 & 1 & Crossover \\
\hline & & 2 & Crossover \& Corners \\
\hline & & & Contamination \\
\hline Total: & 5 & 3 & \\
\hline Pass \% & $63 \%$ & & \\
\hline
\end{tabular}

\begin{tabular}{|r|r|r|l|}
\hline $\begin{array}{l}\text { Ambient } \\
\text { Condition }\end{array}$ & $\underline{\text { Pass }}$ & $\underline{\text { Fail }}$ & Notes: \\
\hline & 2 & & Corners \\
\hline & 3 & 5 & Crossover \\
\hline & & & Crossover \& Corners \\
\hline & & & Contamination \\
\hline Total: & 5 & 5 & \\
\hline Pass \% & $50 \%$ & & \\
\hline
\end{tabular}

Table 25: Control Day 14 Testing for Phase 2 


\section{Salt Water}

Day 2 Tested on 2/21/2014

\begin{tabular}{|r|r|r|l|}
\hline $\begin{array}{l}\text { Refrigerated } \\
\text { Condition }\end{array}$ & Pass & Fail & Notes: \\
\hline & & & Corners \\
\hline & 3 & 5 & Crossover \\
\hline & & & Crossover \& Corners \\
\hline & & 1 & Contamination \\
\hline Total: & 3 & 6 & \\
\hline Pass \%: & $33 \%$ & & \\
\hline
\end{tabular}

\begin{tabular}{|c|c|c|c|}
\hline $\begin{array}{l}\text { Ambient } \\
\text { Condition }\end{array}$ & $\underline{\text { Pass }}$ & Fail & Notes: \\
\hline & 1 & & Corners \\
\hline & 4 & 5 & Crossover \\
\hline & & & $\begin{array}{l}\text { Crossover \& } \\
\text { Contamination }\end{array}$ \\
\hline & & & Contamination \\
\hline Total: & 5 & 5 & \\
\hline Pass \%: & $50 \%$ & & \\
\hline
\end{tabular}

Table 26: Salt Water Day 2 Testing for Phase 2

On day 2 testing for salt water, ambient condition was $23.2^{\circ} \mathrm{C}, 49.8 \% \mathrm{RH}$, and refrigerated

condition was $5.2^{\circ} \mathrm{C}, 84.7 \% \mathrm{RH}$. The Raytek temperature gun measured the actual temperatures to be $21.2^{\circ} \mathrm{C}$ for ambient and $5.4^{\circ} \mathrm{C}$ for refrigerated. The test room temperature was set to 22 and $33 \% \mathrm{RH}$. The temperatures of the boxes for ambient condition were $22.4^{0} \mathrm{C}$, for hermeticity samples, and $22.8^{\circ} \mathrm{C}$ for seal strength samples. The temperatures of the boxes for refrigerated condition were $7.1^{\circ} \mathrm{C}$, for hermeticity samples, and $8.4^{\circ} \mathrm{C}$ for seal strength samples. Furthermore, the contamination did not look visibly different between the two storage conditions. 
Day 6 Tested on $2 / 25 / 2014$

\begin{tabular}{|r|r|r|l|}
\hline $\begin{array}{l}\text { Refrigerated } \\
\text { Condition }\end{array}$ & Pass & Fail & Notes: \\
\hline & 1 & & Corners \\
\hline & 5 & 3 & Crossover \\
\hline & & & Crossover \& Corners \\
\hline & & 1 & Contamination \\
\hline Total: & 6 & 4 & \\
\hline Pass \%: & $60 \%$ & & \\
\hline
\end{tabular}

\begin{tabular}{|r|r|r|l|}
\hline $\begin{array}{l}\text { Ambient } \\
\text { Condition }\end{array}$ & Pass & Fail & Notes: \\
\hline & & & Corners \\
\hline & 3 & 5 & Crossover \\
\hline & & 1 & Crossover \& Corners \\
\hline & & & Contamination \\
\hline Total: & 3 & 6 & \\
\hline Pass \%: & $33 \%$ & & \\
\hline
\end{tabular}

Table 27: Salt Water Day 6 Testing for Phase 2

On day 6 testing for salt water, ambient condition was set to $22.9^{\circ} \mathrm{C}, 50.8 \% \mathrm{RH}$, and refrigerated condition was set to $4.7^{\circ} \mathrm{C}, 90.2 \% \mathrm{RH}$. The Raytek temperature gun measured the actual temperatures to be $21.2^{\circ} \mathrm{C}$ for ambient and $5.4^{\circ} \mathrm{C}$ for refrigerated. The test room temperature was $21.0^{\circ} \mathrm{C}, 33 \% \mathrm{RH}$. The temperatures of the boxes for ambient condition were $22.8^{\circ} \mathrm{C}$, for hermeticity samples and for seal strength samples. The temperatures of the boxes for refrigerated condition were $8.6^{\circ} \mathrm{C}$, for hermeticity samples, and $7.2^{\circ} \mathrm{C}$ for seal strength samples. Ambient condition starts to show changes in contamination with approximately $50 \%$ total water loss of total contamination in sample bags. 


\section{Day 10 Tested on 3/1/2014}

\begin{tabular}{|r|r|r|l|}
\hline $\begin{array}{l}\text { Refrigerated } \\
\text { Condition }\end{array}$ & Pass & Fail & Notes: \\
\hline & 6 & 4 & Crossover \\
\hline & & & Crossover \& Corners \\
\hline & & & Contamination \\
\hline Total: & 6 & 4 & \\
\hline Pass \%: & $60 \%$ & & \\
\hline
\end{tabular}

\begin{tabular}{|r|r|r|l|}
\hline $\begin{array}{l}\text { Ambient } \\
\text { Condition }\end{array}$ & Pass & Fail & Notes: \\
\hline & 1 & & Corners \\
\hline & 2 & 5 & Crossover \\
\hline & & & Crossover \& Corners \\
\hline & & & Contamination \\
\hline Total: & 3 & 5 & \\
\hline Pass \%: & $38 \%$ & & \\
\hline
\end{tabular}

Table 28: Salt Water Day 10 Testing for Phase 2

On day 10 testing for salt water, ambient condition was $23.2^{\circ} \mathrm{C}, 50.0 \% \mathrm{RH}$, and refrigerated condition was $4.8^{\circ} \mathrm{C}, 85.5 \% \mathrm{RH}$. The Raytek temperature gun measured the actual temperatures to be $23.0^{\circ} \mathrm{C}$ for ambient and $4.9^{\circ} \mathrm{C}$ for refrigerated. The test room temperature was $19.0^{\circ} \mathrm{C}$, $56 \%$ RH. The temperatures of the boxes for ambient condition were $22.4^{0} \mathrm{C}$ for hermeticity samples, and $22.2{ }^{\circ} \mathrm{C}$ for seal strength samples. The temperatures of the boxes for refrigerated condition were $9.0^{\circ} \mathrm{C}$, for hermeticity samples, and $10.0^{\circ} \mathrm{C}$ for seal strength samples. Ambient condition shows changes in contamination of approximately $85 \%$ total water loss of contamination in sample bags. 


\section{Day 14 Tested on $3 / 5 / 2014$}

\begin{tabular}{|r|r|r|l|}
\hline $\begin{array}{l}\text { Refrigerated } \\
\text { Condition }\end{array}$ & Pass & Fail & Notes: \\
\hline & 4 & 3 & Crossover \\
\hline & & 1 & Crossover \& Corners \\
\hline & & & Contamination \\
\hline Total: & 4 & 4 & \\
\hline Pass \%: & $50 \%$ & & \\
\hline
\end{tabular}

\begin{tabular}{|r|r|r|l|}
\hline $\begin{array}{l}\text { Ambient } \\
\text { Condition }\end{array}$ & Pass & Fail & Notes: \\
\hline & 1 & & Corners \\
\hline & 1 & 5 & Crossover \\
\hline & & & Crossover \& Corners \\
\hline & & & Contamination \\
\hline Total: & 2 & 5 & \\
\hline Pass \%: & $29 \%$ & & \\
\hline
\end{tabular}

Table 29: Salt Water Day 14 Testing for Phase 2

On day 14 testing for salt water, ambient condition was $23.2^{\circ} \mathrm{C}, 51.1 \% \mathrm{RH}$, and refrigerated condition was $4.9^{\circ} \mathrm{C}, 85.8 \% \mathrm{RH}$. The Raytek temperature gun measured the actual temperatures to be $22.8^{\circ} \mathrm{C}$ for ambient and $4.6^{\circ} \mathrm{C}$ for refrigerated. The test room temperature was $29.0^{\circ} \mathrm{C}$, $78 \% \mathrm{RH}$. The temperatures of the boxes for ambient condition were $23.6^{\circ} \mathrm{C}$ for hermeticity samples, and $23.0^{\circ} \mathrm{C}$ for seal strength samples. The temperatures of the boxes for refrigerated condition were $9.0^{\circ} \mathrm{C}$, for hermeticity samples, and $6.0^{\circ} \mathrm{C}$ for seal strength samples. Ambient condition results in approximately $100 \%$ total water loss of contamination in sample bags. 


\section{Vegetable Oil}

Day 2 Tested on 2/22/2014

\begin{tabular}{|r|r|r|l|}
\hline $\begin{array}{l}\text { Refrigerated } \\
\text { Condition }\end{array}$ & Pass & Fail & Notes: \\
\hline & 2 & & Corners \\
\hline & 5 & 3 & Crossover \\
\hline & & & Crossover \& Corners \\
\hline & & & Contamination \\
\hline Total: & 7 & 3 & \\
\hline Pass \%: & $70 \%$ & & \\
\hline
\end{tabular}

\begin{tabular}{|c|c|c|c|}
\hline $\begin{array}{l}\text { Ambient } \\
\text { Condition }\end{array}$ & Pass & Fail & Notes: \\
\hline & & & Corners \\
\hline & 6 & 4 & Crossover \\
\hline & & & Crossover \& Corners \\
\hline & & & Contamination \\
\hline Total: & 6 & 4 & \\
\hline Pass \%: & $60 \%$ & & \\
\hline
\end{tabular}

Table 30: Vegetable Oil Day 2 Testing for Phase 2

On day 2 testing for vegetable oil, ambient condition was $22.8^{\circ} \mathrm{C}, 50.2 \% \mathrm{RH}$, and refrigerated

condition was $4.6^{\circ} \mathrm{C}, 85.1 \% \mathrm{RH}$. The Raytek temperature gun measured the actual temperatures to be $22.8^{\circ} \mathrm{C}$ for ambient and $3.2^{\circ} \mathrm{C}$ for refrigerated. The test room temperature was set to $19^{\circ} \mathrm{C}$ and $32 \% \mathrm{RH}$. The temperatures of the boxes for ambient condition were $22.8^{0} \mathrm{C}$, for hermeticity samples, and $23.4^{\circ} \mathrm{C}$ for seal strength samples. The temperatures of the boxes for refrigerated condition were $7.4^{\circ} \mathrm{C}$, for hermeticity samples, and $6^{\circ} \mathrm{C}$ for seal strength samples. Furthermore, the contamination did not look visibly different between the two storage conditions. 
Day 6 Tested on $2 / 26 / 2014$

\begin{tabular}{|c|c|c|c|}
\hline $\begin{array}{l}\text { Refrigerated } \\
\text { Condition }\end{array}$ & Pass & Fail & Notes: \\
\hline & 1 & & Corners \\
\hline & 5 & 3 & Crossover \\
\hline & & 1 & Crossover \& Corners \\
\hline & & & Contamination \\
\hline Total: & 6 & 4 & \\
\hline Pass \%: & $60 \%$ & & \\
\hline
\end{tabular}

\begin{tabular}{|r|r|r|l|}
\hline $\begin{array}{l}\text { Ambient } \\
\text { Condition }\end{array}$ & Pass & Fail & Notes: \\
\hline & & & Corners \\
\hline & 4 & 5 & Crossover \\
\hline & & & Crossover \& Corners \\
\hline & & & Contamination \\
\hline Total: & 4 & 5 & \\
\hline Pass \%: & $44 \%$ & & \\
\hline
\end{tabular}

Table 31: Vegetable Oil Day 6 Testing for Phase 2

On day 6 testing for vegetable oil, ambient condition was $23.1{ }^{\circ} \mathrm{C}, 33.0 \% \mathrm{RH}$, and refrigerated

condition was $5.1^{0} \mathrm{C}, 86.2 \% \mathrm{RH}$. The Raytek temperature gun measured the actual temperatures to be $23.2^{\circ} \mathrm{C}$ for ambient and $3.4^{\circ} \mathrm{C}$ for refrigerated. The test room temperature was set to $20^{\circ} \mathrm{C}$ and $40 \% \mathrm{RH}$. The temperatures of the boxes for ambient condition were $23.2^{\circ} \mathrm{C}$, for hermeticity samples, and $22.6^{\circ} \mathrm{C}$ for seal strength samples. The temperatures of the boxes for refrigerated condition were $10.8^{\circ} \mathrm{C}$, for hermeticity samples, and $9.8^{\circ} \mathrm{C}$ for seal strength samples.

Furthermore, the contamination did not look visibly different between the two storage conditions.

Day 10 Tested on 3/2/2014 


\begin{tabular}{|r|r|r|l|}
\hline $\begin{array}{l}\text { Refrigerated } \\
\text { Condition }\end{array}$ & Pass & Fail & Notes: \\
\hline & 6 & 4 & Crossover \\
\hline & & & Crossover \& Corners \\
\hline & & & Contamination \\
\hline Total: & 6 & 4 & \\
\hline Pass \%: & $60 \%$ & & \\
\hline
\end{tabular}

\begin{tabular}{|r|r|r|l|}
\hline $\begin{array}{l}\text { Ambient } \\
\text { Condition }\end{array}$ & Pass & Fail & Notes: \\
\hline & & & Corners \\
\hline & 6 & 4 & Crossover \\
\hline & & & Crossover \& Corners \\
\hline & & & Contamination \\
\hline Total: & 6 & 4 & \\
\hline Pass \%: & $60 \%$ & & \\
\hline
\end{tabular}

Table 32: Vegetable Oil Day 10 Testing for Phase 2

On day 10 testing for vegetable oil, ambient condition was $22.9^{\circ} \mathrm{C}, 49.9 \% \mathrm{RH}$, and refrigerated condition was $4.9^{\circ} \mathrm{C}, 85.5 \% \mathrm{RH}$. The Raytek temperature gun measured the actual temperatures to be $23.0^{\circ} \mathrm{C}$ for ambient and $3.6^{\circ} \mathrm{C}$ for refrigerated. The test room temperature was set to $19^{\circ} \mathrm{C}$ and $55 \% \mathrm{RH}$. The temperatures of the boxes for ambient condition were $22.6^{\circ} \mathrm{C}$, for hermeticity samples, and $22.4^{\circ} \mathrm{C}$ for seal strength samples. The temperatures of the boxes for refrigerated condition were $6.0^{\circ} \mathrm{C}$, for hermeticity samples, and $4.6^{\circ} \mathrm{C}$ for seal strength samples. Furthermore, the contamination did not look visibly different between the two storage conditions. 


\section{Day 14 Tested on $3 / 6 / 2014$}

\begin{tabular}{|r|r|r|l|}
\hline $\begin{array}{l}\text { Refrigerated } \\
\text { Condition }\end{array}$ & Pass & Fail & Notes: \\
\hline & 1 & & Corners \\
\hline & 3 & 3 & Crossover \\
\hline & & & Crossover \& Corners \\
\hline & & & Contamination \\
\hline Total: & 4 & 3 & \\
\hline Pass \%: & $57 \%$ & & \\
\hline
\end{tabular}

\begin{tabular}{|r|r|r|l|}
\hline $\begin{array}{l}\text { Ambient } \\
\text { Condition }\end{array}$ & Pass & Fail & Notes: \\
\hline & & & Corners \\
\hline & 5 & 5 & Crossover \\
\hline & & & Crossover \& Corners \\
\hline & & & Contamination \\
\hline Total: & 5 & 5 & \\
\hline Pass \%: & $50 \%$ & & \\
\hline
\end{tabular}

Table 33: Vegetable Oil Day 14 Testing for Phase 2

On day 14 testing for vegetable oil, ambient condition was $23.2^{\circ} \mathrm{C}, 50.1 \% \mathrm{RH}$, and refrigerated condition was $4.8^{\circ} \mathrm{C}, 85.6 \% \mathrm{RH}$. The Raytek temperature gun measured the actual temperatures to be $23.8^{\circ} \mathrm{C}$ for ambient and $4.8^{\circ} \mathrm{C}$ for refrigerated. The test room temperature was set to $29^{\circ} \mathrm{C}$ and $78 \% \mathrm{RH}$. The temperatures of the boxes for ambient condition were $23.8^{\circ} \mathrm{C}$, for hermeticity samples, and $23.8^{\circ} \mathrm{C}$ for seal strength samples. The temperatures of the boxes for refrigerated condition were $4.4^{\circ} \mathrm{C}$, for hermeticity samples, and $4.8^{\circ} \mathrm{C}$ for seal strength samples. Furthermore, the contamination looked slightly different than Day 10 with $10 \%$ of contaminant dry. 


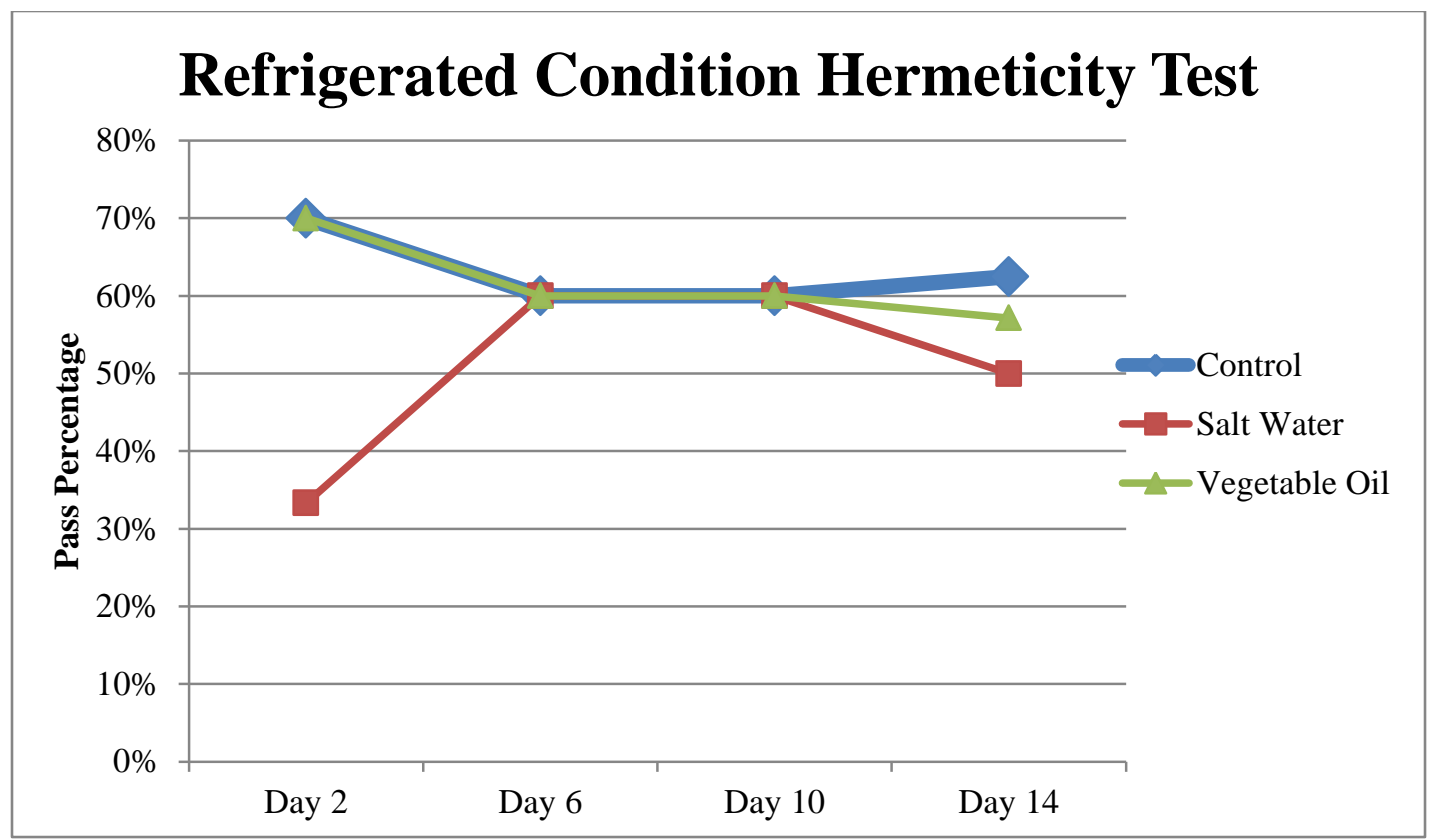

Figure 36: Phase 2 Refrigerated Condition Hermeticity Results for All Contaminants

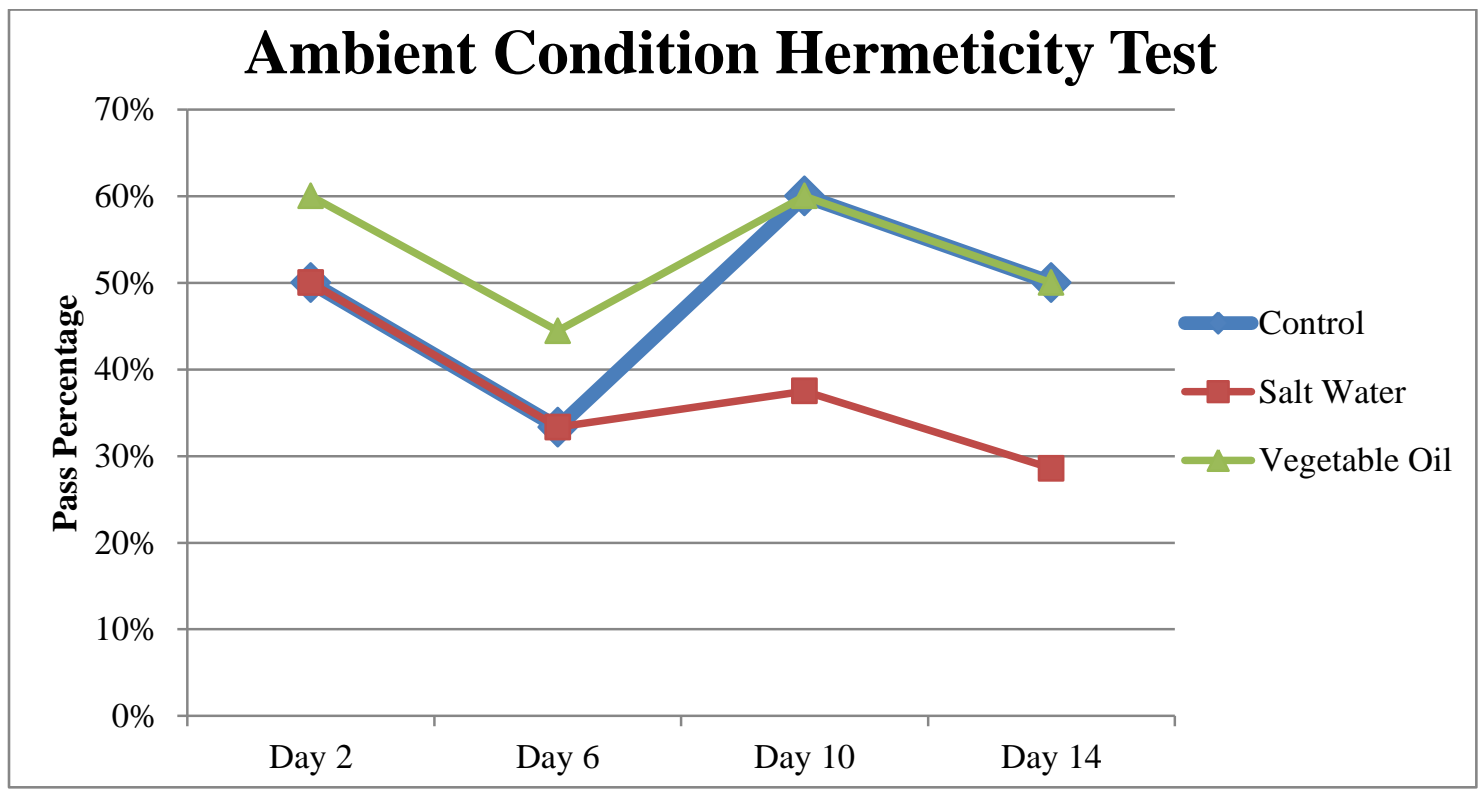

Figure 37: Phase 2 Ambient Condition Hermeticity Results for All Contaminants 


\subsubsection{Phase 2 Hermeticity Statistical Analysis}

\begin{tabular}{|r|r|c|r|}
\hline $\begin{array}{l}\text { Contaminant (Ref. } \\
\text { Control) }\end{array}$ & \multicolumn{1}{|l|}{$\begin{array}{l}\text { Odds } \\
\text { Ratio }\end{array}$} & \multicolumn{1}{c|}{ 95\% C.I. } & P-Value \\
\hline Salt Water & 0.64 & $(0.33,1.22)$ & 0.175 \\
\hline Vegetable Oil & 1.09 & $(0.57,2.08)$ & 0.792 \\
\hline Chamber (Ref. Ambient) & & & \\
\hline Refrigerated Condition & 1.63 & $(0.96,2.79)$ & 0.073 \\
\hline Day (Ref. Day 2) & & & \\
\hline 6 & 0.75 & $(0.36,1.57)$ & 0.439 \\
\hline 10 & 1.02 & $(0.49,2.14)$ & 0.955 \\
\hline 14 & 0.79 & $(0.37,1.69)$ & 0.540 \\
\hline
\end{tabular}

Table 34: Binary Logistic Regression Analysis for Phase 2 Hermeticity Testing

* Odds ratio refers to the category of interest compared to the reference category

The binary logistic regression analysis indicates that salt water will likely have a lower pass rate when associated with the pass rate of the control. For example, salt water is associated with 0.64 odds of having a hermetic seal compared to the control. In addition, vegetable oil is associated with 1.09 odds of having a hermetic seal compared to the control. Therefore, vegetable oil has a similar pass rate compared to the control since the odds ratio is close to 1 . However, the p-value for both salt water and vegetable oil contaminants is 0.175 and 0.792 . Therefore, we are $95 \%$ confident that when accounting for the effect of storage temperature and time there is no significant difference between salt water and vegetable oil contamination compared to the control. Also, the refrigerated conditioning temperature is associated with greater odds of 1.63 of having a hermetic seal compared to ambient conditions.

\subsubsection{Phase 2 Seal Strength Failure Modes}

As mentioned in the methods subchapter, each sample bag had two replicates to represent the average performance of the sample bag using the average of the front and back T-point seals. However, if the seal strength resulted with an insignificant peel failure, then the results of that sample are not included in the represented data. Furthermore, only one seal will represent the seals strength of a sample bag if one of the seals resulted in a material failure. The results of the 
seal strength failure modes are divided into the categories shown in Table 35. The failure types are shown in the following Figures 37 through 41.

\begin{tabular}{|l|l|}
\hline Failure Type & Category \\
\hline Peel & A Failure \\
\hline Material Along Edge of Seal & B Failure \\
\hline Peel + Material & C Failure \\
\hline Delamination & D Failure \\
\hline $\begin{array}{l}\text { Material Away from Edge of } \\
\text { Seal }\end{array}$ & E Failure \\
\hline
\end{tabular}

Table 35: Categories of Failure Modes

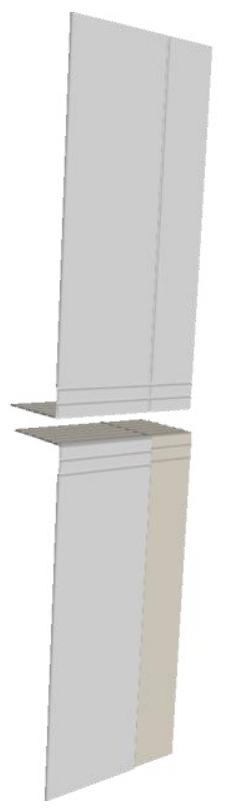

Figure 38: Peel Failure 


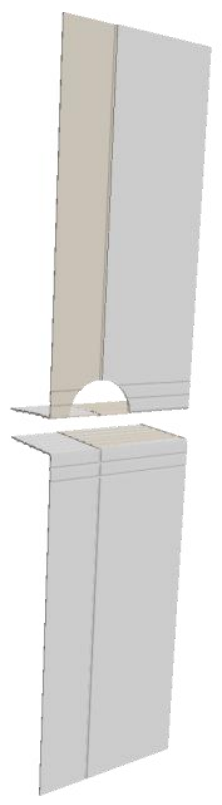

Figure 39: Peel Failure followed by Material Tear Mode at the T-point

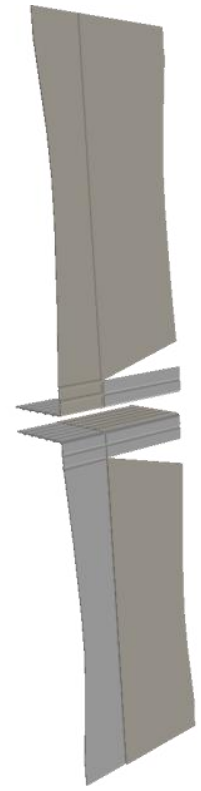

Figure 40: Peel Failure followed by material tearing failure on edge of seal.

*Material failed on the 4 layer of film side of the sample. 


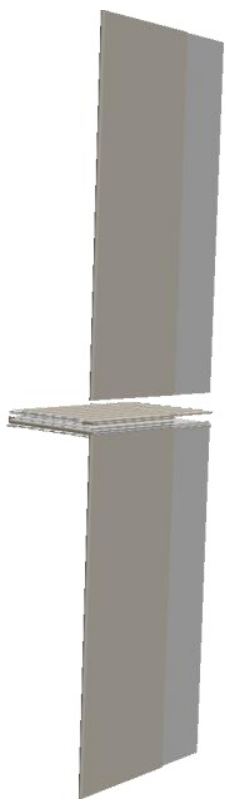

Figure 41: Material Tearing Failure along entire edge of seal. No peel failure observed.

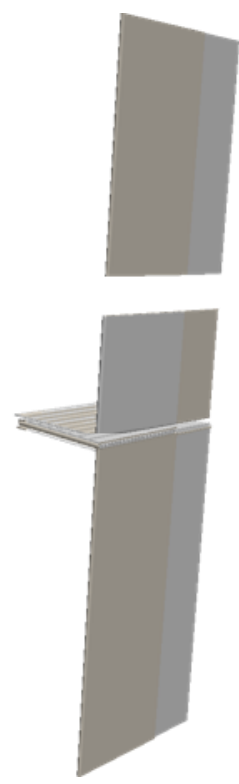

Figure 42: Material Failure not on edge of Seal. No peel failure observed. 


\subsubsection{Phase 2 Seal Strength Results}

The Seal Strength Failure Modes for all three test categories did not show any trend in type of failures for any category. For example, no category resulted in a greater amount of peel failure compared to the other categories. In addition, no category had a shift from peel to material failure or vice versa. The types of failures for each test category and conditioning temperature in Appendix I.

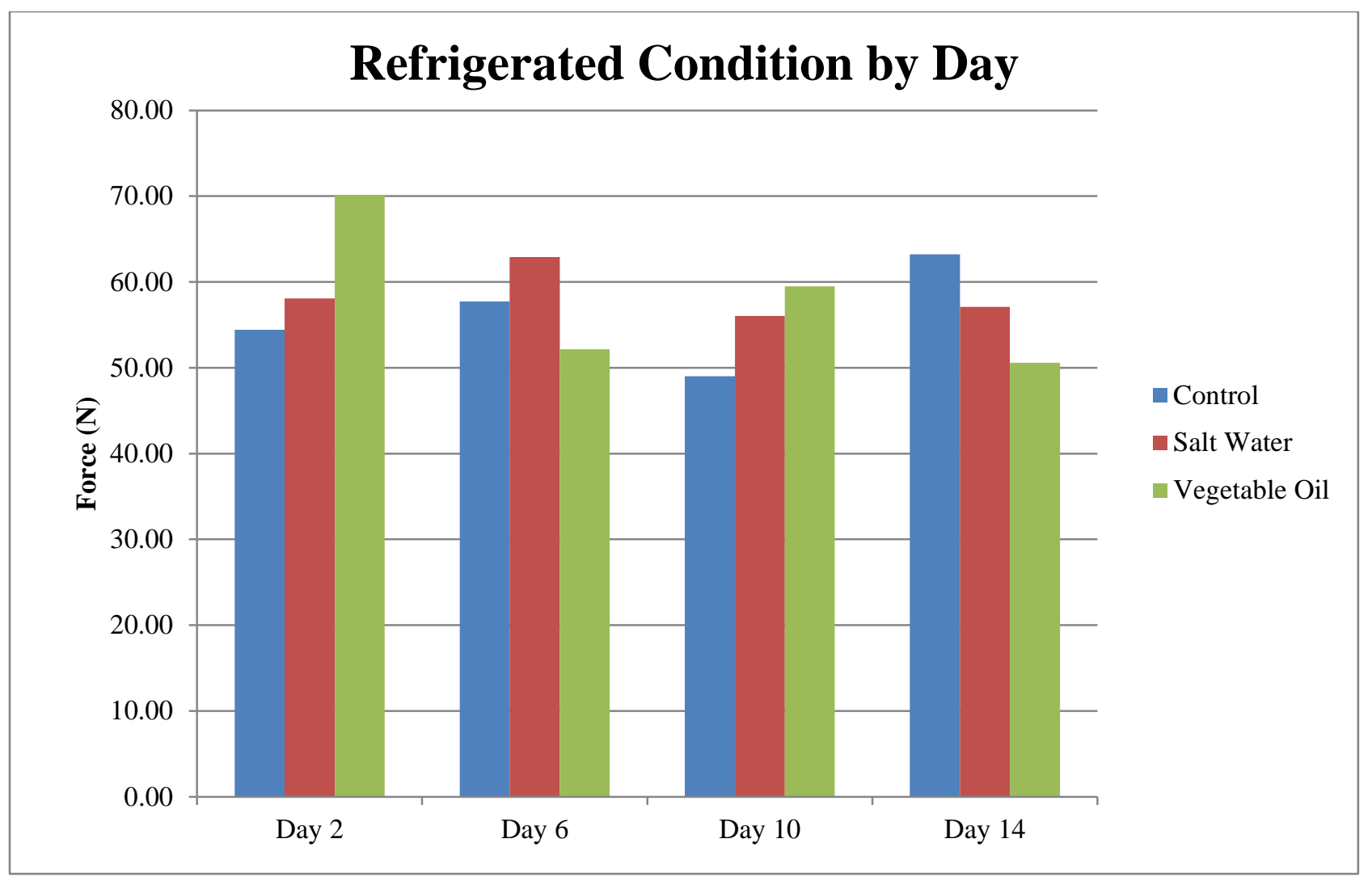

Figure 43: Seal Strength Results for Refrigerated Conditioning Temperature 


\begin{tabular}{|l|c|c|c|c|}
\cline { 2 - 5 } $\begin{array}{l}\text { Refrigerated } \\
\text { Condition }\end{array}$ & \multicolumn{4}{|c|}{ Average Force (N) } \\
\hline Contaminant & Day 2 & Day 6 & \multicolumn{1}{c|}{ Day 10 } & \multicolumn{1}{c|}{ Day 14 } \\
\hline Control & 54.43 & 57.74 & 49.02 & 63.21 \\
\hline Salt Water & 58.08 & 62.91 & 56.04 & 57.12 \\
\hline Vegetable Oil & 70.12 & 52.15 & 59.49 & 50.58 \\
\hline
\end{tabular}

Table 36: Average Force (N) of Represented Samples for Refrigerated Condition

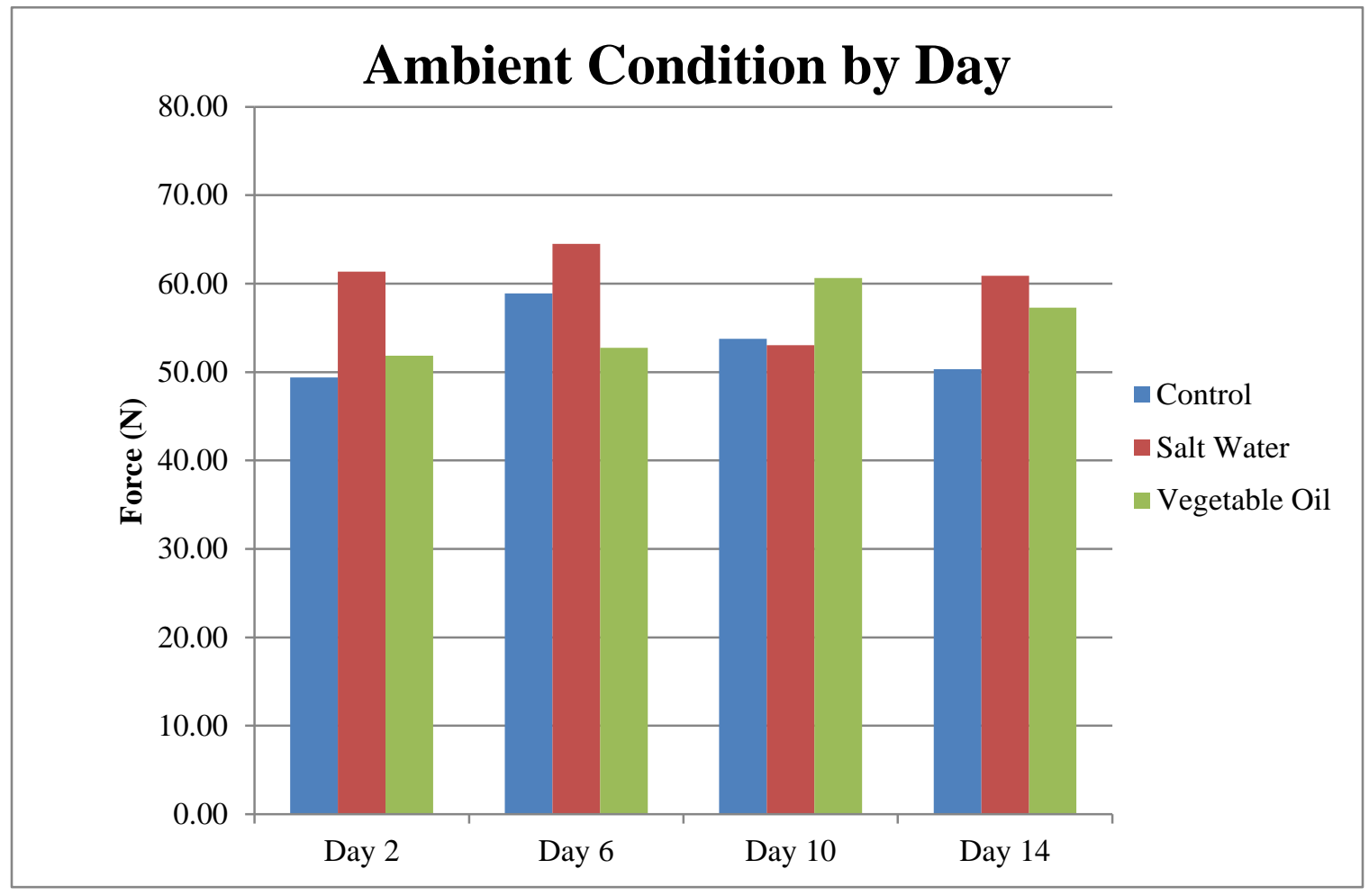

Figure 44: Seal Strength Results for Ambient Conditioning Temperature

\begin{tabular}{|l|c|c|c|c|}
\cline { 2 - 5 } \multicolumn{1}{c|}{ Ambient Condition } & \multicolumn{4}{c|}{ Force (N) } \\
\hline Contaminant & Day 2 & Day 6 & \multicolumn{1}{c|}{ Day 10 } & \multicolumn{1}{c|}{ Day 14 } \\
\hline Control & 49.39 & 58.89 & 53.78 & 50.32 \\
\hline Salt Water & 61.35 & 64.50 & 53.06 & 60.89 \\
\hline Vegetable Oil & 51.86 & 52.73 & 60.66 & 57.28 \\
\hline
\end{tabular}

Table 37: Average Force (N) of Represented Samples for Ambient Condition

The results show no significant difference for seal strength for both contaminants and the control between refrigerated and ambient storage conditions. Throughout the 14 day period, neither the 
control nor either of the two contaminants had a consistently higher or lower seal strength compared to the other two conditions.

\subsubsection{Phase 2 Seal Strength Statistical Analysis}

The second phase of the study requires a multiple comparison of means to analyze the effect of time, conditioning temperature, and contamination with seal strength at $140^{\circ} \mathrm{C}$ and 0.3 seconds sealing condition. The mean was calculated each test day for each contaminant over the 14 day period. A general linear model analysis compared the four recorded mean values for each contaminant shown in Table 38.

ANOVA for Force (N)

\begin{tabular}{|l|r|}
\hline Variables & $\underline{\text { P-value }}$ \\
\hline Day & 0.863 \\
\hline Storage Temperature & 0.606 \\
\hline Contaminant & 0.372 \\
\hline Day*Contaminant & 0.462 \\
\hline Day*Storage Temperature & 0.670 \\
\hline Storage Temperature*Contaminant & 0.742 \\
\hline
\end{tabular}

ANOVA for STRAIN (mm)

\begin{tabular}{|l|r|}
\multicolumn{1}{|l|}{ Variables } & P-value \\
\hline Day & 0.949 \\
\hline Storage Temperature & 0.499 \\
\hline Contaminant & 0.525 \\
\hline Day*Contaminant & 0.847 \\
\hline Day*Storage Temperature & 0.615 \\
\hline Storage Temperature*Contaminant & 0.629 \\
\hline
\end{tabular}

Table 38: General Linear Model (ANOVA) Analysis Results for Phase 2

The p-values for all factors for the FORCE (N) response and STRAIN ( $\mathrm{mm}$ ) response are greater than $0.05(\alpha=0.05)$. Therefore, we are 95\% confident that there is no difference force $(N)$ or strain $(\mathrm{mm})$ when accounting for the effect of day, conditioning temperature, contaminant, day and contaminant interaction, day and chamber interaction, and chamber and contaminant interaction. 


\subsubsection{Phase 2 Summary}

The statistical analysis indicates that there is no significant difference in hermeticity for both contaminants and the control over the duration of Phase 2, nor is there a significant difference between contaminants and the control. In addition, there is no significant difference in seal strength between the contaminants and the control over the 14 day period; nor is there a significant difference in seal strength for each contaminant and the control throughout the 14 day period.

For the refrigerated conditioning temperature, vegetable oil has a similar hermeticity pass rate to the control and salt water has a lower pass rate across the 14 day test period. In addition, the ambient conditioning temperature shows vegetable oil with a higher pass rate for Days 2 and 6, but as stated previously there is no statistical difference. However, the sample size was less on day 14 for salt water and vegetable oil due to samples performing leaks at unwanted wrinkles or poor inflation during hermeticity testing. The increase in inadequate inflation of the sample bags may be the result of gradual air loss over time. The sample bags may have had seal leaks, which allowed for enough air to release from inside the bag. Moreover, the sample bags with inadequate inflation were discarded and not included in the represented data for hermeticity. It was also observed there was a visual difference in the aging of contamination over the 14 day period. The salt solution showed significant water loss from Day 2 to Day 14, which allowed for the salt and the red dye to be left behind. The vegetable did not show significant changes over the 14 days. 


\subsection{Conclusion}

\subsection{Significance of Contaminant Effect on Hermeticity and Seal Strength}

The results of the study measure the effect of liquid contaminant at the T-point of the seal with a linear low-density polyethylene (LLDPE) sealant. Vegetable oil was used to simulate the effect of oil-based snack foods and the salt water solution was used to simulate salty snack foods. As mentioned previously, the T-point was chosen as the point of contamination because it is the most critical point of the seal. It was noted that the vegetable oil contaminant left residuals of oil onto the corrugated box during storage, which was determined in the study's findings that it may not necessarily be due to a failed hermetic seal. During production, the contamination was a continuous stream from bag to bag and may have been the reason for the oil found in the box. Therefore, the hermeticity of the seal should be tested in addition to the visual observations made during quality inspection. Overall, it was determined that liquid contaminants found at the Tpoint do not have a significant effect on the hermeticity or seal strength when using the study's method. Moreover, the effect of storage temperature and time do not have a significant effect on the performance of the LLDPE sealant when liquid contamination present in the seal area. Room temperature may be considered the more common storage temperature compared to refrigerated conditions, but it was important to determine if temperature was a factor to the performance of the sealant. The visual observation of the liquid contaminants between the two storage temperatures was seen to be the most different for the salt water solution. During the 14 day test cycle, the salt water solution progressed to a dry contaminant. Again, this can be due to the water vapor transmission rate of the film. Even though this study was used on a horizontal form, fill and seal, flow-wrap machine, the information can be useful for other snack food operating applications.

In addition to hermeticity, the seal strength performance can be used to determine that the integrity of the seal strength of the T-point is not compromised with liquid contaminants. Each sample size included at least five sample bags with two replicates each at the front and back Tpoints. Therefore, the average of each sample bag was calculated to determine the average seal strength of the sample size. Overall, there was no significant difference between the test categories for the average maximum force experienced by the seal before failure. Prior to the study, it could have been assumed that the contaminants would lower the average seal strength to separate the film at the seal. 


\subsection{Significance of Sealing Temperature and Dwell Time}

The different sealing temperatures and dwell time were chosen based on an acceptable range of sealing conditions and tested during Phase 1 . The Phase 1 test was conducted to test if different sealing conditions result in different hermetic seals. It would be more desirable to have a lower sealing temperature and dwell time for faster production and lower production costs. A high seal temperature and longer dwell time may be assumed to provide a higher hermeticity pass rate. A sealing temperature of $160^{\circ} \mathrm{C}$ and 0.4 seconds dwell time did show a higher pass rate than $140^{\circ} \mathrm{C}$ and 0.3 seconds dwell time. However, the binary logistic regression analysis indicates that the difference between the sealing temperatures and dwell times is not significant. In addition, $120^{\circ} \mathrm{C}$ sealing temperature and 0.2 seconds dwell time did have a significantly lower hermeticity pass rate. The low seal initiation temperature of the LLDPE sealant allows for lower sealing conditions, but increasing the sealing temperature and dwell time will eventually plateau. The hermeticity pass rate will eventually peak given the capacity of the molecular chain entanglement. Therefore, $140^{\circ} \mathrm{C}$ sealing temperature and 0.3 seconds dwell time is the optimal condition for producing a hermetic seal when accounting for vegetable oil and salt water liquid contamination for LLDPE sealant. Although not all sample bags had a hermetic seal, the purpose of the study was to compare the sealant layer's performance with no contamination to liquid contamination.

\subsection{Significance of Results to Past Work}

In comparison to some previous studies, practical and useful experimental conditions for the snack food industry were chosen for the test method. Some past work use dwell times greater than 0.5 seconds, which would lower the production efficiency if it was applied to industry. It may show seal strength and hermeticity trends on a large scale, but the scope of the study was to test a close range of sealing temperatures and dwell time that would most likely be used in industry. Within the sealing conditions investigated, the optimal seal temperature and dwell time were different than the study completed by Mihindukulasuriya and Lim [9] due to the wide range of dwell time and seal temperatures. However, Mihindukulasuriya and Lim [9] determined that vegetable oil has a slightly lower seal strength compared to water and the control. In addition to the findings of Mihindukulasuriya and Lim [9], this study uses statistical analysis to not only test for a difference between contaminants, but if the difference is significant. In addition, no work has been completed for hermeticity using a vacuum chamber, so the test method for the hermeticity in this study can be used for future work. 


\subsection{Future Work}

The suggested future work includes tested granular contaminants with the same method. The contamination system needs to be different in order to apply a consistent stream of contamination. However, the same hermeticity and seal strength methods can be applicable to other contaminants for flexible food packaging. It is also recommended to use twice as many samples for a stronger representation of the effect of liquid contamination on hermeticity and seal strength. In addition, testing the effect of freezing conditions can apply this test method to the frozen food industry. 


\section{REFERENCES}

[1] Flexible Packaging Association. Website accessed 2014 <http://www.flexpack.org>.

[2] Barnes M, Dudbridge M, Duckett T. Polarised light stress analysis and laser scatter imaging for non-contact inspection of heat seals in food trays. Journal of Food Engineering 2012;112:183-190.

[3] American Society for Testing and Materials. F88/F88M-09. Standard test method for seal strength of flexible barrier materials.

[4] Meka P, Stehling FC. Heat sealing of semi-crystalline polymer films. I. Calculation and measurement of interfacial temperatures: effect of process variables on seal properties. Journal of Applied Polymer Science 1994; 51(1): 89-103.

[5] Yuan CS, Hassan A, Ghazali MIH, Ismail AF. Heat sealability of laminated films with LLDPE and LDPE as the sealant materials in bar sealing application. Journal of Applied Polymer Science 2007; 104: 3736-3745.

[6] Matthews J, Hicks B, Mullineux G, Leslie J, Burke A, Goodwin J, Ogg A, Campbell A. An empirical investigation into the influence of sealing crimp geometry and process setting on the seal integrity of traditional and biopolymer packaging materials. Packaging Technology Science 2013; 26: 355-371.

[7] Aithani D, Lockhart H, Auras R, Tansprasert K. Predicting the strongest peelable for 'easy open’ packaging applications. Journal of Plastic Film and Sheeting 2006;247.

[8] Tetsuya T, Ishiaku US, Mizoguchi M, Hamada H. The effect of heat sealing temperature on the properties of OPP/CPP heat seal. I. Mechanical properties. Journal of Applied Polymer Science 2005; 97: 753-760.

[9] Mihindukulasuriya S, Lim LT. Effects of liquid contaminants on heat seal strength of lowdensity polyethylene film. Packaging Technology and Science 2012;25: 271-284.

[10] American Society for Testing and Materials. D5946-09. Standard test method for coronoatreated polymer films using water contact angle measurements.

[11] Esteban B, Riba JR, Baquero G, Rius A, Puig R, Temperature dependence of density and viscosity of vegetable oils. Biomass and Bioenergy 2012;164-171.

[12] Rodenbush CM, Hsieh FH, Viswanath DS, Density and viscosity of vegetable oils. Journal of American Oil Chemists' Society 1999; 76(12): 1415-1419.

[13] The USGS Water Science School. Water Density. Website accessed 2014

$<$ http://water.usgs.gov/edu/density.html>.

[14] Ozguler A, Morris S, OBrien W. Ultrasonic imaging of micro-leaks and seal contamination in flexible food packages by pulse-echo technique. Journal of Food Science 1998; 63(4): 673-678. 
[15] Simanke A, de Lemos C, Pires M. Linear low density polyethylene: Microstructure and sealing properties correlation. Journal of Polymer Testing 2013; 32: 279-290.

[16] Selke S, Culter J, Hernandez R., (2004). Plastics Packaging: Properties, Processing, Applications, and Regulations. 2nd ed. Munich Germany: Hansner Gardner.

[17] Chum S, Swogger K. Olefin polymer technologies - History and recent progress at The Dow Chemical Company. 2008; 33: 797-819.

[18] Hempel A, Gillanders R, Papkovsky D, Kerry J. Detection of cheese packaging containment failures using reversible optical oxygen sensors. International Journal of Dairy Technology 2012; 65(3)456-460.

[19] American Society for Testing and Materials. D4332-13. Standard practice for conditioning containers, packages, or packaging components for testing.

[20] American Society for Testing and Materials. D3078-02 (Reapproved 2013). Standard test method for determination of leaks in flexible packaging by bubble emission. 


\section{APPENDICES}

Appendix A: Excel sheet for bag placement in boxes for Phase 2

\begin{tabular}{|c|c|c|c|c|c|}
\hline $\begin{array}{l}\text { Salt } \\
\text { Water }\end{array}$ & & $\begin{array}{l}\text { Vegetable } \\
\text { Oil }\end{array}$ & & Control & \\
\hline Box \# & Bag \# & Box \# & Bag \# & Box \# & Bag \# \\
\hline 10 & 1 & 12 & 1 & 12 & 1 \\
\hline 11 & 2 & 6 & 2 & 5 & 2 \\
\hline 12 & 3 & 8 & 3 & 8 & 3 \\
\hline 7 & 4 & 4 & 4 & 6 & 4 \\
\hline 10 & 5 & 6 & 5 & 2 & 5 \\
\hline 6 & 6 & 4 & 6 & 10 & 6 \\
\hline 5 & 7 & 6 & 7 & 1 & 7 \\
\hline 9 & 8 & 7 & 8 & 9 & 8 \\
\hline 2 & 9 & 1 & 9 & 11 & 9 \\
\hline 6 & 10 & 5 & 10 & 1 & 10 \\
\hline 8 & 11 & 12 & 11 & 8 & 11 \\
\hline 9 & 12 & 7 & 12 & 7 & 12 \\
\hline 11 & 13 & 2 & 13 & 9 & 13 \\
\hline 3 & 14 & 10 & 14 & 4 & 14 \\
\hline 8 & 15 & 12 & 15 & 8 & 15 \\
\hline 4 & 16 & 8 & 16 & 6 & 16 \\
\hline 5 & 17 & 12 & 17 & 1 & 17 \\
\hline 8 & 18 & 6 & 18 & 12 & 18 \\
\hline 2 & 19 & 8 & 19 & 2 & 19 \\
\hline 11 & 20 & 6 & 20 & 12 & 20 \\
\hline 5 & 21 & 11 & 21 & 4 & 21 \\
\hline 1 & 22 & 12 & 22 & 8 & 22 \\
\hline 8 & 23 & 12 & 23 & 12 & 23 \\
\hline 4 & 24 & 1 & 24 & 12 & 24 \\
\hline 9 & 25 & 1 & 25 & 11 & 25 \\
\hline 4 & 26 & 5 & 26 & 6 & 26 \\
\hline 7 & 27 & 8 & 27 & 11 & 27 \\
\hline 10 & 28 & 3 & 28 & 2 & 28 \\
\hline 7 & 29 & 9 & 29 & 11 & 29 \\
\hline 2 & 30 & 2 & 30 & 3 & 30 \\
\hline 3 & 31 & 6 & 31 & 8 & 31 \\
\hline 12 & 32 & 8 & 32 & 5 & 32 \\
\hline 1 & 33 & 2 & 33 & 3 & 33 \\
\hline 1 & 34 & 6 & 34 & 7 & 34 \\
\hline 4 & 35 & 6 & 35 & 10 & 35 \\
\hline 4 & 36 & 3 & 36 & 11 & 36 \\
\hline 4 & 37 & 3 & 37 & 5 & 37 \\
\hline 12 & 38 & 10 & 38 & 4 & 38 \\
\hline 12 & 39 & 3 & 39 & 1 & 39 \\
\hline 4 & 40 & 5 & 40 & 7 & 40 \\
\hline 5 & 41 & 7 & 41 & 12 & 41 \\
\hline 9 & 42 & 5 & 42 & 4 & 42 \\
\hline 1 & 43 & 1 & 43 & 5 & 43 \\
\hline
\end{tabular}




\begin{tabular}{|c|c|c|c|c|c|}
\hline 3 & 44 & 9 & 44 & 1 & 44 \\
\hline 2 & 45 & 1 & 45 & 8 & 45 \\
\hline 6 & 46 & 8 & 46 & 5 & 46 \\
\hline 5 & 47 & 6 & 47 & 2 & 47 \\
\hline 2 & 48 & 7 & 48 & 10 & 48 \\
\hline 6 & 49 & 11 & 49 & 10 & 49 \\
\hline 5 & 50 & 9 & 50 & 11 & 50 \\
\hline 11 & 51 & 3 & 51 & 5 & 51 \\
\hline 6 & 52 & 6 & 52 & 7 & 52 \\
\hline 2 & 53 & 9 & 53 & 5 & 53 \\
\hline 2 & 54 & 11 & 54 & 3 & 54 \\
\hline 8 & 55 & 1 & 55 & 7 & 55 \\
\hline 7 & 56 & 5 & 56 & 4 & 56 \\
\hline 8 & 57 & 10 & 57 & 7 & 57 \\
\hline 10 & 58 & 10 & 58 & 12 & 58 \\
\hline 7 & 59 & 5 & 59 & 3 & 59 \\
\hline 9 & 60 & 2 & 60 & 6 & 60 \\
\hline 6 & 61 & 3 & 61 & 10 & 61 \\
\hline 7 & 62 & 4 & 62 & 2 & 62 \\
\hline 3 & 63 & 10 & 63 & 1 & 63 \\
\hline 12 & 64 & 11 & 64 & 10 & 64 \\
\hline 2 & 65 & 5 & 65 & 9 & 65 \\
\hline 1 & 66 & 9 & 66 & 10 & 66 \\
\hline 1 & 67 & 2 & 67 & 7 & 67 \\
\hline 12 & 68 & 9 & 68 & 10 & 68 \\
\hline 6 & 69 & 9 & 69 & 9 & 69 \\
\hline 2 & 70 & 1 & 70 & 4 & 70 \\
\hline 11 & 71 & 1 & 71 & 4 & 71 \\
\hline 4 & 72 & 4 & 72 & 2 & 72 \\
\hline 12 & 73 & 8 & 73 & 9 & 73 \\
\hline 8 & 74 & 7 & 74 & 6 & 74 \\
\hline 12 & 75 & 10 & 75 & 2 & 75 \\
\hline 6 & 76 & 4 & 76 & 6 & 76 \\
\hline 5 & 77 & 10 & 77 & 7 & 77 \\
\hline 11 & 78 & 7 & 78 & 4 & 78 \\
\hline 10 & 79 & 11 & 79 & 5 & 79 \\
\hline 7 & 80 & 7 & 80 & 4 & 80 \\
\hline 11 & 81 & 11 & 81 & 9 & 81 \\
\hline 9 & 82 & 7 & 82 & 6 & 82 \\
\hline 11 & 83 & 11 & 83 & 9 & 83 \\
\hline 3 & 84 & 11 & 84 & 10 & 84 \\
\hline 7 & 85 & 1 & 85 & 4 & 85 \\
\hline 1 & 86 & 3 & 86 & 6 & 86 \\
\hline 3 & 87 & 2 & 87 & 9 & 87 \\
\hline 3 & 88 & 4 & 88 & 5 & 88 \\
\hline 5 & 89 & 10 & 89 & 6 & 89 \\
\hline 7 & 90 & 5 & 90 & 3 & 90 \\
\hline 6 & 91 & 2 & 91 & 12 & 91 \\
\hline 5 & 92 & 9 & 92 & 9 & 92 \\
\hline
\end{tabular}




\begin{tabular}{|r|r|r|r|r|r|}
\hline 1 & 93 & 8 & 93 & 3 & 93 \\
\hline 3 & 94 & 12 & 94 & 8 & 94 \\
\hline 3 & 95 & 7 & 95 & 11 & 95 \\
\hline 9 & 96 & 12 & 96 & 8 & 96 \\
\hline 7 & 97 & 12 & 97 & 3 & 97 \\
\hline 9 & 98 & 2 & 98 & 9 & 98 \\
\hline 2 & 99 & 4 & 99 & 11 & 99 \\
\hline 1 & 100 & 3 & 100 & 11 & 100 \\
\hline 10 & 101 & 11 & 101 & 12 & 101 \\
\hline 4 & 102 & 10 & 102 & 3 & 102 \\
\hline 3 & 103 & 9 & 103 & 1 & 103 \\
\hline 5 & 104 & 2 & 104 & 8 & 104 \\
\hline 4 & 105 & 4 & 105 & 7 & 105 \\
\hline 10 & 106 & 3 & 106 & 1 & 106 \\
\hline 10 & 107 & 9 & 107 & 2 & 107 \\
\hline 11 & 108 & 12 & 108 & 2 & 108 \\
\hline 1 & 109 & 2 & 109 & 11 & 109 \\
\hline 12 & 110 & 5 & 110 & 7 & 110 \\
\hline 8 & 111 & 1 & 111 & 6 & 111 \\
\hline 10 & 112 & 5 & 112 & 12 & 112 \\
\hline 10 & 113 & 11 & 113 & 2 & 113 \\
\hline 8 & 114 & 8 & 114 & 8 & 114 \\
\hline 8 & 115 & 3 & 115 & 1 & 115 \\
\hline 9 & 116 & 8 & 116 & 10 & 116 \\
\hline 9 & 117 & 10 & 117 & 1 & 117 \\
\hline 12 & 118 & 7 & 118 & 3 & 118 \\
\hline 11 & 119 & 4 & 119 & 5 & 119 \\
\hline 6 & 120 & 4 & 120 & 3 & 120 \\
\hline
\end{tabular}

Appendix B: Random Box Assignment to Chamber

\begin{tabular}{|c|c|c|c|c|c|}
\hline Salt Water & & Veg. Oil & & Control & \\
\hline Box \# & Chamber & Box \# & Chamber & Box\# & Chamber \\
\hline 1 & B & & $B$ & & $B$ \\
\hline 2 & $B$ & & $B$ & & $A$ \\
\hline 3 & A & & A & & B \\
\hline 4 & A & & $B$ & & $A$ \\
\hline 5 & $B$ & & A & & B \\
\hline 6 & $B$ & & A & & A \\
\hline 7 & A & & A & & B \\
\hline 8 & A & 8 & A & & A \\
\hline 9 & B & & $A$ & & B \\
\hline 10 & A & 10 & B & 1 & A \\
\hline 11 & B & 11 & B & 1 & $A$ \\
\hline 12 & $A$ & 12 & B & & $A$ \\
\hline
\end{tabular}




\section{Appendix C: Random Order of Boxes Assigned by Test Day}

\section{Salt Water}

\begin{tabular}{|l|l|l|l|l|l|l|}
\hline Chamber A & Assigned Test & Box \# & & Chamber B & Assigned Test & Box \# \\
\hline Day 2 & Hermeticity & 4 & & Day 2 & Hermeticity & 6 \\
\hline Day 6 & Hermeticity & 10 & & Day 6 & Hermeticity & 2 \\
\hline Day 10 & Hermeticity & 7 & & Day 10 & Hermeticity & 5 \\
\hline Day 14 & Hermeticity & 12 & & Day 14 & Hermeticity & 1 \\
\hline Day 2/ Day 14 & Seal Strength & 8 & & Day 2/Day 14 & Seal Strength & 9 \\
\hline Day 6/Day 10 & Seal Strength & 3 & & Day 6/Day 10 & Seal Strength & 11 \\
\hline
\end{tabular}

\section{$\underline{\text { Vegetable Oil }}$}

\begin{tabular}{|l|l|l|l|l|l|l|}
\hline Chamber A & Assigned Test & Box \# & & Chamber B & Assigned Test & Box \# \\
\hline Day 2 & Hermeticity & 3 & & Day 2 & Hermeticity & 1 \\
\hline Day 6 & Hermeticity & 7 & & Day 10 & Hermeticity & 11 \\
\hline Day 10 & Hermeticity & 5 & & Day 6 & Hermeticity & 12 \\
\hline Day 14 & Hermeticity & 9 & & Day 14 & Hermeticity & 10 \\
\hline Day2/Day 10 & Seal Strength & 8 & & Day 2/Day10 & Seal Strength & 2 \\
\hline Day 6/Day14 & Seal Strength & 6 & & Day 6/Day14 & Seal Strength & 4 \\
\hline
\end{tabular}

\section{Control}

\begin{tabular}{|l|l|l|l|l|l|l|}
\hline Chamber A & Assigned Test & Box \# & & Chamber B & Assigned Test & Box \# \\
\hline Day 2 & Hermeticity & 2 & & Day 2 & Hermeticity & 1 \\
\hline Day 6 & Hermeticity & 11 & & Day 6 & Hermeticity & 7 \\
\hline Day 10 & Hermeticity & 12 & & Day 10 & Hermeticity & 3 \\
\hline Day 14 & Hermeticity & 4 & & Day 14 & Hermeticity & 6 \\
\hline Day2/Day 6 & Seal Strength & 8 & & Day2/Day 6 & Seal Strength & 5 \\
\hline Day 10/Day14 & Seal Strength & 10 & & Day 10/Day14 & Seal Strength & 9 \\
\hline
\end{tabular}




\section{Appendix D: Random Box Placement by Chamber}

The box placement within each chamber is shown from a top view. Boxes were all placed on the chamber floor except for those boxes that were stacked and indicated in the below images.

\begin{tabular}{|c|c|c|c|}
\hline Chamber A & & & \\
\hline \multicolumn{4}{|c|}{ Back of Chamber } \\
\hline 5 (VO) & $4(S W)$ & $12(\mathrm{C})$ & $3(S W)$ \\
\hline 11 (C) Top Box & 3 (VO) & $10(C)$ & 12 (SW) \\
\hline \multicolumn{4}{|c|}{10 (SW) Bottom Box } \\
\hline \multirow[t]{3}{*}{$7(S W)$} & $2(C)$ & & \\
\hline & & $8(\mathrm{VO})$ & \\
\hline & 7 (VO) & & 9 (VO) \\
\hline $6(\mathrm{VO})$ & $8(C)$ & $4(C)$ & $8(S W)$ \\
\hline
\end{tabular}

$* \mathrm{C}=$ Control, $\mathrm{SW}=$ Salt Water, $\mathrm{VO}=$ Vegetable Oil

\begin{tabular}{|c|c|c|c|}
\hline Chamber B & & & \\
\hline \multicolumn{4}{|c|}{ Back of Chamber } \\
\hline 6(C) Top Box & & $9(C)$ & 2 (VO) Top Box \\
\hline \multirow[t]{2}{*}{$6(S W)$} & & & $11(\mathrm{SW})$ Bottom Box \\
\hline & & $1(\mathrm{C})$ & \\
\hline $5(C)$ & & & $3(C)$ \\
\hline 12 (VO) Top Box & $5(S W)$ & & $7(C)$ \\
\hline \multicolumn{4}{|c|}{$4(\mathrm{VO})$ Bottom Box } \\
\hline & 1 (VO) Top Box & & 11 (VO) \\
\hline 10 (VO) Top Box & 9 (SW) Bottom Box & & \\
\hline \multicolumn{4}{|l|}{2 (SW) Middle Box } \\
\hline 1 (SW) Bottom Box & & & \\
\hline
\end{tabular}

Front of Chamber

$* \mathrm{C}=$ Control, $\mathrm{SW}=$ Salt Water, $\mathrm{VO}=$ Vegetable Oil 
Appendix E: Contamination Consistency

\begin{tabular}{|c|c|c|c|}
\hline \multicolumn{4}{|l|}{ Vegtable Oil } \\
\hline Date & Front (in.) & Middle (in.) & Back (in.) \\
\hline \multirow[t]{10}{*}{$12 / 2 / 2013$} & 0.125 & 0.125 & 0.125 \\
\hline & 0.125 & 0.125 & 0.125 \\
\hline & 0.1875 & 0.125 & 0.125 \\
\hline & 0.125 & 0.125 & 0.125 \\
\hline & 0.125 & 0.1875 & 0.125 \\
\hline & 0.125 & 0.125 & 0.1875 \\
\hline & 0.125 & 0.125 & 0.125 \\
\hline & 0.1875 & 0.125 & 0.125 \\
\hline & 0.125 & 0.125 & 0.125 \\
\hline & 0.125 & 0.125 & 0.125 \\
\hline \multirow[t]{8}{*}{$1 / 18 / 2014$} & 0.125 & 0.125 & 0.1875 \\
\hline & 0.125 & 0.125 & 0.125 \\
\hline & 0.125 & 0.125 & 0.125 \\
\hline & 0.125 & 0.1875 & 0.125 \\
\hline & 0.125 & 0.125 & 0.125 \\
\hline & 0.1875 & 0.1875 & 0.125 \\
\hline & 0.125 & 0.125 & 0.125 \\
\hline & 0.1875 & 0.125 & 0.1875 \\
\hline \multirow[t]{11}{*}{$1 / 21 / 2014$} & 0.1875 & 0.125 & 0.125 \\
\hline & 0.125 & 0.125 & 0.125 \\
\hline & 0.125 & 0.125 & 0.125 \\
\hline & 0.125 & 0.125 & 0.125 \\
\hline & 0.125 & 0.125 & 0.1875 \\
\hline & 0.125 & 0.125 & 0.1875 \\
\hline & 0.125 & 0.125 & 0.125 \\
\hline & 0.125 & 0.125 & 0.125 \\
\hline & 0.125 & 0.125 & 0.125 \\
\hline & 0.1875 & 0.125 & 0.125 \\
\hline & 0.0625 & 0.125 & 0.125 \\
\hline \multirow[t]{10}{*}{$2 / 20 / 2014$} & 0.125 & 0.125 & 0.0625 \\
\hline & 0.125 & 0.1875 & 0.125 \\
\hline & 0.25 & 0.1875 & 0.25 \\
\hline & 0.125 & 0.125 & 0.125 \\
\hline & 0.1875 & 0.125 & 0.1875 \\
\hline & 0.125 & 0.1875 & 0.125 \\
\hline & 0.125 & 0.125 & 0.125 \\
\hline & 0.125 & 0.125 & 0.125 \\
\hline & 0.125 & 0.1875 & 0.1875 \\
\hline & 0.125 & 0.125 & 0.125 \\
\hline STDEV & 0.032632218 & 0.024298526 & 0.0326322 \\
\hline AVERAGE & 0.137820513 & 0.136217949 & 0.1378205 \\
\hline C.o.v. & 0.236773305 & 0.178379765 & 0.2367733 \\
\hline AVERAGE C.O.V & 0.217308792 & & \\
\hline
\end{tabular}


Salt Water

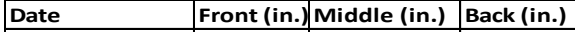

\begin{tabular}{|c|c|c|c|}
\hline & & & \\
\hline \multirow[t]{19}{*}{ 1/11/2013 } & 0.125 & 0.1875 & 0.0625 \\
\hline & 0.125 & 0.125 & 0.125 \\
\hline & 0.125 & 0.125 & 0.125 \\
\hline & 0.1875 & 0.125 & 0.125 \\
\hline & 0.1875 & 0.125 & 0.1875 \\
\hline & 0.125 & 0.125 & 0.125 \\
\hline & 0.125 & 0.125 & 0.125 \\
\hline & 0.125 & 0.125 & 0.1875 \\
\hline & 0.125 & 0.125 & 0.125 \\
\hline & 0.125 & 0.125 & 0.125 \\
\hline & 0.125 & 0.125 & 0.125 \\
\hline & 0.125 & 0.125 & 0.125 \\
\hline & 0.0625 & 0.125 & 0.125 \\
\hline & 0.125 & 0.125 & 0.125 \\
\hline & 0.125 & 0.125 & 0.125 \\
\hline & 0.125 & 0.125 & 0.125 \\
\hline & 0.125 & 0.125 & 0.125 \\
\hline & 0.125 & 0.125 & 0.125 \\
\hline & 0.25 & 0.125 & 0.125 \\
\hline \multirow{17}{*}{$1 / 14 / 2014$} & 0.125 & 0.125 & 0.125 \\
\hline & 0.125 & 0.125 & 0.125 \\
\hline & 0.125 & 0.125 & 0.125 \\
\hline & 0.125 & 0.0625 & 0.125 \\
\hline & 0.125 & 0.125 & 0.125 \\
\hline & 0.125 & 0.0625 & 0.188 \\
\hline & 0.125 & 0.125 & 0.125 \\
\hline & 0.125 & 0.125 & 0.125 \\
\hline & 0.125 & 0.0625 & 0.125 \\
\hline & 0.125 & 0.125 & 0.125 \\
\hline & 0.125 & 0.125 & 0.125 \\
\hline & 0.125 & 0.063 & 0.125 \\
\hline & 0.125 & 0.125 & 0.125 \\
\hline & 0.125 & 0.125 & 0.125 \\
\hline & 0.125 & 0.125 & 0.125 \\
\hline & 0.125 & 0.125 & 0.125 \\
\hline & 0.125 & 0.125 & 0.125 \\
\hline \multirow{11}{*}{$1 / 17 / 2014$} & 0.125 & 0.125 & 0.125 \\
\hline & 0.25 & 0.1875 & 0.125 \\
\hline & 0.1875 & 0.1875 & 0.125 \\
\hline & 0.125 & 0.1875 & 0.125 \\
\hline & 0.125 & 0.125 & 0.125 \\
\hline & 0.125 & 0.1875 & 0.125 \\
\hline & 0.125 & 0.1875 & 0.0625 \\
\hline & 0.125 & 0.125 & 0.125 \\
\hline & 0.125 & 0.125 & 0.125 \\
\hline & 0.125 & 0.125 & 0.125 \\
\hline & 0.125 & 0.125 & 0.0625 \\
\hline \multirow[t]{12}{*}{$1 / 19 / 2014$} & 0.1875 & 0.125 & 0.125 \\
\hline & 0.0625 & 0.125 & 0.125 \\
\hline & 0.125 & 0.0625 & 0.125 \\
\hline & 0.125 & 0.125 & 0.125 \\
\hline & 0.125 & 0.125 & 0.1875 \\
\hline & 0.125 & 0.125 & 0.125 \\
\hline & 0.125 & 0.125 & 0.125 \\
\hline & 0.125 & 0.125 & 0.125 \\
\hline & 0.125 & 0.125 & 0.125 \\
\hline & 0.125 & 0.125 & 0.125 \\
\hline & 0.125 & 0.125 & 0.1875 \\
\hline & 0.125 & 0.125 & 0.125 \\
\hline \multirow[t]{14}{*}{ 2/19/2014 } & 0.125 & 0.0625 & 0.125 \\
\hline & 0.125 & 0.125 & 0.125 \\
\hline & 0.125 & 0.0625 & 0.125 \\
\hline & 0.125 & 0.125 & 0.125 \\
\hline & 0.125 & 0.125 & 0.1875 \\
\hline & 0.125 & 0.125 & 0.1875 \\
\hline & 0.125 & 0.125 & 0.125 \\
\hline & 0.125 & 0.125 & 0.125 \\
\hline & 0.125 & 0.125 & 0.125 \\
\hline & 0.125 & 0.125 & 0.0625 \\
\hline & 0.125 & 0.125 & 0.0625 \\
\hline & 0.125 & 0.125 & 0.0625 \\
\hline & 0.125 & 0.125 & 0.125 \\
\hline & 0.125 & 0.125 & 0.125 \\
\hline STDEV & 0.02707 & 0.026543397 & 0.026543397 \\
\hline AVERAGE & 0.130 & 0.124 & 0.126 \\
\hline c.o.v. & 0.208013 & 0.213811642 & 0.21090264 \\
\hline AVERAGE C.O.V & 0.210909 & & \\
\hline
\end{tabular}




\section{Appendix F: Phase 1 Binary Logistic Regression Analysis Results}

\begin{tabular}{|l|l|r|}
\hline Variable & Value & \multicolumn{1}{|l|}{ Count } \\
\hline PASS & $\mathrm{P}$ & 140 \\
\hline & $\mathrm{F}$ & 126 \\
\hline & Total & 266 \\
\hline
\end{tabular}

\begin{tabular}{|c|c|c|c|c|c|c|c|}
\hline \multirow[b]{2}{*}{ Predictor } & \multirow[b]{2}{*}{ Coef } & \multirow[b]{2}{*}{ SE Coef } & \multirow[b]{2}{*}{$\mathrm{Z}$} & \multirow[b]{2}{*}{$\mathrm{P}$} & \multirow[b]{2}{*}{$\begin{array}{l}\text { Odds } \\
\text { Ratio }\end{array}$} & \multicolumn{2}{|c|}{$95 \% \mathrm{CI}$} \\
\hline & & & & & & Lower & Upper \\
\hline Constant & 1.15226 & 0.368824 & 3.12 & 0.002 & & & \\
\hline \multicolumn{8}{|l|}{ TEMP } \\
\hline 120 & -1.14006 & 0.339598 & -3.36 & 0.001 & 0.32 & 0.160 & 0.62 \\
\hline 160 & 0.468708 & 0.338224 & 1.39 & 0.166 & 1.60 & 0.82 & 3.10 \\
\hline \multicolumn{8}{|l|}{ DWELL TIME } \\
\hline 0.2 & -1.10157 & 0.338602 & -3.25 & 0.001 & 0.33 & 0.17 & 0.65 \\
\hline 0.4 & 0.650081 & 0.337086 & 1.93 & 0.054 & 1.92 & 0.99 & 3.71 \\
\hline \multicolumn{8}{|l|}{ CONTAMINANT } \\
\hline Salt Water & -1.19825 & 0.349380 & -0.343 & 0.001 & 0.30 & 0.15 & 0.60 \\
\hline Vegetable Oil & -0.79306 & 0.342643 & -2.31 & 0.021 & 0.45 & 0.23 & 0.89 \\
\hline
\end{tabular}

A.

Log-Likelihood $=-153.664$

Test that all slopes are zero: $\mathrm{G}=60.689, \mathrm{DF}=6, \mathrm{P}-\mathrm{Value}=0.000$

\begin{tabular}{|c|c|c|c|c|c|c|c|}
\hline & & & & & & $95 \%$ & \\
\hline Predictor & Coef & SE Coef & $\mathrm{Z}$ & $\mathrm{P}$ & $\begin{array}{l}\text { Odds } \\
\text { Ratio }\end{array}$ & Lower & Upper \\
\hline Constant & -1.08937 & $\begin{array}{r}0.37158 \\
9 \\
\end{array}$ & -2.93 & 0.003 & & & \\
\hline \multicolumn{8}{|l|}{ TEMP } \\
\hline 140 & 1.14006 & $\begin{array}{r}0.33959 \\
8 \\
\end{array}$ & 3.36 & 0.001 & 3.13 & 1.61 & 6.08 \\
\hline 160 & 1.60877 & $\begin{array}{r}0.35148 \\
6 \\
\end{array}$ & 4.58 & 0.000 & 5.00 & 2.51 & 9.95 \\
\hline \multicolumn{8}{|l|}{ DWELL TIME } \\
\hline 0.3 & 1.10157 & $\begin{array}{r}0.33860 \\
2\end{array}$ & 3.25 & 0.001 & 3.01 & 1.55 & 5.84 \\
\hline
\end{tabular}




\begin{tabular}{|c|c|c|c|c|c|c|c|}
\hline 0.4 & 1.75165 & $\begin{array}{r}0.35393 \\
4\end{array}$ & 4.95 & 0.000 & 5.76 & 2.88 & 11.53 \\
\hline$\frac{\text { CONTAMINAN }}{\mathrm{T}}$ & & & & & & & \\
\hline Salt Water & -1.19825 & $\begin{array}{r}0.34938 \\
0\end{array}$ & -3.43 & 0.001 & 0.30 & 0.15 & 0.60 \\
\hline Vegetable Oil & -0.79306 & $\begin{array}{r}0.34264 \\
3 \\
\end{array}$ & -2.31 & 0.021 & 0.45 & 0.23 & 0.89 \\
\hline
\end{tabular}

Log-Likelihood $=-153.664$

Test that all slopes are zero: $\mathrm{G}=60.689, \mathrm{DF}=6, \mathrm{P}-\mathrm{V}$ alue $=0.000$

\begin{tabular}{|r|r|r|r|r|r|r|r|}
\hline & & & & & \multicolumn{2}{|c|}{$95 \%$ CI } \\
\hline Predictor & Coef & SE Coef & \multicolumn{1}{|c|}{ Z } & P & Odds Ratio & Lower & Upper \\
\hline Constant & 0.510002 & 0.569797 & 0.9 & 0.371 & & & \\
\hline TEMP & & & & & & & \\
\hline 120 & -1.37256 & 0.727119 & -1.89 & 0.059 & 0.25 & 0.06 & 1.05 \\
\hline 160 & 1.46725 & 0.892633 & 1.64 & 0.100 & 4.34 & 0.75 & 24.95 \\
\hline DWELL TIME & & & & & & & \\
\hline 0.2 & -0.548748 & 0.736750 & -0.74 & 0.456 & 0.58 & 0.14 & 2.45 \\
\hline 0.4 & 0.504548 & 0.775221 & 0.65 & 0.515 & 1.66 & 0.36 & 7.57 \\
\hline CONTAMINANT & & & & & & & \\
\hline Salt Water & 0.409607 & 0.744460 & 0.55 & 0.582 & 1.51 & 0.35 & 6.48 \\
\hline Vegetable Oil & 0.643941 & 0.765339 & 0.84 & 0.40 & 1.90 & 0.42 & 8.53 \\
\hline & & & & & & & \\
\hline $120 *$ Salt Water & -0.358683 & 0.797668 & -0.45 & 0.653 & 0.70 & 0.15 & 3.34 \\
\hline $120 *$ Vegetable Oil & -1.01009 & 0.838314 & -1.20 & 0.228 & 0.36 & 0.07 & 1.88 \\
\hline $160 *$ Salt Water & -2.35386 & 0.999294 & -2.36 & 0.018 & 0.10 & 0.01 & 0.67 \\
\hline $160 *$ Vegetable Oil & -1.70942 & 1.003910 & -1.70 & 0.089 & 0.18 & 0.03 & 1.29 \\
\hline DWELL TIME*ONTAMINANT & & & & & & & \\
\hline $0.2 *$ Salt Water & -1.27796 & 0.855884 & -1.49 & 0.135 & 0.28 & 0.05 & 1.49 \\
\hline $0.2 *$ Vegetable Oil & -1.59413 & 0.879009 & -1.81 & 0.07 & 0.20 & 0.04 & 1.14 \\
\hline $0.4 *$ Salt Water & -1.43438 & 0.897785 & -1.60 & 0.11 & 0.24 & 0.04 & 1.38 \\
\hline $0.4 *$ Vegetable Oil & -0.457805 & 0.928398 & -0.49 & 0.622 & 0.63 & 0.10 & 3.9 \\
\hline TEMP*DWELL TIME & & & & & & & \\
\hline $120 * 0.2$ & 1.11455 & 0.847171 & 1.32 & 0.188 & 3.05 & 0.58 & 16.04 \\
\hline $120 * 0.4$ & 1.09731 & 0.801991 & 1.37 & 0.171 & 3.00 & 0.62 & 14.43 \\
\hline $160 * 0.2$ & 0.0459875 & 0.869460 & 0.05 & 0.958 & 1.05 & 0.19 & 5.76 \\
\hline $160 * 0.4$ & 2.03994 & 1.012900 & 2.01 & 0.044 & 7.69 & 1.06 & 55.99 \\
\hline & & & & & & & \\
\hline
\end{tabular}


Appendix G: Phase 2 Binary Logistic Regression Analysis Results

\begin{tabular}{|l|l|r|}
\hline Variable & Value & \multicolumn{1}{|c|}{ Count } \\
\hline Pass/Fail & P & 119 \\
\hline & F & 105 \\
\hline & Total & 224 \\
\hline
\end{tabular}

\begin{tabular}{|c|c|c|c|c|c|c|c|}
\hline & & & & & & \multicolumn{2}{|c|}{ 95\% C.I. } \\
\hline Predictor & Coef & SE Coef & Z & $P$ & Odds Ratio & Lower & Upper \\
\hline Constant & 0.120593 & 0.350294 & 0.34 & 0.731 & & & \\
\hline \multicolumn{8}{|c|}{ Contaminant } \\
\hline SW & -0.45402 & 0.33467 & -1.36 & 0.175 & 0.64 & 0.33 & 1.22 \\
\hline VO & 0.08707 & 0.329785 & 0.26 & 0.792 & 1.09 & 0.57 & 2.08 \\
\hline \multicolumn{8}{|l|}{ Chamber } \\
\hline B & 0.489777 & 0.272929 & 1.79 & 0.073 & 1.63 & 0.96 & 2.79 \\
\hline \multicolumn{8}{|l|}{ Day } \\
\hline 6 & -0.29295 & 0.378383 & -0.77 & 0.439 & 0.75 & 0.36 & 1.57 \\
\hline 10 & 0.021318 & 0.378133 & 0.06 & 0.955 & 1.02 & 0.49 & 2.14 \\
\hline 14 & -0.23968 & 0.391007 & -0.61 & 0.54 & 0.79 & 0.37 & 1.69 \\
\hline
\end{tabular}

Log-Likelihood $=-151.278$

Test that all slopes are zero: $\mathrm{G}=7.098, \mathrm{DF}=6, \mathrm{P}$-Value $=0.312$

\section{Appendix H: Phase 2 General Linear Model Analysis Results}

\begin{tabular}{|l|l|r|l|}
\hline Factor & Type & Levels & Values \\
\hline Day & fixed & 4 & $2,6,10,14$ \\
\hline Chamber & fixed & 2 & A, B \\
\hline Contaminant & fixed & 3 & C, SW, VO \\
\hline
\end{tabular}

Analysis of Variance for Force, using Adjusted SS for Tests

\begin{tabular}{|c|c|c|c|c|c|c|}
\hline Source & $\underline{\text { DF }}$ & $\underline{\operatorname{Seq}} \mathbf{S S}$ & Adj SS & $\frac{\text { Adj }}{\text { MS }}$ & $\underline{\mathbf{F}}$ & $\underline{\mathbf{P}}$ \\
\hline Day & 3 & 27.08 & 27.08 & 9.03 & 0.24 & 0.863 \\
\hline Chamber & 1 & 10.91 & 10.91 & 10.91 & 0.3 & 0.606 \\
\hline Contaminant & 2 & 86.48 & 86.48 & 43.24 & 1.17 & 0.372 \\
\hline Day*Contaminant & 6 & 240.32 & 240.32 & 40.05 & 1.08 & 0.462 \\
\hline Day*Chamber & 3 & 60.19 & 60.19 & 20.06 & 0.54 & 0.67 \\
\hline Chamber*Contaminant & 2 & 23.22 & 23.22 & 11.61 & 0.31 & 0.742 \\
\hline Error & 6 & 221.53 & 221.53 & 36.92 & & \\
\hline Total & 23 & 669.73 & & & & \\
\hline
\end{tabular}


Analysis of Variance for STRAIN, using Adjusted SS for Tests

\begin{tabular}{|c|c|c|c|c|c|c|}
\hline Source & $\underline{\text { DF }}$ & $\underline{\operatorname{Seq} S S}$ & Adj SS & $\frac{\text { Adj }}{\text { MS }}$ & $\underline{\mathbf{F}}$ & $\underline{\mathbf{P}}$ \\
\hline Day & 3 & 8.2 & 8.2 & 2.73 & 0.11 & 0.949 \\
\hline Chamber & 1 & 12.49 & 12.49 & 12.49 & 0.52 & 0.499 \\
\hline Contaminant & 2 & 34.78 & 34.78 & 17.39 & 0.72 & 0.525 \\
\hline Day*Contaminant & 6 & 59.83 & 59.83 & 9.97 & 0.41 & 0.847 \\
\hline Day*Chamber & 3 & 46.65 & 46.65 & 15.55 & 0.64 & 0.615 \\
\hline Chamber*Contaminant & 2 & 24.25 & 24.25 & 12.13 & 0.5 & 0.629 \\
\hline Error & 6 & 145.09 & 145.09 & 24.18 & & \\
\hline Total & 23 & 331.28 & & & & \\
\hline
\end{tabular}

Appendix I: Seal Strength Failure Modes by Test Category and Conditioning Temperature Salt Water

\begin{tabular}{|r|r|r|r|r|}
\hline & \multicolumn{5}{|c|}{ Failure Mode Category } \\
\hline \multirow{2}{*}{ Refrigerated Condition } & A & B & C \\
\hline & $\mathbf{2}$ & 1 & 1 & 7 \\
\hline $\mathbf{6}$ & 4 & 0 & 2 \\
\hline 10 & 3 & 5 & 5 \\
\hline & 14 & 4 & 3 & 5 \\
\hline Total & 12 & 9 & 19 \\
\hline
\end{tabular}

\begin{tabular}{|r|r|r|r|r|r|}
\hline Ambient Condition & \multicolumn{4}{|c|}{ Failure Mode Category } \\
\cline { 2 - 6 } & Day & A & B & C \\
\hline & $\mathbf{2}$ & 3 & 0 & 1 \\
\hline $\mathbf{6}$ & 2 & 1 & 6 \\
\hline 10 & 4 & 5 & 3 \\
\hline & 14 & 1 & 3 & 8 \\
\hline & Total & 10 & 9 & 18 \\
\hline
\end{tabular}


$\underline{\text { Vegetable Oil }}$

\begin{tabular}{|r|r|r|r|r|r|r|}
\hline & \multicolumn{6}{|c|}{ Failure Mode Category } \\
\hline & Day & A & B & C & D \\
\hline & $\mathbf{2}$ & 2 & 0 & 2 & 0 \\
\hline $\mathbf{6}$ & 4 & 3 & 3 & 0 \\
\hline 10 & 3 & 1 & 4 & 0 \\
\hline 14 & 4 & 2 & 2 & 1 \\
\hline Total & 13 & 6 & 11 & 1 \\
\hline
\end{tabular}

\begin{tabular}{|c|c|c|c|c|}
\hline \multirow[t]{2}{*}{ Ambient Condition } & \multirow[b]{2}{*}{ Day } & \multicolumn{3}{|c|}{ Failure Mode Category } \\
\hline & & A & B & C \\
\hline & 2 & 1 & 1 & 1 \\
\hline & 6 & 4 & 0 & 4 \\
\hline & 10 & 2 & 3 & 3 \\
\hline & 14 & 5 & 4 & 2 \\
\hline & Total & 12 & 8 & 10 \\
\hline
\end{tabular}

\section{Control}

\begin{tabular}{|r|r|r|r|r|r|r|r|}
\hline & \multicolumn{7}{|c|}{ Failure Mode Category } \\
\hline Refrigerated Condition & \multicolumn{1}{|c|}{ A } & B & C & D & E & 1 \\
\hline & $\mathbf{2}$ & 4 & 4 & 2 & 0 & 0 \\
\hline 6 & 5 & 2 & 7 & 0 & 0 \\
\hline 10 & 4 & 4 & 2 & 1 & 1 \\
\hline
\end{tabular}

\begin{tabular}{|c|c|c|c|c|}
\hline \multirow[t]{2}{*}{ Ambient Condition } & \multirow[b]{2}{*}{ Day } & \multicolumn{3}{|c|}{ Failure Mode Category } \\
\hline & & A & B & C \\
\hline & 2 & 3 & 2 & 3 \\
\hline & 6 & 4 & 4 & 5 \\
\hline & 10 & 4 & 7 & 3 \\
\hline & 14 & 5 & 5 & 2 \\
\hline & Total & 16 & 18 & 13 \\
\hline
\end{tabular}


Appendix J: Seal Strength Raw Data Results
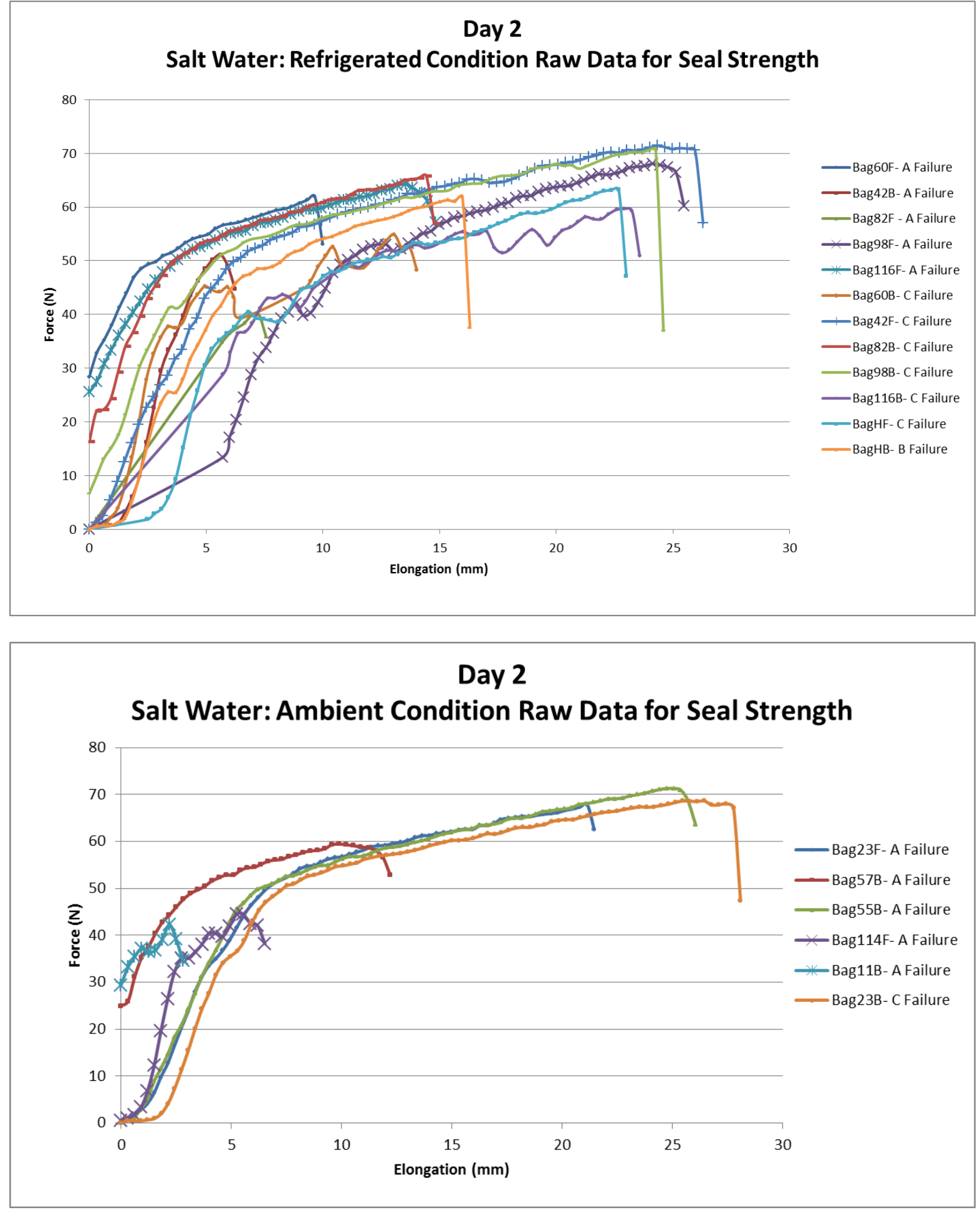

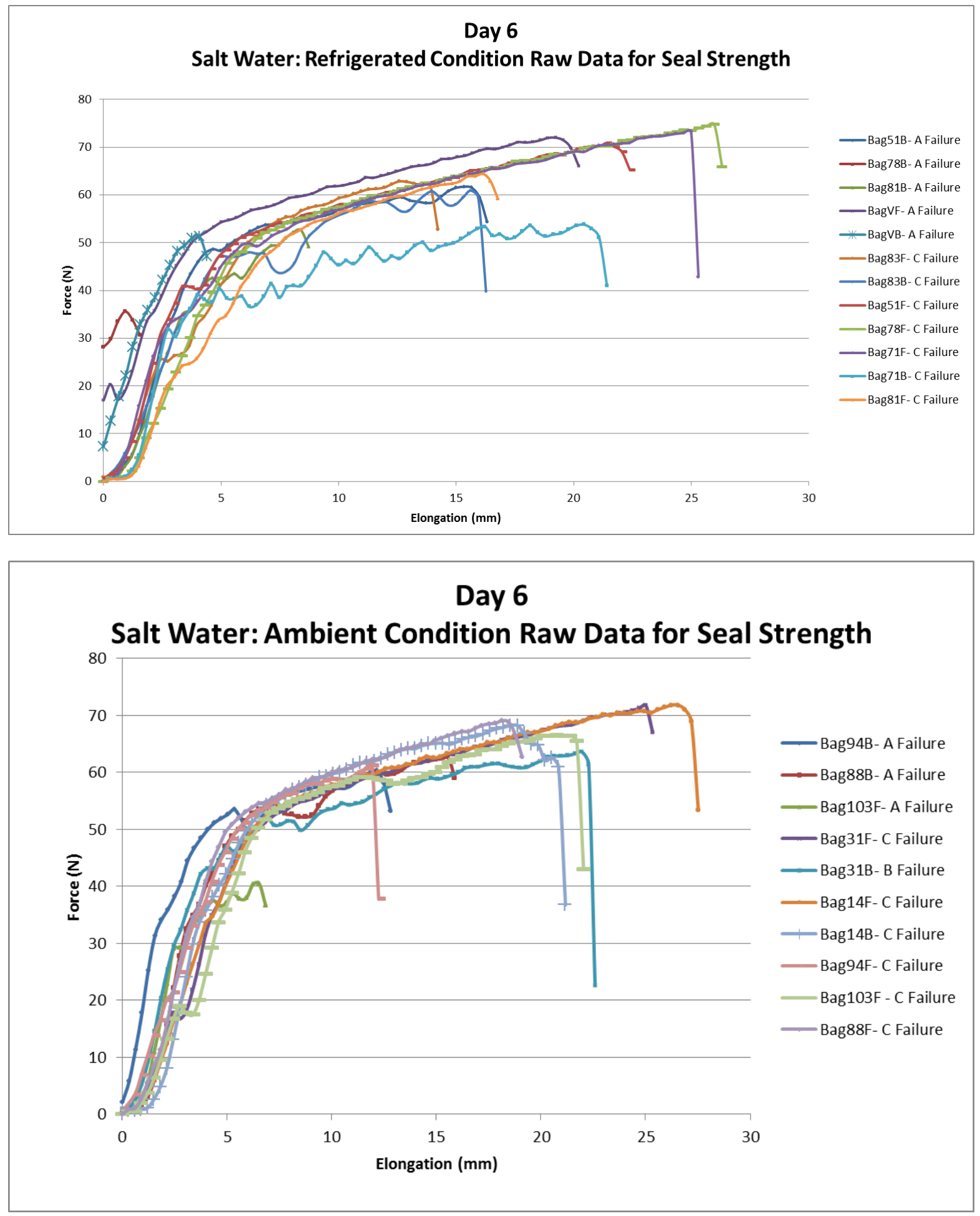

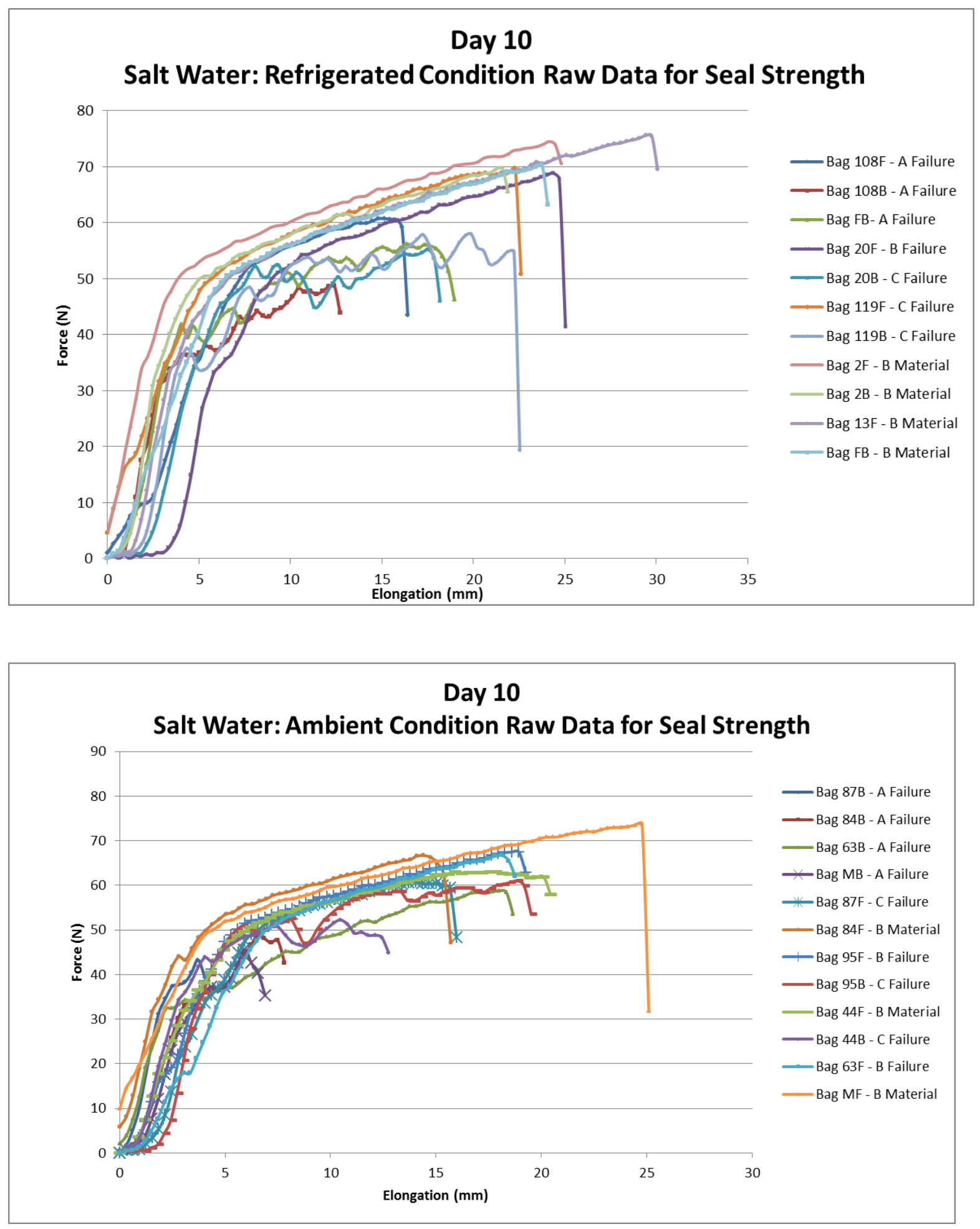

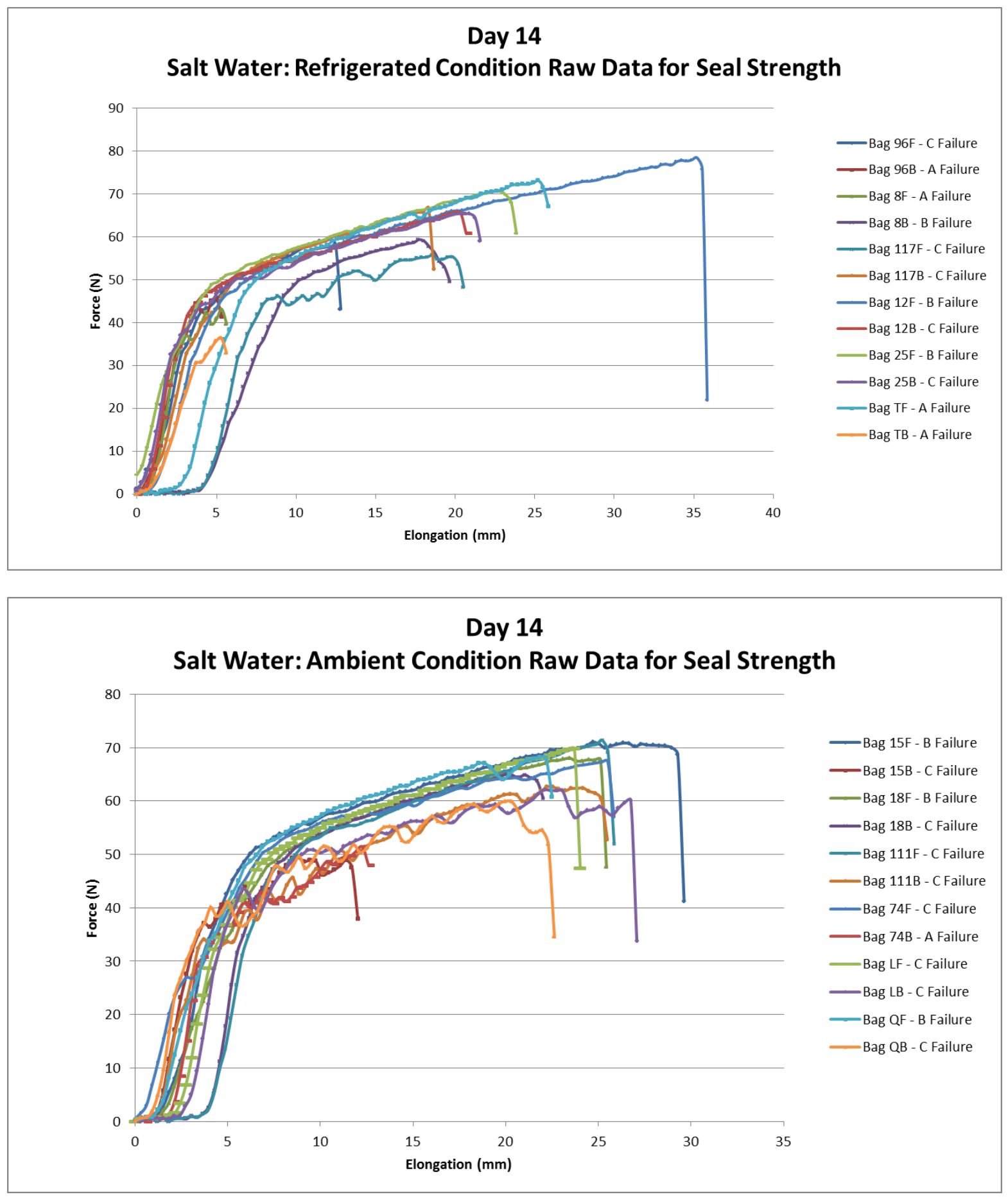

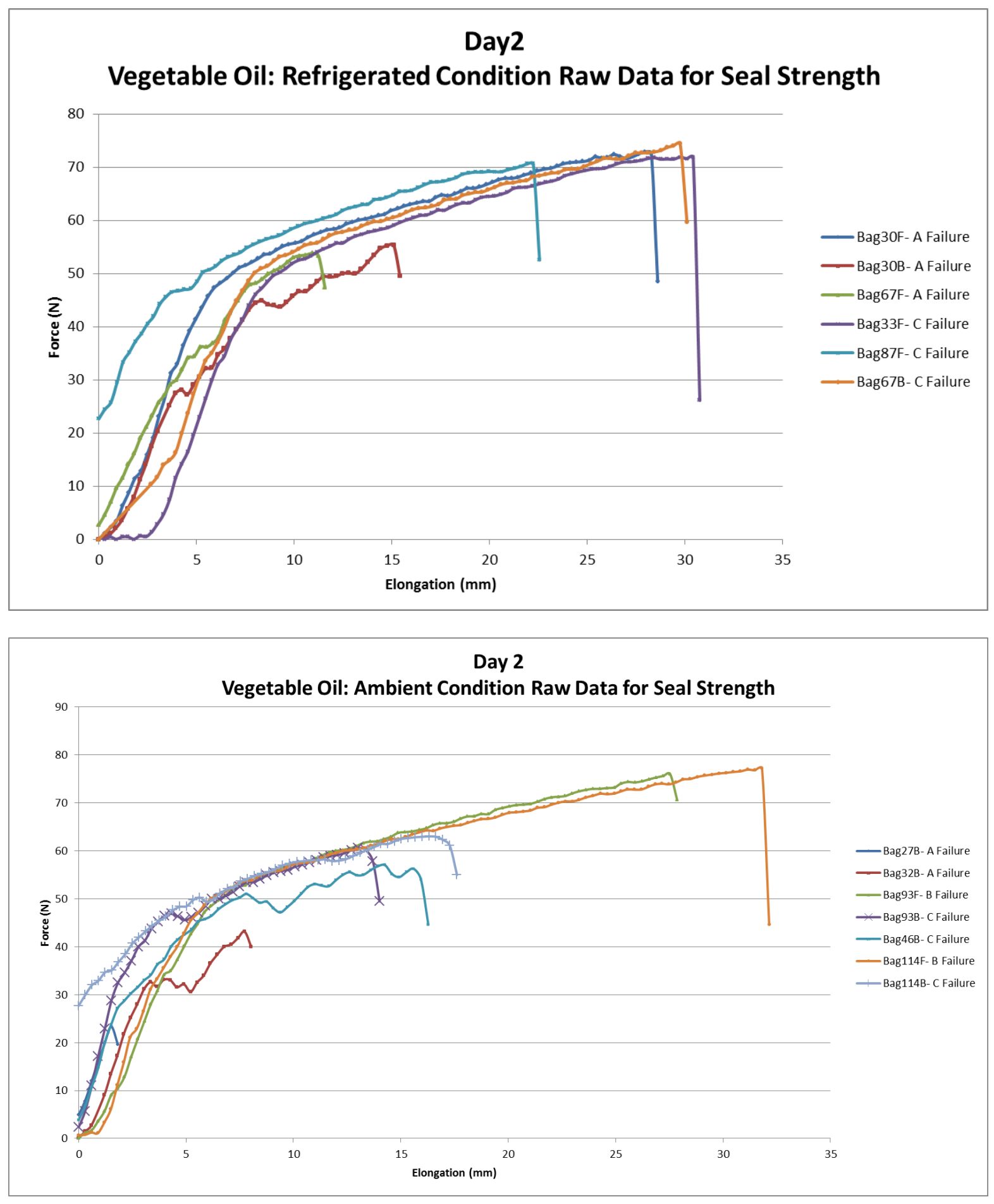

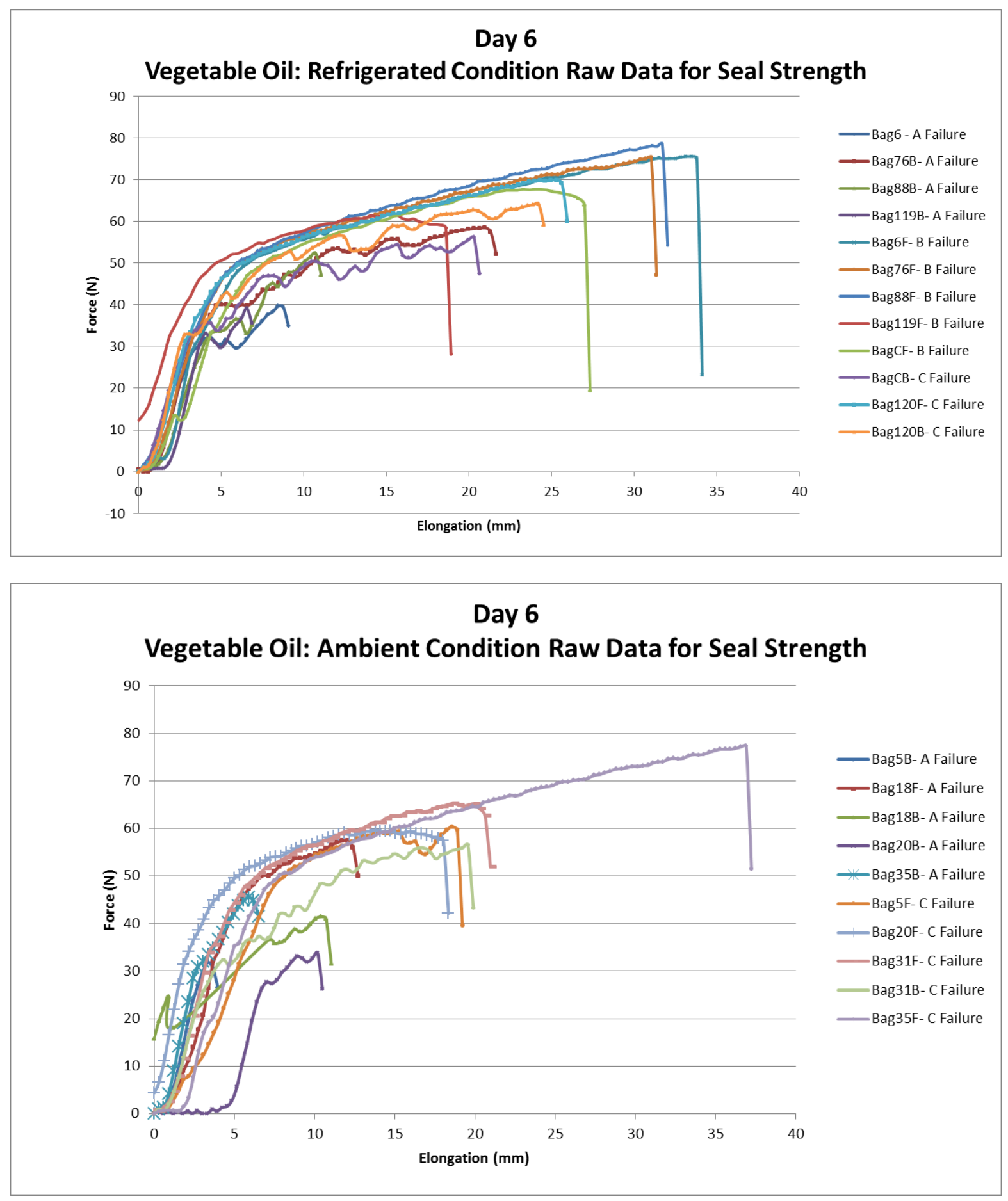

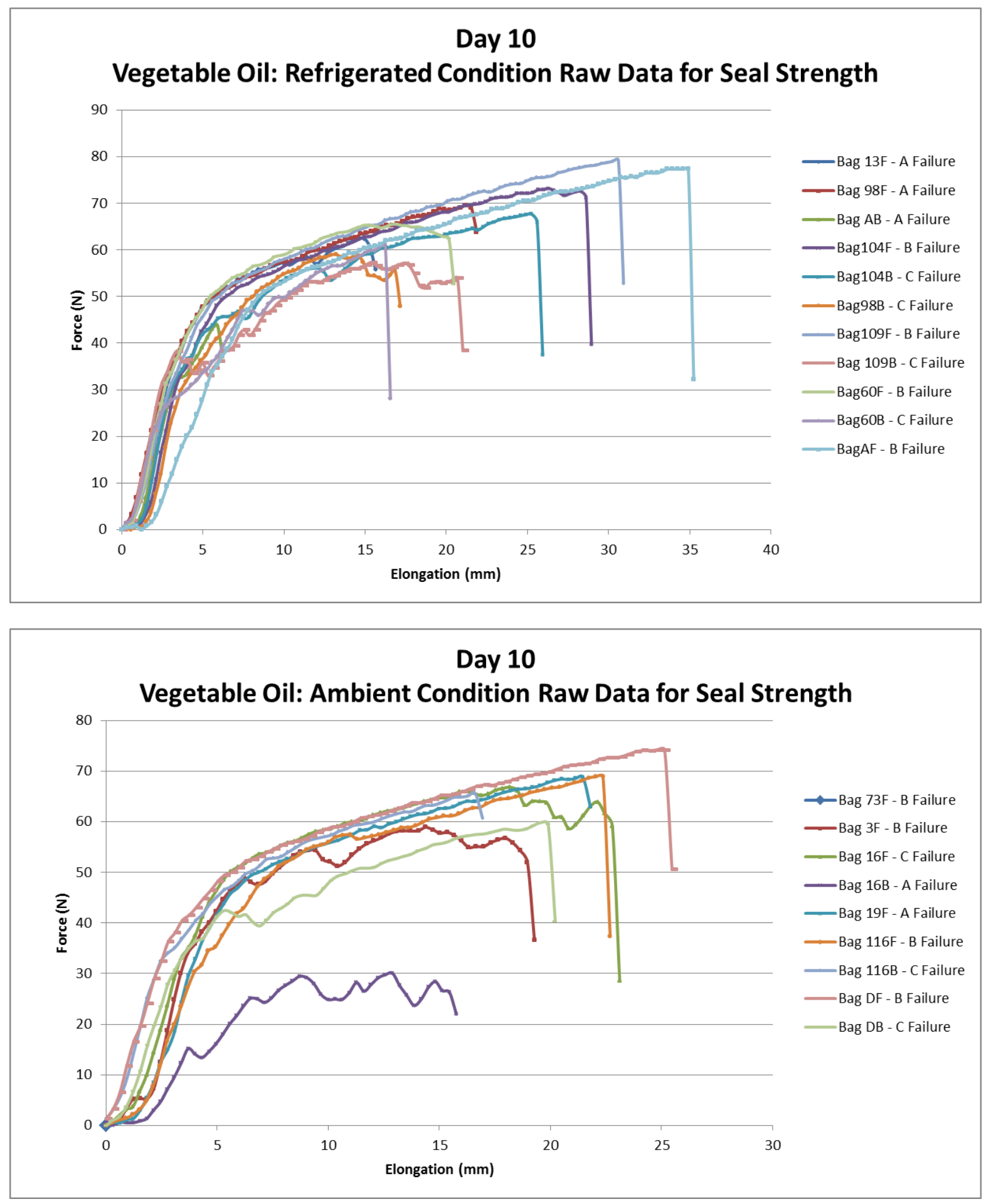


\section{Day 14 \\ Vegetable Oil: Refrigerated Condition Raw Data for Seal Strength}

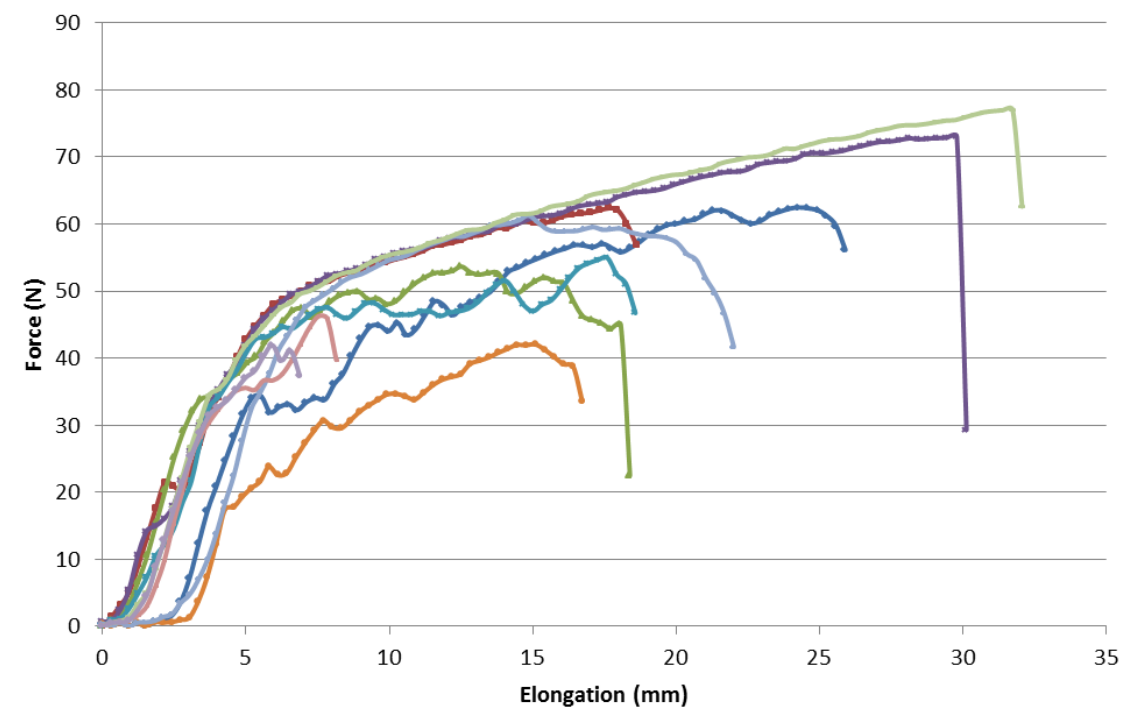

_Bag 105F - A Failure

__Bag 105B - D Failure

_Bag 72F - C Failure

_-Bag 72B - B Failure

_Bag 4F - C Failure

_Bag 4B - A Failure

_Bag 62F - B Failure

_Bag 62B - A Failure

_Bag 99F - B Failure

_Bag 99B - A Failure

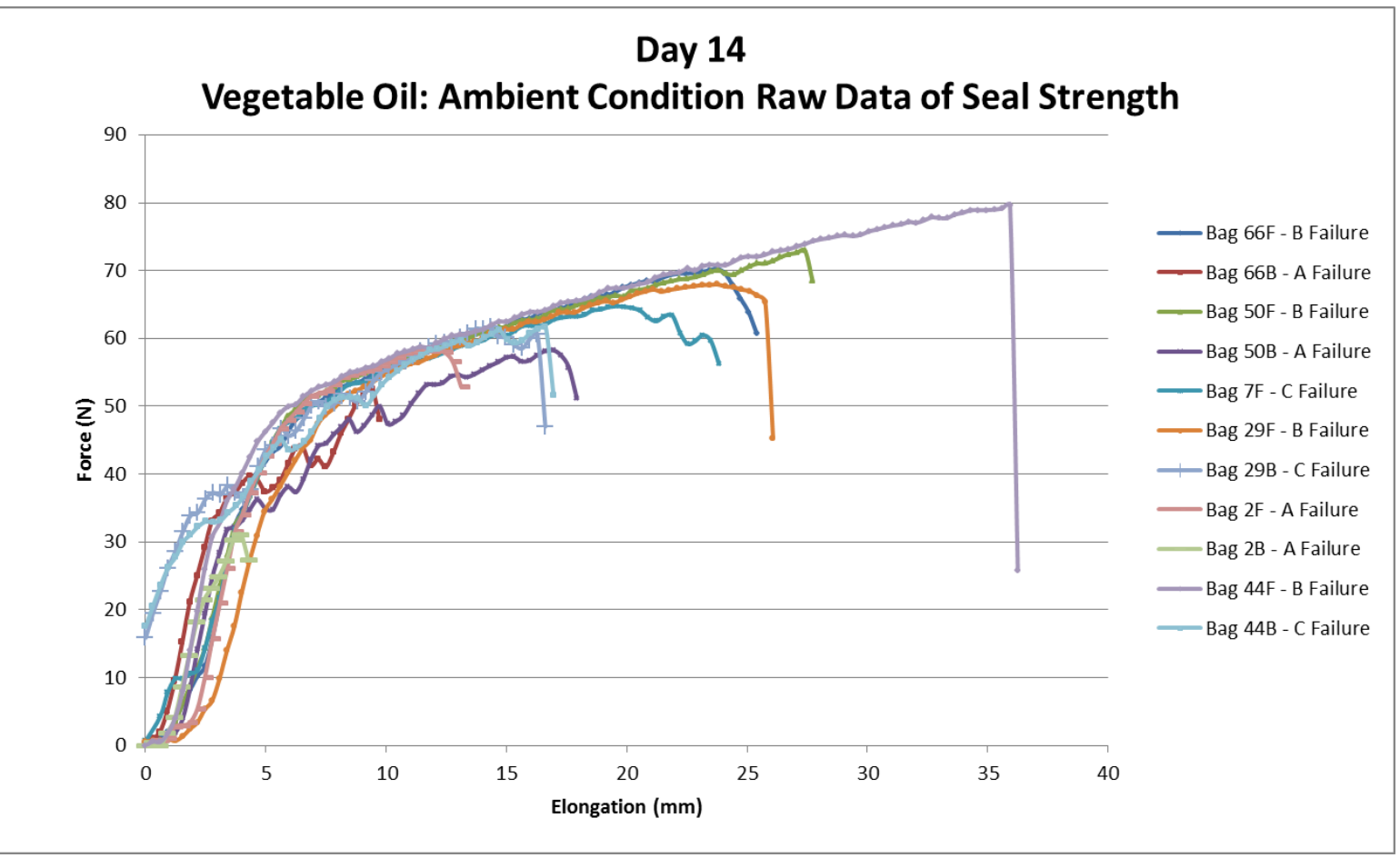



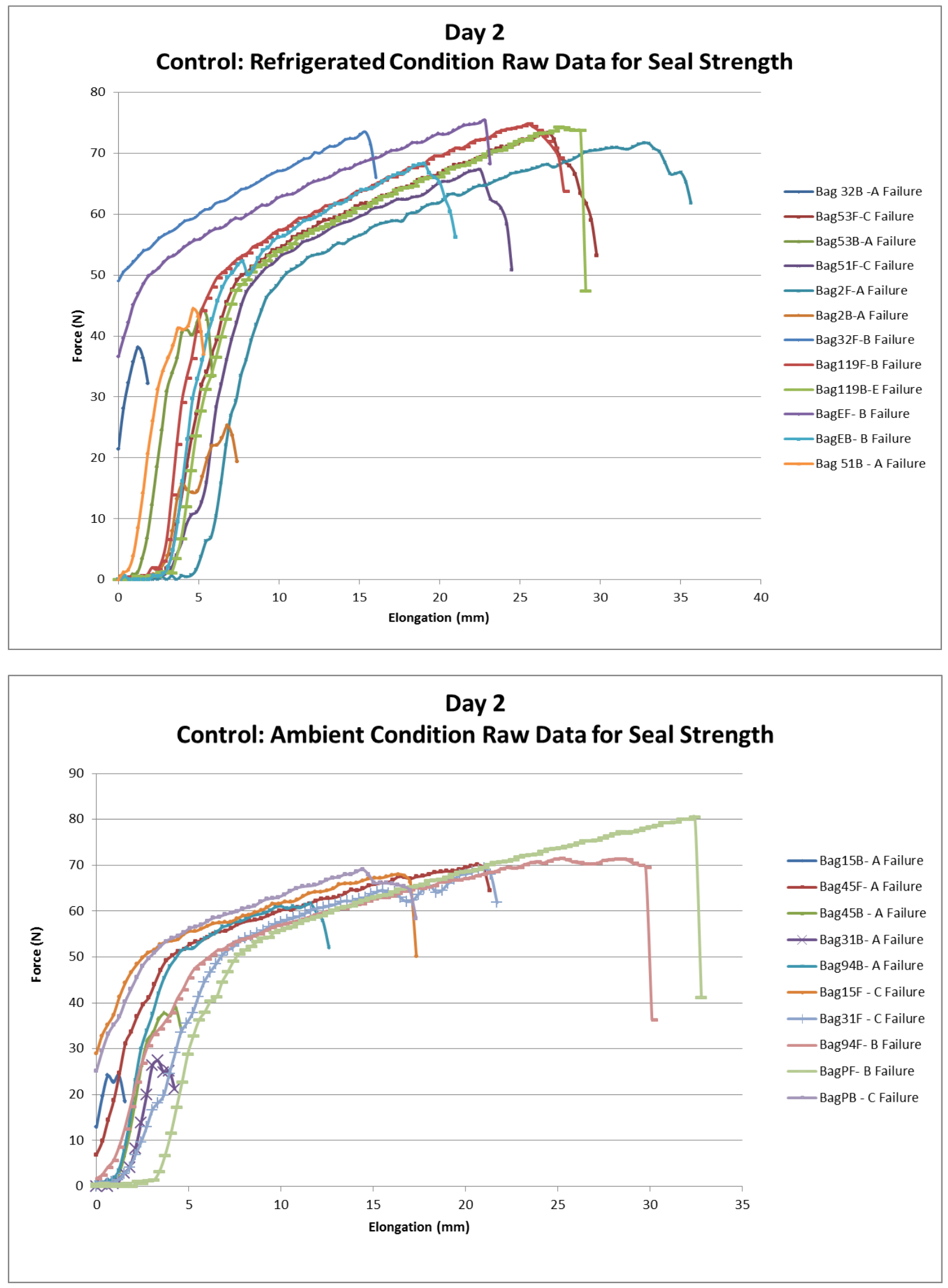

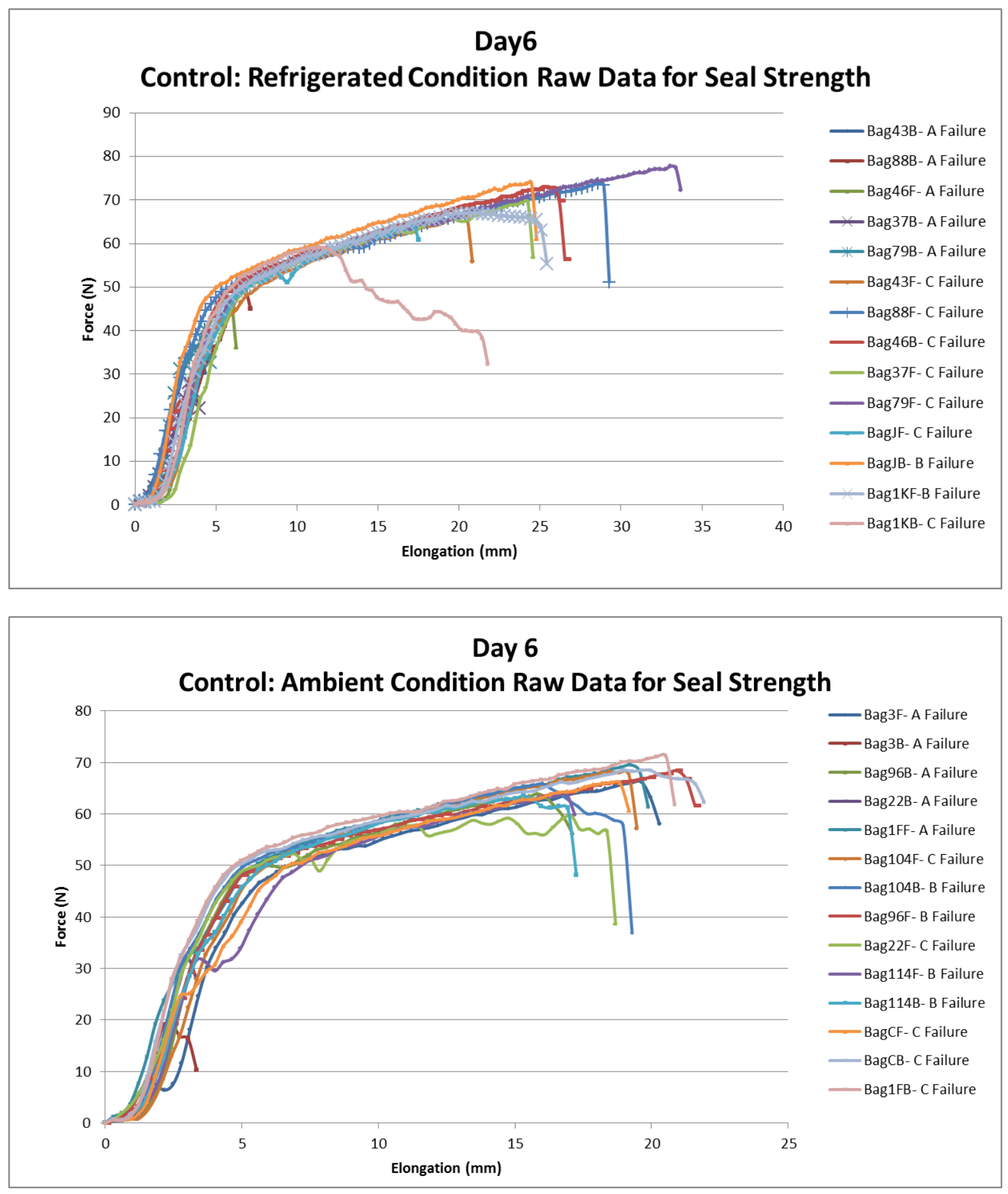

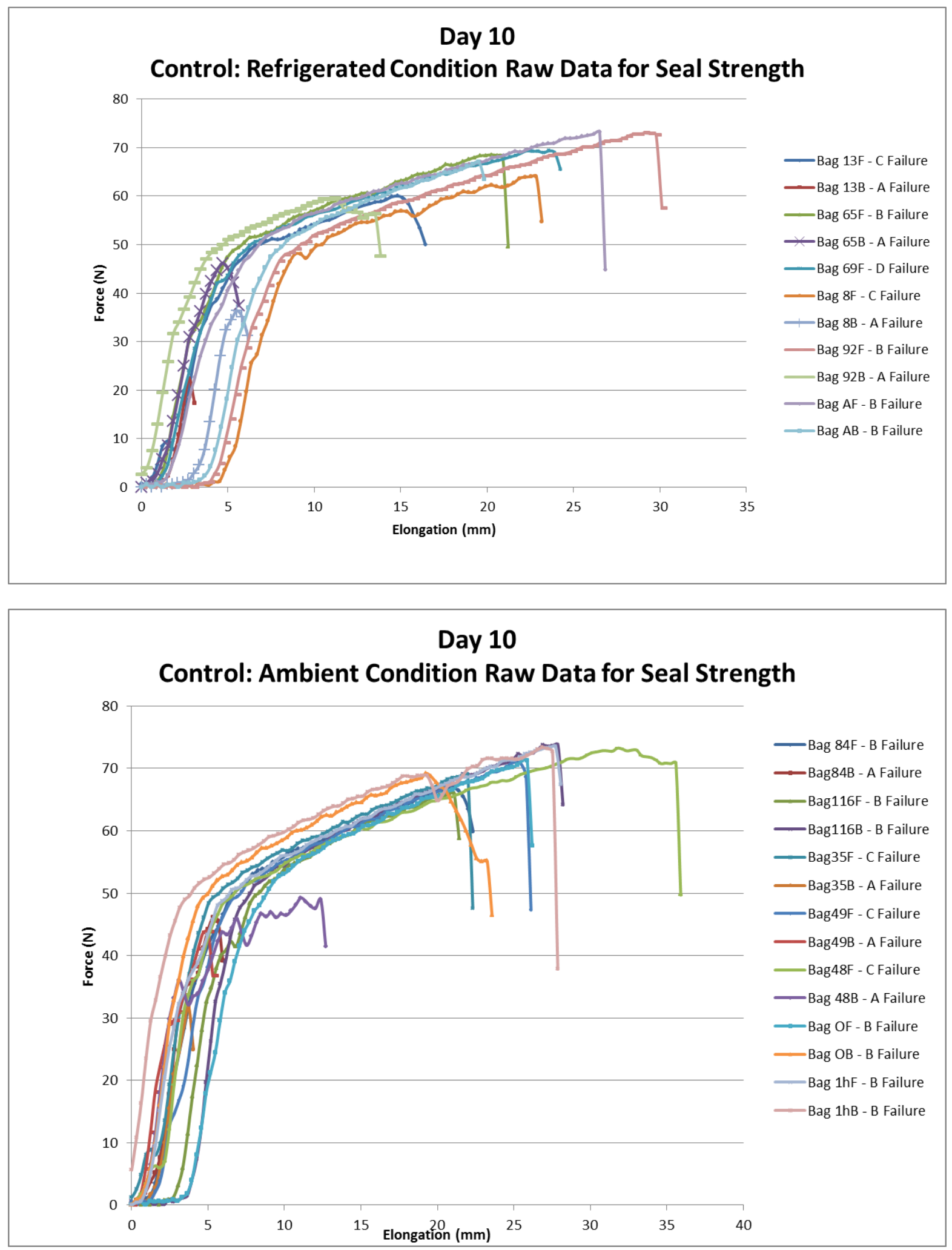

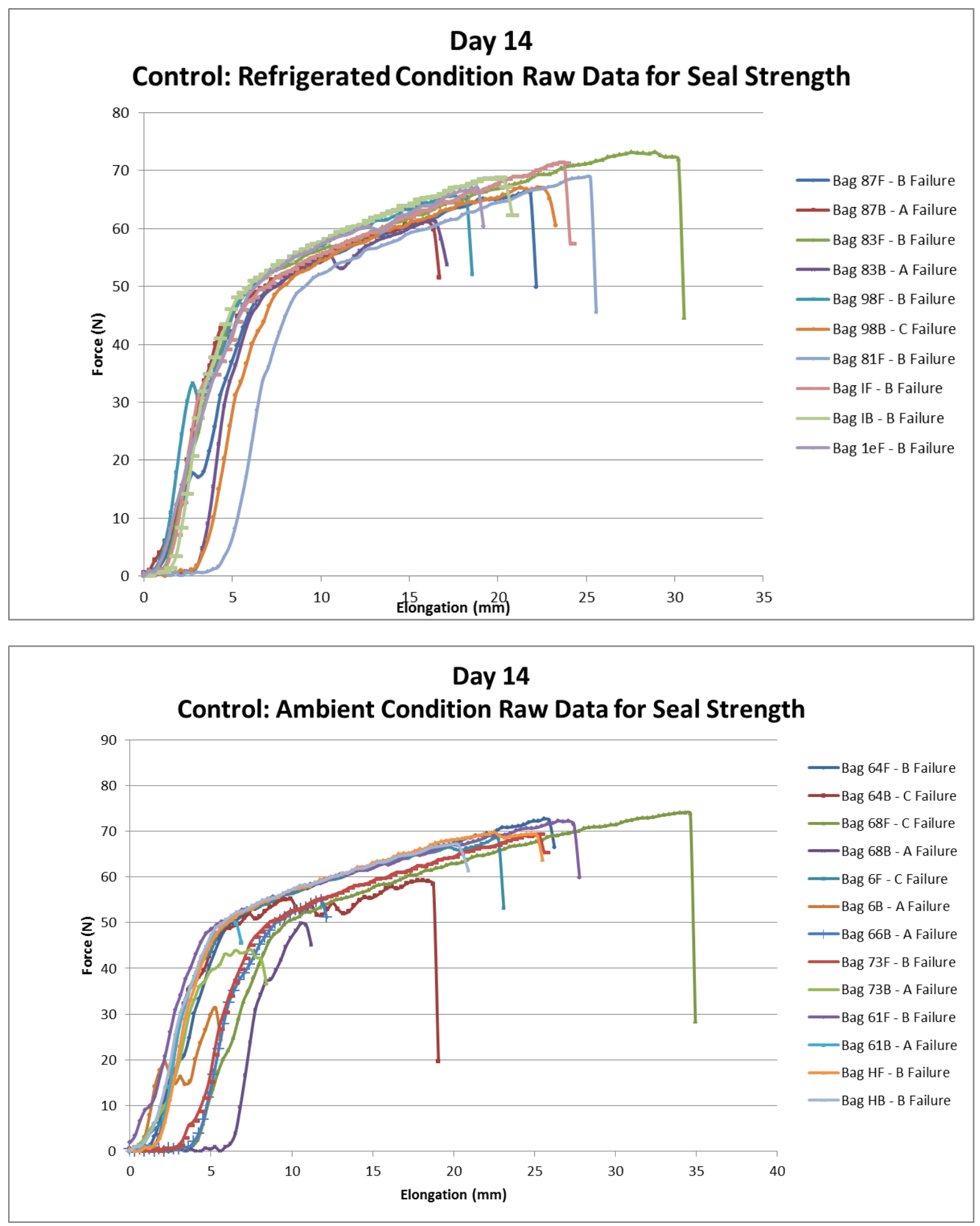